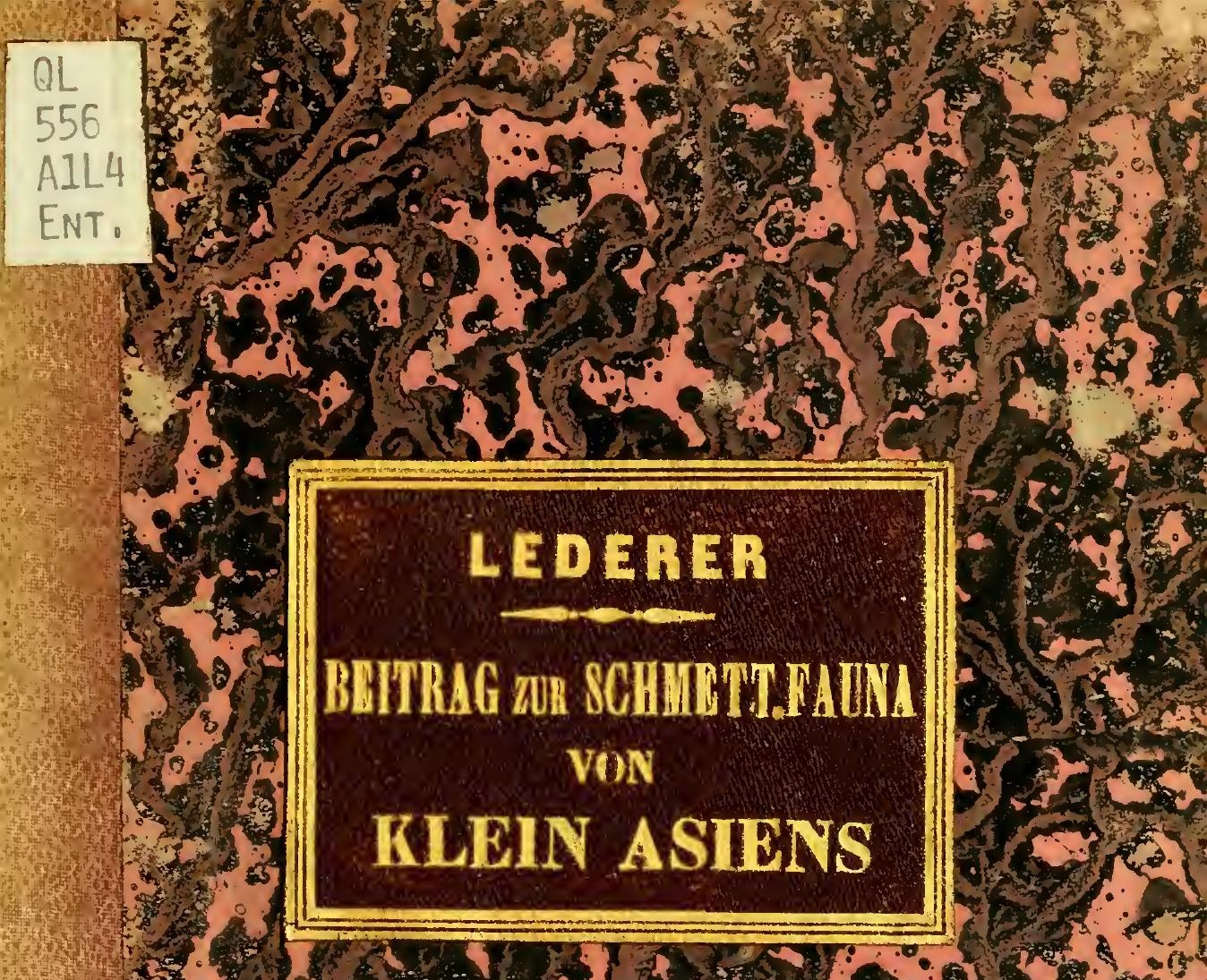
10, 3.

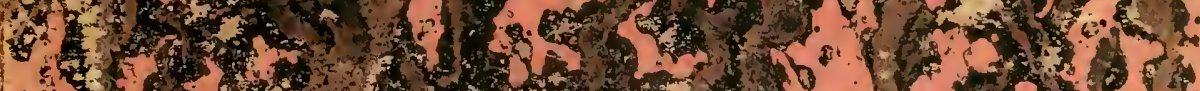
H

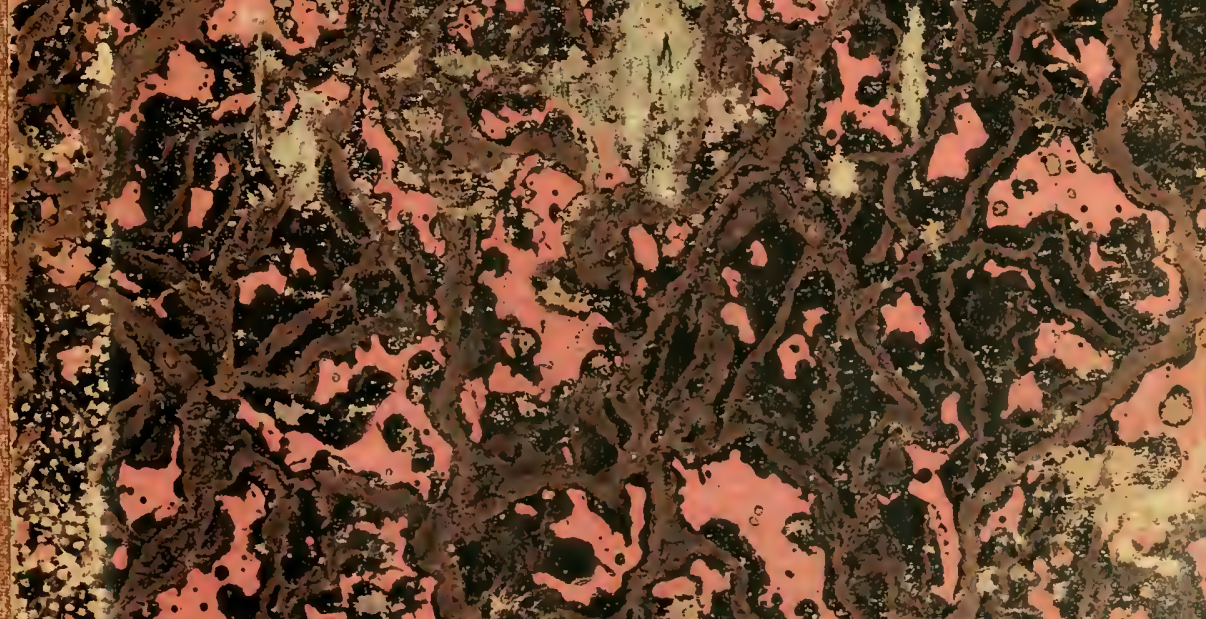




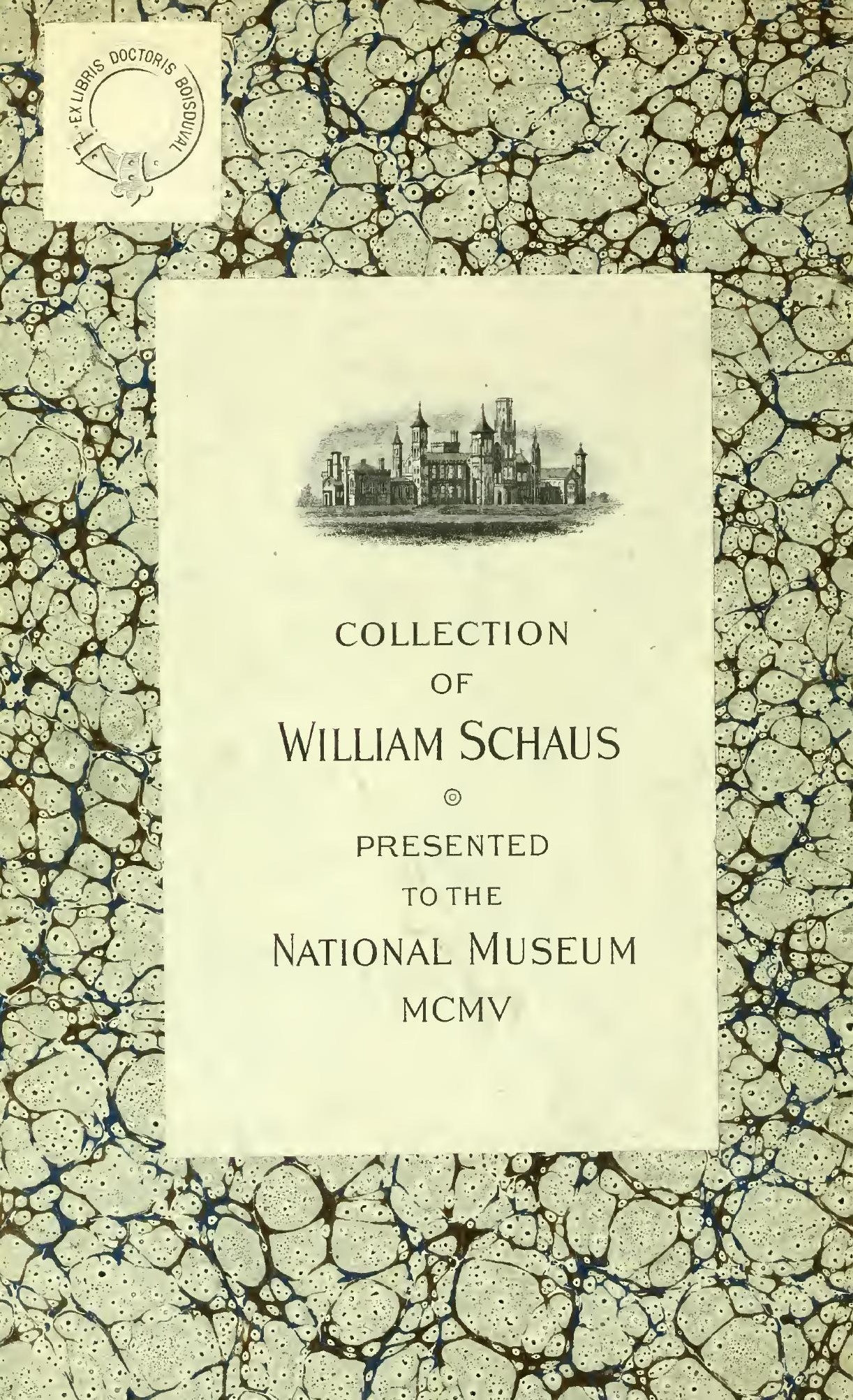






\section{Beitrag \\ Zur \\ Schmetterlings-Wauna}

\section{von \\ Cypern, Beirut und einem Theile Klein-Asiens.}

\section{Voll \\ Jations Lederen.}

(Aus den Schriften des zoologisch-botanischen Vereins in Wien. 1855.)

Im Jahre 1853 sandte ich einen Insectensammler, Namens Franz $\mathrm{Z}$ ach, welcher frïher in Herrn Doctor Frivaldzky's Auftrage Candia und Smyrna bereist hatte, nach Cypern, daselbst Insecten, besonders Schmett rlinge und Käfer zu sammeln.

Die Localität hätte jedoch nicht ungünstiger gewählt werden könıen, denn die Gegend von Larnaca, wo $\mathrm{Z}$ a ch nach einer vierwochentlichen Reise am 7. Mai anlangte, ist kahl, wasserarm und der Boden kreidig, fast olune Vegetation: es ist daher nicht zu wundern, dass sich daselhst ausser einigen in ganz Europa gemeinen Schmelterlingen und den gewöhnlichen Mittelmeer-Käfern fast gar nichts findet.

Eine Excursion nach dem Innern der Insel lieferte ebenfalls ein ungenügeudes Resultat, denn ausser einigen Käfern, worunter Morio colchicus, Buprestis detrita und der auf dem Stavro vuno (Krenzberg) gesammelte Calais Parreyssi das Beste, war auch hier nichts zu finden; ein eben so klägliches Ergebuiss hatte die Bereisung des Nordrandes der Iusel zu Folge und so hat denn die Aufaählung der auf Cypern gesammelten Schmetterlinge kaum anderes Interesse, als das, zur geographischen Verbreitung dieser Thiere einen kleimen Beitrag zu liefern.

Da mir auch Herr Professor Engen Truqui, damals sardinischer Vice-Cousul anf Cypern, nun in Smyrna, der diese Insel durch drei Jahre bewohnte und auch eine Käferfanna derselben herausangeben beahsichtigt, die Armuth an Insecten bestätigte, so liess ich meinen Sammler nach Beirut gehen, wo er an 2\%. Juli 1853 ankam und bis Anfangs August 1854 verblieb.

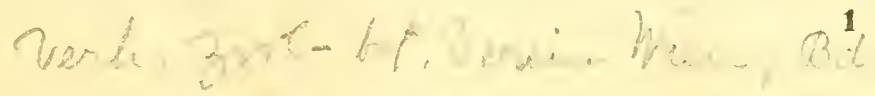


Beirnt liegt in Mitte schöner Gärten an grïnen Hügelı, welche vom Hochrïcken des Libanon - dessen höchste Puncte wohl 10000 Fuss hoch mnd mit ewigem Schnee bedeckt sind - hernieder steigen und in balber Ilöhe des Gebinges in zerklüftetes Felsenterrain ibergehen. Die Berge sind mit Pinien und Fichtenwilderu meilenweit hedeckt, die Thiiler und Schluchten leich bewässert, mit Maubeer-, Oliven-, Citronen- nnd Johannisbrolbäımen bewachsen und voll ïppig grïner blumenreicher Weideplätze.

In der Nähe der Starlt münden zwei Flïsse in das Meer, nämlich eine Stunde oher Beirut der gleichnamige Fluss (Fluss vou Beirul) und noch zwei Stunden nördlicher der llundslluss (Nahr el Kelb), der Lycus der Alien. Die Ufer sind häulig mit Oleanderhiischen, schönen Sträıchern mud Blımen bewachsen; weiter uach dem Gebirge zu werlen sie lelsig, die Felsen sind voll Schluchlen, Tunnels mnd Kliften, zwischen welchen allenthalben Quellen hembrieseln; anch sind hier drei Höhlen, iı welchen sich IVasser befindel mol eine derselben ist von einem reissenden filusse durchströmt.

Iı dieser Gegend wal unn allerdings besser zu sammeln, als anf dem dürreu Cypern und es waren besouders die Ufer des Hunlsfinsses, welche sich am ergiebigsten zeigten. Schmellerlinge waren, wic sich ans nachstehender Aufählnng ergibt, verhältnissmässig trenig, dagegen wurden viele soltone Käfer gefunden, mnter denen ich nur Siagona Oberleithneri und Jenissoni (in Frïhahr unter Steinen), Nebria Kralteri (an den Ufern des Hundsflusses), Procrusles impressus, Carabus Hemprichi und Ehrenbergi, Temmorlynchus relusus, Amplicoma purpurea Redlewbacher und eine ihr älnoliche kleinere Art, die auch in Anatolien vorkommi (purpurea $\mathrm{K} \mathrm{dm.} \mathrm{in} \mathrm{lit.)} \mathrm{Calcophora} \mathrm{stigmatica} \mathrm{(in} \mathrm{ungeheneren,} \mathrm{schön} \mathrm{grüngläızenden}$ Exemplaren in Frïhjahre gemein anf Schlehenstränchern), Perolis chlorana und eine nene Art (beile in Gesellschaft der vorigen, doch selten), Acmaeodera oltomana, hyaciulhina, villosula, birillis nnd discoidea (alle im Frïhjulure anl hiilienden Ilieracien), Melyris bicolor, eine nene Adesmia, einen schönen Lixus bei amgustalus, doels doppelt so gross (Gödeli Koll a r in lit., anl wildem Safran), Prinobins Germari (in Gesellschaft von Hamalocerus velutimus, miles und eines mir liemden Prionus in Mandel- und Eichstämmen) Plugtoecı egregia und humeralis (au schatligen Stellen auf Mentha), Purpuricenus dalmulimus (iib)er t80 Stïcke auf Handelblïlıen), eine kleine Adimonia mit verkïrzten Flügeldecken (im Frühjahre im Grase geschöpft), Rhaphidopalpa foveicollis und Chrysomela Sahlbergi nenne, aher noch manche andere sellene oler nene Ant anführen könnte.

Nachdem ich in nachstehender Aufzählung den Fremuden der Lepidopterolegie ein Bild der Schmetterlingsfanna von Cypern und Beirnt gebe, scheint es mir nichl ohue Interesse auch das von Herrn $\mathrm{Ki} n d$ e r m a n in Klein-Asien vou 1848 bis 1850 Gesammelte anfunführen, "m so mehr, als sich in den Producten des Libanon gegen die der lileinasialischen Ge- 
birge eine hedentende Versehiedenheit ergibt*). Manche der kleinasiatischen Arten mag wohl noch anf dem Lihanon zu finden sein; anch darf es bei Kinderma al's nncrmädlicher Thätigkeit und bekannten Rontine nicht wnndern, dass dessen Einsammlnng reieher ausfiel, als die des minder bewanderten $Z$ ach.

Ueher die von Kind erman n explorirten Gegenden kann ich folgende Notizen nach seinen Briefen gochen:

Er langte am 3. Mai IRts in Samsun an, dessen Umgebung ïberaus romantisch ist, schöıe Berge, bewaldele Ehenen, Sandllïchen etc. enthält, kurz zum Einsammelı sehr günslig gelegen scheint, aher dennoch an Insecten sehr arm ist. Bei Kinde rman n's Ankunft war die Vegetation noch weit zuriek, Eichen und Platanen waren noch nieht vollkommen grïn und von Inseeten ausser Lygcuena anteros, Euplocamus Fuesslinellus (die von II erieh-Seh affer Fig. 24l-243 ahgehildete Varietä) und dem schönen Geotrupes fulyens niehts zu finden: in der Hollnung später eine reiehere Ausbente zu machen, verweilte er noeh drei Woehen, da aber anch dann ansser Pieris damone und Zethes insularis nichts llog, verliess er diese Gegend und zog nach dem wärmer gelegenen Amasia.

Anfangs Juli traf er daselbst ein. Die Stadt schildert er als in einem engen Thale an einem Finsse zwisehen hohen, steilen, felsigen Bergen gelegen. Von diesem Thale laufen hunderte von grösseren mud kleineren in das Gebirge ans, so dass man in vielen Jahren kaum die Uälfte derselben durchiorschen könnte und ungefähr sechs Stunden nördlich liegl Schneegebirge, dessen Höhe K i ndermann auf 6000 Fuss schätzt. Hier wurde eine reiche Ausbente gemaeht. Als Kindermann ankam, llog Pieris ausonia, chloridice und enpheme (alle schon defect), Lycuena boetica, telicanus, trochilus, balcanica, Polyommatus hipponoe, Theclu Nogelli, Satyrus anthelea, Mniszechi, Hesperiu Marloyi, tessellum, lavaterae, Zygaena ganymedes, Liparis terebynthi, Orgyia dubia, IIeliothis Frtvaldssiyg und dos, Ileliodes rupicola, Acontia uremia, Plusia graphica, Ophinsa algira und stolida, Thalpochares pannonica und Wagneri, Leptosia leda, Pyralis consecratalis etc. Im Lanfe des Juli ersehienen Polyommalus ochimus und ignitus, Vanessa jonia, Satyrus mammra, Bischoffi statilimus var. fatu, Hesperia alcides, Heliothis rhodites und vieles Andere; im Angust lieferten wieder die Hochgebirge und Alpen viel Gutes.

Im lahre 1849 wurcle bei Tokat gesammelt, das ehen so giünstig gelegen und von noch höheren Bergen umgeben ist, wie Amasia, aber wenig andere Arten lieferte, was bei der geringen Eufernung beiler Städte wohl auch nicht zu wunderu ist.

18.50 reiste $K i$ il d e $m$ an n mit einer Karawane nach Diarbekir. Auf der leise beribrte er Charput, fand aher die Gegend wenig zum Einsammeln

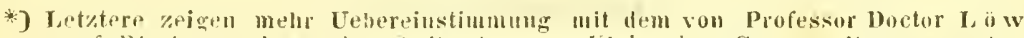

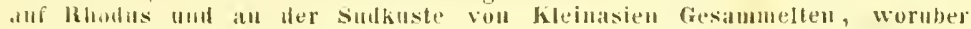

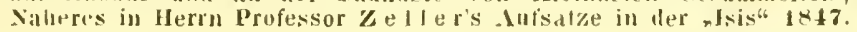


geeignet, da die Stadt nur von ein paar trockenen Hïgelketten und Feldern umgeben, das Gebirge aher zu weit entfernt und von räuberischen Kurden bewolnt ist. In Diarbekir langte $\mathrm{K} i \mathrm{nde} \mathrm{r} \mathrm{m}$ a $\mathrm{n}$ am 15. Mai an, war aber von der Lage dieser Stadt wenig erbaut. Die ganze Gegend entlıält nichts, als Getreidefelder; nur am Tigris abwärts sind die Ufer ein wenig erhöht und befinden sich schöne Gärten, die aber trotz der üppigsten Vegetation nur gemeine europäische Arten enthalten.

K i nderman n beschloss also wieder zurïck nach dem kleinen Orte Bakir Maden zu gehen, den er auf der llinreise passirt hatte und dessen Lage ilım gefiel; aber auch hier war ausser den allenthalben gemeinen Thais Cerysii, Doritis apollinus, Thecla Nogelli, Zygaena ganymedes und einigen Spannern nichts zu finden und die Einsammlung beschränkte sich meist auf Käfer, von denen aber auf der ganzen Reise herrliche, darunter viele ausgezeichnete nene Arten gefunden wurden.

Von Argana Maden kehrte K in de r ma n n nach Tokat zurück. Unterwegs sammelte er einige Tage und zwar um Ende Juni bei Siwas, dessen Hochebenen mit den russischen Steppen viel Aehnlichkeit haben und auch manche russische Art, als Erebia afra, Plerogon gorgoniades, Cucullia argentina und Aspilates mundataria lielerten.

\title{
Verzeichniss
}

\section{der von Franz Z a ch auf Cypern gesammelten Schmetterlinge.}

\section{R h 0 p p a l 0 c c e r $\begin{array}{lll} & \text { a. }\end{array}$}

\section{Equites H.-Seh.}

\section{Prapilio L.}

Hachaon $\mathrm{L}$.

\author{
Thereis $\mathrm{F}$ a b.
}

Cerysii Go d.

\section{Pierides B.}

Pieris S chk.

Brassicae L.

Rapae L.

Daplidice $\mathrm{L}$. 
menatocera $\mathrm{P}$.

Cleopatra L.

\section{Lycaenoidae $\mathbf{B}$.}

Polyomemereles L a t.

Phlaeas L.

tycremer $F$ ab.

Boetica L.

Telicanus $\mathrm{H}$ e rbst.

Balcanica $\mathrm{F}$ re ye $\mathrm{r}$

Trochilus Freyer.

Lysimon $\mathrm{Hb}$.

Cyllarus Fab.

Alexis $\mathrm{H} \mathrm{u} \mathrm{fu}$. (agestis S. V.)

Icarus $\mathrm{H} \mathrm{u} \mathrm{f}$. (alexis $\mathrm{S}$. V.)

\section{Libytheoidae 13.}

Libythen Fab.

Celtis F a b.

\section{KNmphalides $B$. \\ Limenitis $\mathrm{F}$ ab.}

Camilla S. V.

Melituen Fab.

Phoebe S. V.

Vanessa $\mathrm{F}$ ab.

Cardui L.

Atalanta L.

Polychloros L.

Triangulum $\mathbf{F}$ a b.

\section{Danaides 1 .}

Drence is L a t.

Chrysippus L. Von Mitte Hai an durch den ganzen Sommer.

\section{Satyroidae B.}

\section{Soryons' $\mathrm{L}$ a $\mathrm{t}$.}

Hermione L. Die Binden "lianm halb so breit, als bei unsern Exemplaren, auch beim Weibe fast so verloschen, wie beim Hanne; die Hinterllïgel unten heller weissgrau. 
Briseis L. und Var. pirata $\mathrm{H}$ ï b $n$ e $r$. Binde sehr gross mit lehluafter Juterseite; Var. pirata oben sehr lebhatt ockergelb.

Anthelea $\mathrm{Hb}$.

Pex+ener H.-Sch.

Roxellana F a b.

Maera. L. Var. adrasta Es p.

Meguera $\mathrm{L}$.

Coemongosplere H.-Sch.

Pamphilus L. und Var. Cyllus Es p.

\section{Hesperioidae.}

rrespenire L a t.

Maloarmm 0.

Marrubii R b.

Alveus $\mathrm{H}$ b.

Alveolus $\mathrm{H} \mathrm{b}$.

Eucrate Es p. und Var. orbifer $\mathrm{H} \mathrm{b.}$

Actaeon Es p.

Nostradamus F a b.

\section{II e t e r $\begin{array}{ccccc}0 & \boldsymbol{c} & \boldsymbol{e} & \mathbf{r} & \mathrm{a}\end{array}$}

\section{Sesioidae 13.}

\section{Sesin F ab.}

Rhingiaeformis II b. Nur ein Weib.

Luctuosa m. (Vereinsschriften 1852.) Ein Mänuchen.

Fervida m. Tafel 5, Figur 10; Weihchen. Fast doppelt so eross, us chrysidiformis; derselbe Habitus. Körper schwarz, Palpen mehr aulwälts gekrümmt, als bei chrysidiformis, sonst eben so gebildet, nebst Stirn und Hüften orangegelb. Beine ehenfalls orange, nur die untere Halíte ler Schienen schwarz. Fühler orange, fein stahlhlan heschuppt, Thorax mennigroth, eben so das erste Segment des Hinterleibes und die Vorderflügel; Vorderrand und Saum der letzteren schwarz, auch die Rippen sammwäris schwärzlich angeflogen. Hinterflügel mit dickem menuigrothen Mittelfleck und roth hestäubten Rippen, Vorderwinkel und Basis; alle FIügel mit schwarzgrauen Fransen. Unterseite mit derselben Zeichnung, der Vorderrand der Vorderflïgel jedoch mur gegen die Spitze zu schwarz. Hinterleib oben zweites und drittes Segment schwarz, 4., 5. und 6. einfärbig goldgelb, unten jedes Segment zur oberen Hallte gelb, zur unterna schwarz. 
Afterbuschel oheu millou gelb, seitwäts schwarz, unteu schwarz mit gellen Seitentheilen. Das einzelne Stück wurde am 24. Mai nul dem Starro vun gefangen.

Miniarea m. (minianiformis Fre yer.)

\title{
Syntomides II.-Sch. \\ Ninclin B.
}

Ilyalina F r e y e r.

\section{Psychoidae H.-Sch.}

\author{
royehe s e h k.
}

Villosella 0 .

\section{Saturniina II.-Sch.}

Sraterenire Schk.

Caecigena Cupido. Die Raupen im Mai aul dem Staro vuno auf Pappelstrauchern.

\section{Liparides B}

Coecocommon steph.

Solitaris Fre yer. Auf Cypressen.

\section{Lithosioidae B.}

Nolle L e a cll,

Exasperata m. Tafel 5. Figur 11. Nur diess eine IVeibchen. Nahe an chlamydulalis, $1 / 3$ kleiner. Palpen anfwärts gebogen, brïunlich, anliegend heschuppt; Endglied cylindrisch. Halskragen und ein breiter Streif über den Thorax schwarz, alle übrigen Körperlleile weiss; Beine kurz und dick; Hintersehienen mit 2 Paar Sporuen. Vorderlliigel weiss. Angehäufte schwarze Atome bilden ein wenig scharf hegrenztes Miltelfeld, in dem nahe an seiıer Aussenseite (auf der Querrippe) ein grober schwarzer Strich steht; unter ihm, parallel mit der äusseren Grenze der Millelbinde, stehen noch einige grohe schwarze Schuppen. Dem Miltellelde folgt ein schmales Band rou der Grundiabe, sodann hat der Raum bis zum Saume durch gehäulte schwärzliche Atome wieder ein graues Ansehen. An dichtesten stehen diese Atome längs des Saumes; vor diesem findel sich die Spur einer verwaschenen hellen Wellenlinie, welche vou der spitze his gegen die Mille zu in abgesetzten Strichen innen rostroth begrenat ist; an der Inncuseite dieser rothen Begremzung stelen noch grobe schwarze Schuppen, die am Vorderrande am meısten gehänft, daselhst eine Art abgerissencr Zacken bilden, nach innen zo aber nur spärlich vorhanden sind. Die Hinterflitgel sind asch- 
grau, mitten von einem verwaschenen helleren Bande durchzogen; die Frausen breit, auf den Vorderflügeln bräunlichgrau, auf den hinteren weissgrau. Unten sind die Vorderflïgel bräunlichgrau, die hinteren weissgrau, nach aussen elwas dunkler, zeichunugslos.

\section{Euprepioidae. \\ Emagries $\mathrm{B}$.}

Chrysocephala H b. (coscinia 0.) Nur ein Stïck.

Grammica L.

$$
\text { Deiopeire C } 1 \mathrm{r} \text { is. }
$$

Pulchella L.

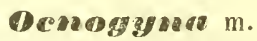

Lömi \%. Ein Weibchen; wurde zufällig unter Wanzen eingesammelt und stimut grnau mit Hern Professor $Z$ e 11 e r's Beschreibung (Stelliner Zeilung 1846, p. 8.)

\section{Noctuina.}

Dianthoccire B.

Comta S. V. Das Schwarz sehr matt, das IVeiss lchmgelb überflogen. Aysocer $G$ ॥ é $I$.

Mnsculosu IIb. Drei Stiicke an dïren Stellen bei Tage auf Disteln.

Cberenderime Tr.

Anceps II.-Sch. Nur ein Stïch.

Exigua II b. In Menge.

\section{Plensice T r.}

Gamma L.

Graphica II.-Sch. Nach Herrn G $\mathbf{n}$ e 1 ée ist diese Art die wahre circumflexa Li nn é; circumflexa S. V. nennt er daher gulla.

$\mathrm{Ni} \mathrm{Hb}$.

\section{Heliothis T $\mathrm{r}$.}

Peltigera S. V.

Dphioesre T r.

Tirrhaea Fab.

Illumaris II b.

Algiva $\mathrm{L}$.

\section{Trenepeguer H.-Sch.}

Squalens m. Tafel 5, Figur 12, Weih. Aehulich der albidentaria Freyer, Fliigel aber kïrzer und breiter, der Saum aul' den histeren 
z.wischen Kippe 3 und 5 nicht eingezogen, die Fïrhung lelumgelh, die Wellenlinien nicht su gleichunissig üher die gan\%e lilïg(lliche und nieht so liell. Körper lehungells, Pailpen aulwïrts gebogen, lindglied fast so lang, als das zweite, cylindrisch, muliegend heschuppt, Zunge spiral, Beine schwach längshaarig, luuhler leim llanne mit ziemlich langen diumnen Wimpern, IJinterleib mit schwachen erhabenen Schöpfchen anf dem 2., 3. und 4. Segmente. Flägel lehmgelh, niebt so blälichgrau, wie bei albidentaria, Zeichunngsanlage nugefilır dieselbe, nur treten hier die beiden Mittellinien anflidlend hervor und sind die übrigen Wellenlinien melır verloschen, willrend bei albidentaria alle gleichmiissig sind. Auf den Vorderfligeln sind die heiden Mittellinien scharl', schwirzlich; dic innere macht einen schwachen Bogen mach aussen, die äussere springt auf hippe 3 und 4 melı oder weniger deullich ror, wendet sich daun melır einwïrts (wodureh das Mittelfeld verschmilert wirl) und liuft dann in grohen Strichen dem luneurande zu. Parallel mit ihr zieht an ihrer Anssenseite ein bläulichgrauer, von einer verwasehenen weisslichen Linie durchzogener Streif; dahiuter werden die Flügel bis zum Saume erdgrau und vor diesem, auf der Flügelfäche selbst zieht eine ahgesetzle schwarze Linie. Von Makelı ist nur die Nierenmakel durch einen bleichen Fleck angedentet. Dic Hinterllügel haben wie bei albidentaria mehrere parallele Linien, welche am Inneurande dentlich, nach vorne verloschen sind und von welchen die die Fortsetzung der ïusseren Mittellinie der Vorderlïgel bildende am schïrsten ist. Die Fransen aller Flügel sind erdgran, breit, sehwach wellenrandig. Die Unterseite ist bleicher, als dic obere, hat eine schwache Andeutung der lichten Wellenlinie und schwarz punctirte Linie vor dem Saume, sonst aber keine Zeichnung. Hanche Exemplare waren bedeutend matter gezeichnet, als las abgehildete. Der Schmetterling wurde an Pllanzen gefangen, welche an rom Wasser durclirieselten Felsspalten wuchsen.

Thalpochares in.

Marginula H.-Sel.. Nur ein Stïck.

Ostrina Hb. In allen Varieläten.

Parva Hb.

Velox Hb. Fast rloppelt so gross, als gewöhnlich, aher allo defect.

Hypen T r.

Obsitalis II b.

Lividalis $1 \mathrm{l} \mathrm{b}$.

\section{Geometroidae.}

Encerstis IIb.

Herbaria II b. 
Acialation $\mathrm{Tr}$.

Rufaria II b

Deyeneraria $\mathrm{Hb}$.

Imilaria $\mathrm{H} \mathrm{b}$.

Turbidaria H b.

Mrecevia Curtis.

Aestimaria Hb.

\section{Hornanirs Tr.}

Perversaria B.

$$
\text { Agotastat H.-Seh. }
$$

Ononaria Fuessly. Selir kleine Exemplare.

Stena.her II.-Sch.

Sacraria L.

\section{Crambites H.-Sch.}

$$
\text { Irepeynet } \mathrm{T} \text { r. }
$$

Floralis IIb.

$$
\text { Horys T r. }
$$

Cespitalis $\mathbf{S}$. V.

Samguinalis $\mathbf{L}$.

Stenophengyr Guén.

Noctuella S. V. (hybridalis H b.)

stenia G II $\mathrm{Cll}$

Suppandalis Hb.

Carnealis $\mathrm{T}$ r.

Denponelectire $\mathrm{Z}$.

Fovealis $\mathrm{Z}$.

Eestonere $\mathrm{C}$ u $\mathrm{r}$ i is.

Incertalis D ap.

Scmonecer II.-Sch.

Punctellı Tr.

Neplopteryx Z.

Dabliella Tr.

$$
\text { penapelisa Z. }
$$

Carmella L. 


\section{Tortricina.}

Metimin Gu en

Thurificana m. Die Beschreibung und Abhildung sehe man bei den Beiruter Arten.

\section{Tineina.}

\section{Dennessenice Z.}

Ledereri Z. Limnaea 1854. Tafel 5, Figur 13. Ls worde nur diess cine Stiick crbentet.

\section{Verzeichnis}

\section{der von Franz $\mathbf{Z}$ a c $\mathrm{b}$ bei Beirut gesammelten Schmetterlinge.}

\section{R ll 0 c p p a l}

\section{Equites H.-Sch.}

\section{Perpitio L.}

Machaon L.

\section{Theais $\mathrm{F}$ a b.}

Cerysii God. Im Mïrz und April hä̈fig an Wegen, Feldrainen ete.; das Weilıchen weit seltener, als das Männchen.

\section{Dorilis Fa b.}

Apollimus Herbst Im Februar und Marz an denselhen Stellen, wis: der vorige.

\section{Pierides 1 .}

eiesis s chk.

Rapae L.

Mesentina Go d a r t. Im September an Ricinus Hiegend.

Daplidice L. Das Grïn der Unterseite mehr gellhtich und viel spärlicher, als hei unsern Exemplaren: bei manchen Stücken vom Weiss fast ganz verdrä̈lgt. 


\section{Anthoctertis $B$}

Glauce II b.

Ausonia. Es p.

Belia F a h.

\section{reacoptrersin Steph.}

Sinapis L. Grosse Exemplare; Hinterflingel unten selır bleich gezeichnel; bei einigen Stiiclien ganz zeichnungslos (Var. diniensis B.)

\section{Ielusecis B.}

Fausta 0livier. Tafel 1, Figur 1. Mïnnchen. Das Characteristische dieser Gatlıng ist bein Männchen ein an Rippe 1 der Vorterflügel nicht weit von der Basis stelenden blasigen Knop , mngefähr wie ilın das Männchen von Chrysippus auf den Ilinterfligeln laat; ich finde dieses Merkmahl bei B o is d oval nicht angegeben. Der Schmetterling lìgt in Gärten häılig rom Juli bis in den September.

\section{Colins $\mathrm{F}$ a b.}

Edusa Fab. und Val. helice $\mathrm{Hb}$.

\section{Hronatuena B.}

Cleopatra L. Im Frihjahre nicht selten.

\section{Eycaenoidae 13.}

\section{Crigrupires L u c a s.}

Acamas KI $\mathrm{I}$. (Symbolue physicae; deras IV, lab. XL, Fig. 7 9). Tafel 1, Figur 2, Weibchen Den ganzen Sommer hindurch in ganz diirren Gegenden anf Disteln elc. Nach Ilénétries (Descriplion des inscrles recucillis par feu Mr. Le $\mathrm{l}$ m a $\mathrm{n} n$ ), auch bei Lenkoran, auf den Steppen von Kisil Koum. Der Schmellerling häl das Miltel von Thecla und Polyommalus. Von beiden Gatfungen unterscheidet er sich durch die wie bei Rhodocera allmählig von der basis zur Spit\%e verdickten Fiiller und die zweischwänzigen Ilinterllügel ( ler längste Schwanz sleht auf Rippe 1. wo die heiden genannlen Gallıngen ungeschwinzt sind) von Theola noch durch die nackten Augen ans. Oh bej den Exoten Uchergänge zu den übrigen Lycaenen-Gatlungen vorkommen, ist mir mbekannt, loch wahscheinlich, da die bisherige Einhlucilnng in Thecla, Polyommatus und Lygraena sulbst hei den Europäern nichl stichlältig und wohl richtiger nur zwei Gallungen, die eine mil harigen, die audere mit nacklen Angen anzmelmen wälen.

\section{Thecela Fa b.}

Ilicis Es p. in allen Uebergingen zur Valr. caudalula Z.

Spinis. Y. Beide (ieschlechlor mit viel linger geschwimzlen HinterIligelu, als dic hesigen. (Heluntho hlug Symbolae physicaetab. IL. Ry. 10, 11.) 
Poryommerces L a t.

Thersamon Es p. Erscheint in zwei Gencralionen im April mud auli. Die im Sommer lliegenden falter hahen in heiden Geschlechlern lang geschwänzte llinterllügel, die der firülingsgeneralion sund grwöhnlich ungeschwänzt, es kommen aber anch Ueherginge vor; die geschwäinte Varietait ist Omphale Klug (Symbolae physicate tab. XL, fig. 12-14.)

Phlaeas L.

Eycoesere if a b.

Boetica L.

Telicanus ll erbst.

In Juni anf blühendem Spartium etc.

Balcanica Freyer. In Mai und Juni aul Sträucherı lliegend. Ilrrr M a ॥ I fand diese Art ancls hei Spalato.

Gamra Koll a lu lil. Tafel 1, Figur 3. Männchen. Grösse und lilïgelschuitt von lylas. Palpen wie bei dieser Art gebildet, oben schwarz, unten weiss, Beine weiss, Tarsen und Fühler schwarz geriugelt, Kolbe der lelzteren comprimirt, lang oval, schwarz, an der Spitze mnl ganzen Unterseite lebhaft rostgelb; llinterleib oben schwarz mil weissen llinterüudern der Segmente, unten weiss; Ingen nackt. Oberseite der Flïgel beim Manne zart röthlichblan, ungefähr wie bei argiolus, aber noch mehr rölılich, mit schmalem selıwarzen, nach innen uicht sehr scharf hegrenzten Saume, an welchen anf den Hinterhiigeln an Inuenwinkel zwei rerloschene schwarze Flecken (Andentung der Zeichnung der Unterseite) stehen; beim Weibe im Discus schmntzig lichlbrau, gegen Vorderrand und Sanm zu allüilig dunkler, anf den Vorderfïgeln daselbst last scluwarzbraun und mit einem an der Stelle der Querrippe befindlichen dunkelbramen, wic bei balronica gelormten Flecken, wn welchen der Grund heiderseits heller, fast weisslich wird; auf den Hinterllügelı mit schmutzig braunen nach innen heller begrenzlen handlechen, von lenen die zwei nm lnuenwinkel stehenden am deutlichsten und dunkelsten, dir ührigen aber verloschen sind. Fransen hei beiten Geschlechtern weiss, anf Rippe 1 slets beim Manne sehwarz, beim Weihe bran bezoichuel, an' den ïbrigen Rippen nur sellen schmal domkler durchschnitten. Die Unterseite ist beim Manne weissgran, heim Weibe etwas mehr hrämulich mit schwarzer Saumlinie. Die Zeichung eriunert an Teliromns mul balcanica. Mit ersterer Art lat gamra die malte bianderartige Zeirhmung gegen die Spilze der Vorderlliggel und anf deu Iliuterlligelu, mit letzlerer den dunklen Längstriemen unler der Vorderandsrippe der Vorlerflïgel gemein; dieser ist aher hier nur dicht an der Basis schwarz, soust rostlarbeu. Die Vorderlliged haheu hinter der Mitte der Millelzelle einen anf den Innemand derselben aufliegrenten grossen schwarzbrumen Puncl, einen von gleicher Gröse am Samme in Zelle 2, vicl elwas kleimere edenfalls dicht am Saume hefoulliche in Zelle 3-6, eincu oder zwej solu undentliche unter dem in Zelle 3 hefindlichen. Anf der Ourrippe steht riu schrigger, licht liallich- oder granbranuer Fleck, millen zwisehen diesem und 
der Flïgelspitze cine gerade, vom Vorderrande sammärts ziehende Binde von derselben Farhe, linter ihr ein paralleler schmälerer nud undenllicherer striemen, unter ihr, mehr nach innen gerielit ein oder zwei undentliehe Flecken, vor den Randpuncten eine ebenfalls weniger scharfe hrännliche Linie; diese ganze Zeichunng ist heller umzogen und auch die Grundfarhe wird gegen den Inuenrand zu heller. Die Hinlerflügel - heim Manne an der Basis schwach grïnspanfärbig - haben nngelähr dieselbe lichtkaffehbranne Zeichnung. wie die vordern, uämlich cinen Querfleck auf der Mittelrippe, eine gerald Binde dabinter, hinter ihr ein Striemen, sodann die Linie vor den Raudflecken. Ausserdem haben sie noch mehrere tief schwarze Flecken; nimlich einen von der Basis zur Mitte der Vorderrandsrippe ziebenden bis all diese freichenten geralen strichförmigen (wie bei balcanica), hinter ihm nahe am Vorderrande (in Zelle 7 ) zwei runde, der äussere weiter vom imreren, als dieser vou dem Wurzelfleck entfernl; unter dem inueren auf dic Mitte des Innenrandes der Mittelzelle anfsitzend, einen von gleicher Grösse, dicht nnter ihm (in Zelle 1 b) einen kleineren, zwei mit den ührigen gleich grosse oder doch nur wenig kleinere am Innenrande, beide den in Zelle 7 hefindlichen zwei Flecken in gerader Linic gegenüber stehend. Raudfeclien sind 5 his 6 vorhanden; sie sind ebeufalls lief schwarz, die beiden an Innenwinkcl stehenden am grösslen, sanmwärts erzglänzend beschuppt, der in Zelle 2 stehende noch an seiner Innenseite mehroder weniger denllich rostgelh mmogen; der in Zelle 3 ist am verloschensten, die in Zelle 4,5 und 6 belinllichen sind zwar kleiner als die am Innenwinkel, aher scharf ansgedrückt. Der Schmelterling lliegt im Juni und Juli auf Bromberblïthen: Herr Kots chy brachte iho auch aus Sennaar.

Lysimon $1 \mathrm{~h}$ h. Im .Juli anf Klecfeldern.

Galba Kollar in lil. Tafel z, Figur 4, Mänuchen. Von ohen kaum rou lysimon zu unlerscheiden. Der Mann hat dasselbe Blau nud deuselben breiten schwarzen Saum, die flinterflïgel haben aber in Zelte 2 einen schwiirlichen, durch cine helle Linie rom Sanme getrennten Randfleck; das Weib ist oben einfähig hrann, der schwarze Fleck in Zelle a der llinterllugel ist noch deullicher und hlailich mmogen, die iihrigen Zellen haben ebeufalls Sparen von Raudflecten, hesonders gegen den Innenwinkel zu und die lichte Randlinie ist elwas schärfer. Die Unterseite ist licht brännlichyran, wie bei lysimon oder trochilus, heim Weibe nur wenig dunkler, als heim Manne. Die Zeichnnng nähert sich hier mehr dem trochilus. Anf den Vorderfligelı stimut sie ganz mit dieser Art, mur sind die Kerne der Flecken uicht so schwarz, sondern matthanu, daher nicht so scharf vortretend. Die Hinterfligel hahen ebenfalls viel Achuliches mit trochilus, besilzen aber keine orangegelhe Randlunde. Die Form und Lage der mallhranuen angenartigen Flecke st dieselbe, wie bei trochilus; in Zelle 7 stehen zwei schwarze, hell umzogene Flecke, unler dem inneren, mohr wurzelwurts noch ciner, alle an gleicher Stelle wie bei genannter Art; der bei trochilus darunter befindlicise vierte tejult jedoch bei galba, der an 
Innenrande selbst stehende - bei trochilus. scharfe - ist hier nur malt vorlanden und von den Randflecken sind un die in Zelle 2 belindlichen grossen liefschwarz und mit Erzschuppen helegt, die ïhrigen aber lileiu und matthraun. Ich crhiclt nur \& Stïcke, welche in Gesellschaft von Iysimon

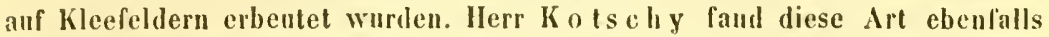
in Sennar.

\section{Hylas S. V.}

Icurus II $\mathrm{f} \mathrm{n}$ a $\mathrm{gel}$ (ulexis S. V.) und Var. thersiles B.

\section{Nymphalides B.}

\section{Eimencitis Fab.}

Camilla S. V. Die weissen Flecke grösser, der Wurzellleck der Vorderlliigel hellblan.

\section{Netituea $\mathrm{F}$ a b.}

Phoebe S. V. Kleine hellgefärbte Exemplare.

Trivia S. V. Var. persea Kolla $\mathrm{r}$ iFauna von Siidpersien in den Annalen der kais. Akad. d. Wissenschaften 1849). Im April in Mehrzahl gefangen und auch die Raupe später auf Verbasceen gefunden. Der Schmellerling ist oben ungemein hell gefärbt, (fast wie gewöhnliche didymaMiinnchen) und die schwarze Zeichnung selı fein, es finden sich jedoch Ueberänge zu rrivia. Von Herrn Kols ehy auch in Sïdpersien gefunden.

Weacesin $\mathrm{F}$ a b.

Polychloros L.

Triangulum F a b.

\section{Danaides $B$.}

\section{Danceis $L$ a $t$.}

Clirysippus L. Im ganzen Sommer nicht selten; die Var. alcippus wurde nichit gefunden.

\section{Satyroidae B

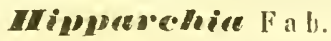

Tilea KIug (Symbolae physicae tab. NXIY. Pig. 15-18.) Tafel 1, Figur 5, Mänchen. Nahe an lachesis und verhält sich dazn - oberllächlich betrachtet - ungefilhr wie Var. procida zn galathea. Von französischen Entomologen wnde mir titea für lachesis Var. erklïrt, doch mit Unrevhl, denn characteristisch ist anf dea Vorderflïgelı der schwarze Mitlelllock, der bei titea am Vorderrande selbst heginnt, daselbst am breitesten isl mud nach iunen schmal zuliult, bei lachesis aber ersi unler dem Vorderrande, 
anf der Vorderrandsrippe anfängt und da ein sclumaler viereckiger Fleck ist, an welchem ein mehr als doppelt so breiter hängt. Feriler stelı auf der Unterseite in der Millelzelle vor dem Flecken am Zellenschlusse constant noch ein scharfer schwarzer Fleck; die Kappenzüge aller Flügel sind ohen ganz verloschen oder bis anf wenige weisse Fleckchen verdrängt, da das Schwarz his an den Sanm reicht, "nten aber fein und bogenförmig (bei lachesis fast so scharf und spitz, wie bei clotho); die Miltelzelle der Hinterliigel ist oben fast bis ans Ende schwarz, ïberhant das Schwarz vou ter ganzen Basis an viel reichlicher; die Miltelbinde anf der Unterseite der Hinterluigel ist ans viel zarteren, feineren und anders geformten schwarzen Strichen gebildel mol ilure Auslïllmng nicht dunkler als der ührige Flïgelgrund, wälıend sie bei lachesis ans groben schwarzen Strichen besteht und steingrïn ansgefüllt ist. Der Sclmetterling lliegt im Mai häufig an Inndsllusse in Celsigen Gegenden.

\section{Sictyones $\mathrm{L}$ a $\mathrm{t}$.}

Asterope K I $1 \mathrm{~g}$. (Symbolae physicae tab. XXIX, fig. 11-13.) Tafel 1, Figur 6, Weibehen. Den ganzen Sommer liudurch allenlhalben häufig.

Psisidice K I $1 \mathrm{~g}$. (Tafel XXIX. fig. 9, 10.) Diese nach Herrn P'rofessor Dr. Klıg am Berge Sinai llegende Art fand $\mathrm{Z}$ ach auch in den Gebirgen des libanon im Juli, brachte aber nur $\mathbf{6}$ Stiicke mit, da er zur Flngzeit des Schmetterlings am Fieber erkrankte und keine Excursionen machen konnte. Der Schmelterliug hat einige Aehulichkeit mit statiliuus Var. fatua Fre yer, die Färbung der Oherseite zieht aber melı ins Grane und die Millelbinde der Unterseite der llinterfligel ist anders gelormt. Diese besteht ans zwei dicken sammtschwarzen Linien, von denen die innere gerade und fast senkrechl rom Vorderrande bis zur inneren Hiltelrippe zieht, anf diese aufstösst und da plötzlich verlischt, die äussere aber in Zelle 3 sich sehr dem Sanne nühert, daselbst einen scharfen Winliel macht, dann aber fast gar lieine Vorspriinge mebr bildet.

\section{Proverye H.-Sils.}

Maera L. Var. adrasta II b.

Mecaera L. Genall wie dic liesigen.

Egeria L. Var. meone Hb.

Epinentere H.-Sch.

Janira L. Var. Lelmessia Z. In allen Uebergängen zur Var. Lispulla Hh.

Coemonymanfier it -Scll.

Pamphilus L. und Var. lyllus Esp. 


\section{IIesperioidae.}

Hespentive L a 1.

Malcarum 0. Die Falter der Sommergeneration oben sehr hell gefälht, fust wie lavalerue.

Marmbii Rb. und Var. gemina L e d. Die Exemplare der Sommergeneration elenlalls nit sehr heller Oherseite. Dass gemina doch nur Vur. marmbii, davon habe ich mich seither dureh Vebergainge ïberzengt.

Proto Esp.

Nomas m. Tafel 1, Figur $;$, Mann. Iclı erhielt nur ein Pärelıen, das im Mai am Ilundsllusse gefangen wurde. Der Schmetterling ist obeu nicht von tessellum z.n unterscheilen, unten sind aher dic llinlertlïgel sammt den Fransen einfürbig gelblichweiss (wie bei lavalerae) mit von oben sehwach Aurchscheinender Zeichuung. Körper, Beine, Palpen und Uuterseite der Fühler sind wie die Unterseite der Hinterfïgel gefärbt, auclı die Vorderflügel haben unten beinahe dieselhe Farbe, um die Mittelfeclie herum und gegen die untere Ilällte des Saumes zu ziehen sic aher melı ins Bleichgraue. Der Vorderrand der Vorderflügel des Mänuclıens hat deuselben häutigen Umschlag, wie tessellum.

Hypoleucos m. Tafel 1, Figur 8, Manı. Der Schmetterling ist mit alveus $11 \mathrm{~b}$. verwandt, eben so gross, hat aber viel külzere, breitere und rundere Flïgel, als diese unl andere verwandte Arten und ganz verschiedene Unterseite. Die Oberseite ist grünlichgran, beim Weibe mehr olivbrau, wie bei carthami.. Die Fransenbezeichnng und die Flecken sind wie bei dieser Art, letzlere nur reiner weiss, etwas grösser und aul den Vorderllïgelı nicht so scharf eckig. Die Flecken der inneren Binde der Ilinterflïgel sind ebenfalls rein weiss; ein Fleck in der Mitle lieser Bincle tritt selbst bei matt gezeichneten Exemplaren besonders vor (ungefähr wie bei alveolus) während bei carlhami die ganze Binde ans gleichmässigen, nit dunklen Atomen überzogenen schmalen Längsflecken bestelıt, bei alveus und Var, fritillum ebenfalls nicht so deutlich hervortritt. Auf der Uuterseite sind die Vorderfligel dunkelgrau, gegen den Vorderrand zu melır grünlich; die Flecken sind hier ebenlalls runder, weniger vom Grunde ahstehend und mehr gelhlich als hei den verwandten Arten. Die Hinterllügel sind bleich grünlichgelb, gegen den Saum zu dunkler, melı ins Olivbranne ziehend; durch die Mille des Flügels zicht von der Basis bis zum Saume ein heller Längsstrahl und die Zeichnung der Oberseite ist ebenfalls durch lichtere, aher ganz unbestimmte, verloschene Flecke angedeutet; sonst fundet sich keine Zeichmung. Die liransen sind weiss, auf allen Rippen mit Ausuahme vou 1 und 5 schwarzgrau gescheckt. Das Männchen hat ebenfolls am Vorderrande der Vorderilügel einen Umschlag. Die Fühlerkolbe ist unten lebhaft rostgelb. Der Schmetterling fliegt vom Mai his in den Juli as feuchten Stellen und ist ziemlich selten. 
Encrale E.s p. und Var. orbifer II l.

Arlaeon Es p. Meide häifig.

Thrax F a b. Tafel 1, Figur 9 Mann, 10 Weib. In Sommer an leuchten Stellen. Durch ein Versehen des Stechers wurde diese Art slatt der nachfolgenden newen abgebildet; ich beschriuke mich daher daranf, hei letzterer blos die Unterschiede von lhrar anzugeben. Der Schmelterling komml schon bei Tarsus (in Karamanien) vor und ist bis Ostindien verbreitef.

Zelleri m. Grösse, Bilłung der Körpertheile mnd Flïgełschnilt genan wie bei nostradamms, der Schmelterling also viel kleiner mol schlanker als thrax. Zeichunng dem Weibe vou lhrax sehr ähulich, in bejlen Geschlechtern gleich. Vorderflügel spälicher behart als bei thrar, mit denselben durchsichtigen weissen Flecken, Miltelzelle aber nur mil einem, und zwar dem an der Innenseite des Vorderrandes Jer Mittelzelle befindlichen; Querbinde aus ; elen so geformten und gestellten Flecken hestehend, die Irei dem Vorderrande zunächst stehenden aber in gerader schräglinie nach aussen gestellt. Ilinterfligel mol Fransen wie bei lhrax. Die Unterseite ist lebhalt grïulich oder gelblich oliv, auf den Vorderfligeln vom Discus bis zum Innenrande, anf den hinteren am Innenwinkel graubraun. Die Vorderlïgel haben dic Flecke der Oberseite, die histeren in dor Mittelzelle keinen Punct, hinter ihr aher drei kleine helle, dunkler umzogene Flecken, als Fortsetzung her Vorderlingelzeichnung. Die schlankere Gestall, geringere Grösse nnd gleiche Zeichnung beider Geschlechter unterscheilen Zelleri leicht von thrax die durchsichligen Glasflecken vom I'eibe von nostradamus. Der Schmetlerling wurde in wenig Exentularen im Juni aul Brombeerstranchen gefangen.

Nostradamus Fab. Im Sommer an trockenen Orten nicht selten.

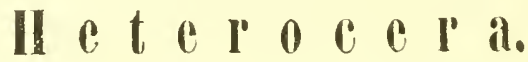

\section{Sesioidae B.}

\section{Sesire $F$ all.}

Azonos m. Tafel 2, Fignr 1. Mann. Grösse von tenthrediniformis : clwas plumper, fiügel ein klein wenig hreiter nol rumder. Die färlung des ganzen Geschöpfes ist ein stellenweise stahlblan oder grïnlich glinzenles Schwarz, nur die Ränder der Augen, der Halskragen, das milllere Drittel der Schenkel und die Mitte der Unterseite des Alterhiischels sind beichgelb. Palpen und Fähler sind wie bei tenthrediniformis gljildet, schwarz. Die Vorderlligel haben Innen- und Vorderrand, Saum und MitlefHeck breit schwarz, so dass von Glasstellen das Wurzelfeld nur als ein sehr schmaler, von einer dicken schwarzen Ader durchschniltenen Striemen nud die äussere llakel als ein haum so breiter als langer, runder, von drei schwarzen Adern durchsehnitlener. Fleck überbleiben. Die Jlinterlligel haben 
cinen ziemlich dicken schwarzen Miltellech, der aber nicht äber den ganzen Zellenschluss reicht, sonderu ggegen Rippe $\&$ zu erlischt. Die Fransen aller Filigel sind schwaryeran, die Unterseite ist so gezeichnel, wie die obere. Das einzige Stück wurde im Mai am Ilundsllusse auf einel Pflanze silzend getrollen.

Pipisiformis m. Tafel 2, [ïgur 2. Männclıen. Mit culiciformis verwand! nur halb so gross. Körper grüulich stahlblau; Brust, Augenränder, Oberseile des virten Hinterleibsegmentes, Seilcurinler des llinlerleibes, cin schmaler Samm des Afterhüschels auf der Oherseite nud eimzelne llaare in ler Mille desselhen auf der Unterseite blass goldgelb. Pulpen aufwärts gekrümm, schr spitz zulaufeul, oben schwarz, unt'n weiss. Fühler stahlhau mit einigen weisslichen Scluppen vor der Spitze und langen Wimpcru; Beine slahlblau, Schenkel an Aufang mud Ende der Inncuseite und längs der ganzen Aussenseite geblichweiss; Tarsen nur am Anfange schwach stahlblau ungellogen, soust elueulalls gelblichweiss. Die Zeichung der Vorderlligel ist ungefälı dieselbe, wie bei culiriformis. Vorder- mnd Innenrand sind schmal schwarz, die Mittelhinde ist rerbïlnissmässig schmal und stösst auf den lumenrand ganz auf; der Sanm ist wenig hreiter als die Mitlelbinde; das Wurzclleld ist von einer diclien schwarzen Ader durclizogen, der änssere (ilasfleck ziemlich eben so breit als boch und von vier schwarzen Adern (unf der Tafel sind unr drei angegehen) durchschuillen. Die Ilinterfligel fïlıen einen dicken schwarzen Miftelpunct, der von Rippe 5 zn 4 selu fein zuläuft. Alle Fransen sind schwarzgran. Unten ist die Zeichnung wie oben, unr linden sich längs des Vorderrandes, um den Miltelfeck und aul den Rippen blass goldfarbe Schuppen. Der Schmetlreling wurle unr in zweigul erbaltenen männlichen Exemplaren in Frühling an Weizenähren am HundsUnsse gefangen.

lchnemmoniformis S. V. Wenige Stiicke im Soumer anl dïrren Bergen erhentel.

\section{Sphingoidae 13}

\section{Deilegleitra 0.}

Syriaca m. Aul' der zweilen 'fafel sibiriseher Schmetterlinge : Figur 9 der

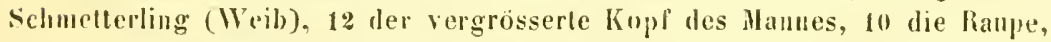
11 dic Puppe abgebildet. Her Pog ge bestimmle mir diese Art als den is Nord-Amerika vorkommenden Sphinx myron Cra me o nder pampinatrix Abbol, worm sie aber sicher verschirden ist, und sich sehon durch den gezacklen Vliigelsanm unterscheidel; ich liess daher die Abbildung crst nachlraglich anterligen. Grösse von elpewor, Flügelschnill von porrelius, der Saum tritt jedoch auf den Rippen zackig vor, besonders anl den Vorderllügeln (in meiner Abbildung isl diess viel zu schwach ansgedrückl). In Bildung der Korpertbeile stimml der Schmelterling inil porcellus, nur sind die Fuhler am Ende nicht hakenformig ungebogen, soudern laufen dasclbst in eine schlanke, wenig gelirummle spitze ans; unlen sind sic wie 
bei allen verwandlen Arten mil zwei Reihen steifer Borsten beselzl; ebenso haben die Ilinterschienen zweI Par slarke Spormen. Färbung mul Zeichnung ähuell deu Smerinthen, doch ur scheinbar, denn der Verlauf der Binden zeigte mehr Uebereinstimmung mit porcellus, zudem verweist die lange slarke Spirulzunge, fler Fliigelschnitt und die Raupe den Schmellerling zu Deilephila. Die Farbe der Vorderfingel ist beim Nann ein maltes, blass rosenroth beduftetes Grau, beim Weibe mehr braun, in's Weinrothe ziehend. Dieselbe Farbe hahen alle Köpertheile bis auf die Schulterdecken, welche an der Basis, und die Segmente, welche an den Hinterrindern hell gerandet sind; ferner die Fühler, leren Oberscite fast weiss ist. Die Zeichnung der Vorderflïgel besteht aus trübwolkigen Flecken und Querbändern von der Farbe dürren Laubes. Nahe an der Basis zicht sehr verloschen vom Vorderrande bis zur Mille der Flügelbreite ein düuner Querstreif, hinter ihm ein hreiterer, einwärls gebngener, nach bejden Seiten in dic Grundfarbe verwaschener Wisch, sodann lolgt ein dunklerer Querstrich an Ende der Miltelzelle, anf der Qnerrippc. Nahe hinter diesem beginnt der Mlittelschatten. Dieser ist an seiner Inmenscile am schärfsten von der Grundfarbe abgegrenzl, nach anssen aher in dieselbe verwaschen, und in der Gegend der Querrippe etwas answärts geschwungen, sonst fast gerade. Parallel mit ihn läult im Saumfelde, und zwar bei der Mille desselben, eine dicke, grohstrichige dunkle, beiderseits heller begrenzle Linie, welche anl' den Rippen schwache Vorspringe nach aussen macht. Die Flügelspitze ist durch einen lichten Wisch getheilt; dieser Wisch setzt sich geschwungen und modeutlich begrenzl his zum Innenwinkel inrt, und ist an seiner Innenseite am Vorderund Inuenrande des Flügels dunkler gewölkt. Die Fransen sind etwas dunkler als der Flugelgrund und trelen anf allen Rippen zackig vor: die Zacken sind ungefähr wie bei Smer. popmli, doch weniger tief eingeschnitlen, und an ihren Spitzen weniger slark abgerundet. Die Ilinterflïgel sind beim Mann hleichbrau, heim Weibe rothbrau, an Vorderrande beller. Am Saume zieht ein dunkles, eiuwäls verwaschenes Band, das rom Vorderrande gegen den Inıenwinkel spilz zuläuft, nahe vor und parallel mit ilım ein verwischler dunkler Streif. Die Zacken sinn sehwäeher als anf den Vorderliigelu, die Fransen bleicher, am Innenwinkel fast weiss. Unten sind alle Flügel beim Manue gelblichgrau, beim Weihe rothbrann mil dunklerem Nittelschatten, einem Bogenstreif dahinter und einem wolkigen Sammande. Die Raupe ist chagrinartig rauh, griun mit einem langen rölllichen Horne, zwei weisslichgelben Quersireifen, welche hinter dem Kopfe beginnen, ïber die Mitte des Riickens ziehen und sich beim Horne vereinigen, und rothen Luflöeherı, deren jedes in einem undeutlichen lichten Schrägstriche steht; gleich der von porcellus und elpenor ist sie anf dem dritlen und vierlen Gelenke sehr dick und nach vorne rüsselformig verschmälert (meine Abbildung ist in der Form uicht gelungen). Die Puppe ist licht grauhraun, anf den Fliggelscheiden dunkler gesprenliclt, in deu Leihciuschuillen und anf deu Lufllochern dunkclbraun. Vie Raupe land 
\%peh im Hni und Anfungs Juni um Hundsllusse in feuchten, schatligen Gegenden auf wilden Wein, der sich un Bummstämme schlingt; die Entwicklung crfolgte schon 5-6 Wochen nach der Verpuppung.

Alecto L. Die Ranpe (ihre lieschreibung wurle mir nicht mitgetheilt) Ende Mlai und im Juni, dann wieder im Ilerlste an Weinstöcken, doch nur an solchen, welche als Spaliere an den llänsern gezogen werden. Von der ersten Generalion erscheinen die Schmellerlinge schon 14 Tage nach der Verpuppung; von der zweiten ïherwintert die Puppe und liefert den Schmetterling in Frühjahre.

Celerio L. Die Raupe im Mai und Angust an denselhen Stellen, wie alecto, doch weil seltener. Der Schmelterling schon 14 Tage nach des verpuppung.

Licornica Esp. (lineala F ab.) Die Raupe in Mai selten anf Weinstöcken : der Schmellerling nach 5-6 Wochen.

Nerii L. Ebenfalls in 2 Generationen. Die Ranpe im Frihling und Herhste, ziemlich hänlig; die Schmetterlinge kleiner und matter gefirb, als die hiesigen und Dalmatiner.

\section{Zygaenoidae $B$.}

\section{zysuence F a b.}

Grasliui m. Tafel 2, Fiğ 3 Mann, 4 die Raupe; Grösse elwas unter achilleae; Flïgel kürzer und runder, wie bei oxylropis oder rhadamanthus. Die Behaarung des Körpers ist dicht und elwas filzig abstehend, schwarz. Dieselbe Farbe haben Beine und Fühler. Letztere sind sehr dick und plump und endigen wie bei rhadamanthus in eine dicke, oben stark abgestumpte Kolhe. Die Vorderllügel simd malt slahlblan oder grtinlichschwarz. Ihre gewöhnliche Zeichuung besteht in drei Paar untereiuander stehenden scharf hegrenzten, lebhaft zinnoberrothen Flecken, von denen dic inneren zwei Paare durch die Innenrandsrippe der Miltelzelle schmal getheilt siud, das äussere Paar aber slets zusammenhängl. Die zwei Flecken an der Basis sind am längsten, beide gleich lang und jeder fast doppelt so lang, als breit; der obere stösst fast ganz an den Vorderrand an. Von dem Mittelpaare ist der untere Fleck grösser, als der obere, mnregelmässig geforml und schräg nach aussen gestellt. Vou dem äısseren Paare hat der obere Fleck ziemlich die Form des dritten und vierten, in der Grösse hält er aber las llittel zwischen beiden; er steht nngefähr so, dass die Querrippe gerade durch seine Mttle zieht und an ihm hängt sanmwärts zwischen lippe 3 und 5 der sechste Fleck, der gewöhulich langs der Rippe 3 selır scharf abgegrenzt ist und ziemlich nahe vor dem Samme endel. Die Hinterllügel sind zimoberroth mil schmalem schwarzen Saume. Unten sind die Vorderlïgel dïnn heschuppt und die rothe Zeichunng ist nebelartig in einander verllossen; die Ilinterfligel sind wic oben. Varietäten sind nicht selten; es hängen oft der erste nnl drilte Fleck oder beide Mittelpaare, am sellensten alle Flecke zusammen. Dic lianpe ist sammlschwarz mil glinzend 
schwarzem Kopf, gelben Beinen und gleichfabigen Nacken und zwei Reihen hass rosemrolhen Wärchen - je zwei nebeneinander auf jedem Gelenke - ïber den liacken. Sie wurle im Februar mul März aul verschied(nen niederen Pllanzen gelunden und lielerte im April den Schmelterling, welcher zu derselben Zeil aurh im Freien zahtreich erbentet wurbe. Das Gespinust wurle mir nicht milgetheilt.

Ino L e a c I.

Geryon Var. obsema $Z$.

Heydemeirhi II.-Se h.

Ampelophaya Ba il e-Barelli.

\section{Psychoidae 11.- Sich.}

posgertersili.

Villosella 0 . Nichl selten.

Bruandi m. Tafel 2, Figur 3, Mänuchen, 6 Sack der liaupe. Nahe an apiformis. Etwas schlanker, die Flïgel bach anssen sehr erweitert und gerundet, die vordern am Innen- und Vorderrand fast gleich lang, alie hinteren halım länger als breil, kürzer als bei allen verwanden Arlen. Körper etwas schlankel, als bei apiformis, dicht wollig, aher weniger zotlig; die Wolle schwarzbrann, auf Röelien nnd Oberseite des Ilinterleibes mehr gelhgrau. Fühler vou $1 / 3$ Vorderrandslänge mit langen, diunen, ziemlieh regelmässig gestellten, filzig bchaarlen Kammzähnen, welche gegen die spitze zu allmälich hïrzer werden. Vorderflïgel an der Basis vom Vorderrande bis zur iuneren Mlllelrippe gelblichgran, in der Millelzelle fast ohne Beschuppung, die ans ihr entspringenden Rippen, der Ranm von ilır bis z.um Vorderand und Same und von Rippe 1 z.um Innemand schwargrau beschuppt. Ilinterfliigel ziemlich gleichmässig grau, nur am Inuen- und Vorderrande und Sam clwas dunkler; die Rippen scluwärzliclı. Fransen selumal, scliwarz. Die Vorderfligel haben 12 hippen, 2 und 3 , sonlert, 4 und 5 aus einem Punct (bei einem Lxemplare sind sie gesondert, loch sehr nahc an einander) 8 mol 9 an eincm Sticle, 10 und 11 ans dem Vorderande ler Hittelzelle, 12 lrei. Ilinterfligel mit zweilheiliger Mittelzelle und 8 Rippen; 2 und 3,6 und F gesondert, 4 und 5 geslielt (stalt beiden zuweilen nur eine vorhanden), 8 frei ans der Wurzel. Das Weih verlässt die Puppenhiilse nicht. Diese ist schwar, vorn mul hinlen lichtbrann, von den verwadten Aiten nicht zu unterscheiden. Die Ranpe leht auf dürren Grasern. Dic Säcke wurlen schon Anfangs danner eingelragen; sic sind ans quev und dicht an einander liegende Stengeln verfertigt und mit graner Seide mmsponen. Die Rampen leblen in der Gefangenschaft $2-3$ Monate ohue Nahung zu sich zu nehmen und licferlen Ende April und Anlangs Hai den Schmellerlingr. Die meisten Raupen slabben und aris einer

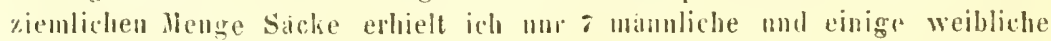
selunctlerlinge. 


\section{Bombycides 13 .}

Hombyx l).

(vocles IIh. Der Schmellerling differirt, die Färbung abgerechnet, nicht erheblich ron trifolii: die liaupe jedoch (ron der ich ein halhwïchsiges und zwei erwachsene Exemplare ansgeblasen vor mir habe) ist dunkler behant, als die ron trifolii, mchr der ron quercus ähnlich und hal einfärbigr braune Nackenllecke ohne Orange, was für die Artrechte spricht. sic wurle zahlreich im Vriblinge auf versehiedenen Pfanzen gefunden, doch staben fast alle obler verlockneten als Puppen: ilur Cocon ist wie das von trifolii und quercus; aus einer milgebrachlen Puppe erhielt ich ein schüncs Münuchen am 2. October.

\section{Liparides 13 .}

\section{Cractocessonper Ste pli.}

Solitaris Fre ye r. Raupe im Frïhjahre auf Cypressen, Schmelterling im Sommer.

\section{Despentide II.-Sch.}

Allamlica II.-Sch. Drei defecte Männchen in Hochsommer Nachmitlags in den Strassen der Stad Hiegend gefunden. Her r i cli-Schäffer's Abbilılung gleicht gar nicht der $R$ a m bu rschen in der Fanne d'Andalousie; es dïrflen hier wohl zwei verschiedene Arten anznnehmen sein wud zu ersterer wabrscheinlich Iapidicola II.-Sch. ats kleinere Varictäl gehören.

\section{Drygira 0 .}

Trigotephras B. Nur zwei Manuchen erhahen. In Andahsien fand ich die Ranpe nicht sellen im Mai an Eichbüschen: sic gleicht der von antiqua, hat aber mehr Blan.

\section{Euprepioidae.}

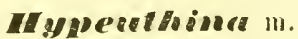

Fulgurita m. Tafel 4, Figur 1, Weib. Ich erhiell uแr 3 Mäunchen und 2 Weibchen, über deren Vorkommen mir nichts Näheres milgaheilt wurde. Die Aelulichkeit in Zcichnung und zum Theil anch im Habitus mit Cynaeda dentalis reranlassten nich, dieses Thier bei den Pyraliden abbilalen zu lassen, un ich aber zum Untersuchen komme, finde ich, dass der Schmelterling dem Geaider und den vorhandenen Ocelten nach unr hei den Fuprepioiden unlergebracht werden kann. Zu den Pyraliden kann er nicht gehören, denn er hat nur zwei freie Imnenrandsrippen der Hinterfligel und diese hahen drej; ron den Noctuen enternen ihn die aus dem Vorderande 
Jer Mittelzelle, hei den Noctuen frei ans der Wurzel entspringende Rippes der Hinlerflïgel; von den Lithosiden und Geomelriden die Ocellen, von den Drepanuliden ebenfalls die Ocellen und das Geäder; an die ïbrigen Zünlte (If e r r ch-S chäffer's Nycleoliden, über welche weiter unten,) ansgenommen, ist ohnehin nicht zu denken. Zufolge der Fliggelform, die meh" von den Lithosiden (z. B. Selina) als ron den Euprepiiden bat, betrachle ich den Schmellerling als Bindeglied beider (iibrigens nur durch die bei ersteren fehlenden, bei letzteren vorhandenen Ocellen getrenulen, also anch ein sehr ungenïgendes Merkmahl basirten und wohl richliger sammt Ilerrich-Schäffer's Nycleoliden in eine Zunft zn vereinigenden) Familien und stelle ihn der vorhandenen Ocellen wegen zu lelzlerer, wo Fr der platlen Slirne, schwachen Zunge und des Geäders wegen eine eigene Gattung bildet. Von sämmtlichen Enprepiiden hat nul Emydia keine Rippes der Hinterflügel (bei allen übrigen Gallungen ist sie so stark wie die andern Rippen), diese Gallung hat aber lieine Anhangzelle, eine verlicale Stirn, Spiralzunge und anders geformte Fühler. Ich gehe vorerst die Beschreihnng dor Körpertheile: Körper schlank, anliegend heschuppt, Ilinterlrih ohme Sclöpfe, beim Weibe wenig dicker als beim Manne und ziemlich spitz zulanfend; die Afterklappen des llannes länglich halbkugellörmig, gnt \%usammenschliessend. Beine anliegend beschuppl, nur die Schienen aussen mit

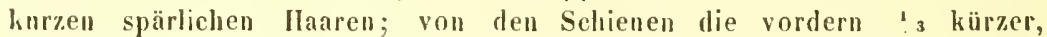
die mitlleren eben so lang, die hinteren 1/3 länger als ihre Schenkel; die hinteren mit langen Mittel- und Endspornen. Augen nackl, ziemlich gross, stirne platt, in form einer länglichen Blase vorspringend, Palpen schwach und lä̈ngend, mit sehr kinrzem, stumpfen Endgliede, liurz beschuppt, gnt bis zum Stirnvorsprung reichend. Zunge un aus zwei ganz kuryen, weichen Fïlen bestehend. Ocelten seillich ter Fühlerbasis, dicht ober dem Augenrante. Fühler nicht ganz halb so lang, als der Vorderrand der Vorderliügel, beim Manne dick, mit sehr kurzen Kammzähnen; die Zähne nicht linger als der Durchnesser des Fühlerschaftes, jeder Zahn mit einem ihn an Lïnge übertreffenden Pinsel steifer Haare heselzl; beim Weihe borstenlïrmig. Halskragen und Schulterdecken wie bei Emydia geformt. Mippenbildung: Vorderlyigel mil 12 Rippen und einer anf die Hillelzelle aufsilzenden Anlrangzelle. Rippe 1 läuft nahe ober den Innenrande des Flïgels, 2 entspringt aus dem Innenrande der Mittelzelle, 3 vor, 4 aus der nn!eren Ecke derselben, 6 aus der oberen, 5 sehr nalse an 4,7 und 6 aus der Spilze der Anlıngzelle, 9 aus 8, 10 aus dem Vorderrande der Miltelzelle, 12 zielı frei, als Vorderrandsrippe. Die Hinterfiigel haben eine Haftborste und acht Rippen; Rippe 3 und 4, 6 und 7 enlspritigen aus einem Puncle, ersteres Paar aus der unteren, letzleres aus der oberen Ecke der Mittelzelle, 2 ans ihrem Innen-, 8 aus ihrem Vorderrande, 5 fehlt. Beschreibung der Flügellorm und Zeichnung: Vorderflingel gestreckt, (beim Manne kïrzer als beim Weibe) an der Basis schmal, nach aussen erweitert, mil banchigem Saume, geradem Vorder- und Innenrande, etwas vortrelender stumpler Spitze, 
kïrzerem, stark gerundeten Intuenwinkel. IIinterllügel am Innen- und Vorderwinkel gerundet, ilır Saum zwischen Rippe 4 und 6 ein klein wenig eingezogen. Die Vorderllïgel sind hellgran; sie erscheinen hier und da durch lichtere Stellen etwas lä̈gsstreifig und haben an Vorderrande gegeu die Spitze zu einige dunklere Strichelcheu. Zwei bleich strolıgelbe, tief schwarz unterstrichene Längsstriemen ziehen von der Basis nach aussen; der eine stösst mit seiner oberen Scite an den Inncnrand Jer Mittelzclle und reicht bis zur Flügelmitte; der andere steht in der Mittelzelle selbst und zwar so, dass er dieselhe theilt, nïmlich seine obere Seite an den Vorderrand der Zelle stösst und der schwarze Streif unter ilım durch die Mlitte der Zelle zieht; auf den Zellenschlusse steht ein auswärts gekelırter lıalbmondförmiger lichter Fleek, hinter welchem der Längsstrahl sich in die Grundfarbe verliert. Von der Fłïgelspitze zum unteren Längsstriemen läuft eine Reilie geschwungener unregelmässiger lichter Splitterflecke, welche aussen schwärzlich aufgehlinkt sind und zwischen beiden Striemen ist die Grundfarbe elwas dunkler grau, als anf der übrigen Fläche. Die Saumlinie ist schwarz punctirt. Die Fransen sind breil, gran, auf den Rippen sclımal hellgelb durclıselmitten. Die Hinterflügel sind bleich gran, an Basis und Fransen etwas heller. Unten ist ausser dem hellen Mondlleck der Vorderfingel keine Zeichnung vorhandeu; die Fransen der Vorderflügel sind hier bleicher gescheckt, als oben. Heine drei Männchen siud etwas dunkler gefürbt, als die zwei Weihchen, aher nicht ganz rein, daher ick lieber das Weibchen abbildete.

\section{Crallimanepher Lat.}

Hera L. Sehr grosss.

\section{Anectire Steph.}

Oertzeni m. Tafel 2, Figur 9, Weibchen, 8 Raupe. Anf den ersten Anblick der pudica ähnlich, Thorax und Halskragen sind aber einfarbig schwarz (bei pudica ersterer gelb gestreift, letzterer ganz gelb), die Fïbler lichtgelb, an der Spitze bräunlich (bci pudica schwarz), der Längsstriemen der Vorderflügel verbindet stets nur die beiden mittleren Querbänder, wälsrend er bei pudica bis zum Saume zielıt, alle Striemen sind viel höher fleisclifarb angeflogen, dic Hinterflügel lebhafter roth etc. Fïhler und Beine sind wie bei pudica gebildet und der Schmellerling variirt auf gleiche Weise. Er wurde Mitte October in 8 Exemplaren an Steinen sitzend gefunden. Die Raupe war im Jänner und Februar unter Steinen häufig, doch entwickelte sich auch nicht Ein gutes Exemplar. Sie ist schmutzig gran mit steifen borstigen gelbbraunen llaaren, lichtem Seitenstreife, einer sclımäleren Linie über demselben, lichtbraunem Kopf und röthlichen Füssen.

Den Schmetterling benannte jch zu Ehren des Ilerru August von 0 e $r$ tze $n$ in Friedland in Meckleuburg und es gereichl mir um so mehr 
zum Verguigen, diesem licbenswïrligen Ehrenmanne und eifrigen Entomologen diesen Beweis meiner Hochachtung geben zu könneu, als Eudorea Oertzeniella Herich-Schäl'fer nit pallida Stephens zusammenfällt.

\section{Denogynat m.}

Clathrata m. Tafel 2, Fignr 7, Männchen. Nur diess eine Stïck erbalten. Der Schmelterling ist etwas grösser als maculosa oder parasita und hat dieselbe Flügelform. Kopf, Brust und Thorax sind dicht wollig behart, die Behaarıng bildet zwischen den Fülılern tinen Schopf; dieser ist milten scliwarz, an den Seiten schmutzig weiss. Der Halskragen ist sclimulig weiss, schwarz gerandel, der Thorax blass fleischfarb, die Mitte desselben und die jeder Schulterdecke schwarz; die Brust schwarz, vorn gelblichweiss, der Hinterleib weisslich fleischfarl, mit einem schwarzen Streifen, der auf dem ersten Segmente die ganze Breite desselben einnimml, gegen das Ende zu sich aber allmälig versehmälert; die Behaarung ist anf den ersten Segmenten zottig, gegen das Ende des Leibes geht sie allmälig in anliegende Beschuppung ïber. Die Beine sind kurz, ganz in den dichten Zotten der Brust versteckt. Ohne sie loszubrechen, kann ieh nur die vordereı genan beselıen, delen Schenkel hochcarmoisinroth nnd deren Schienen schwarz, sehr kurz mit einer starken Kralle am Ende sind, dann die hinteren, deren Schicnen bloss Endspornen haben. Die Fühler hahen wie bei nuculosa lange diunne Kammzähne bis zur Spitze; der Schaft ist schmutzig weiss, die Kammzähne sind schwarz. Die Vorderfligel sind schwarzbraun mit schmutzig weissen gillerartigen Striemen. Einer derselben zieht von der Mille der Basis, wo er blass lleischlarb angeflogen ist, gerade zum Saume und lïnft da dicht oher dem Innenwinkel aus, ein anderer hinter $2 / 3$ der Fliigellänge vom Vorderrande zur Hille des Innemrandes ziehender durchlirenzl ihn; in dem dalurch abgeschlossenen Hittelfelde sleht am Vorderrande ein schmaler, lïnglicher, elwas einwärts gebogener Striemen, im Saumfelde ein Zackenstreif, von welchem der erste Zacken am Vorderrande nahe vor der Flügclspilze beginnt und in das obere Drittel des Sanmes zieht, der zweite in clas obere Drittel des Querstriemens, der dritte in das Ende des Längsstriemens auslänft. Die Ilinterllügel sind schmulzig weiss mit einem unregelmässigen schwarzen Querbande vom Vorderrande ïber den Zelleuschluss bis zu Rippe 2 , einem grösseren gleichfärbigen Fleck yor der Flïgelspitze, der nicht ganz an ten Satm anstosst und zwei kleineren an den Saum anslossenden gegen den Inuenrand zu. Alie Fransen und der Innenrand der Vorderflïgel sind schunutzig weiss. Unten haben alle Flïgel dieselbe Zeichnung wie ohen, nur ist das Schwarzbraun matter und ler längsstriemen der Vorderflïgel lehhafter lleischfarb, als oben. Die grleich gehildeten mul gefäblen Vorderbeine könuton in meinen clathrata 
den Mann zu Löwi vermuthen lassen. Dem widersprechen aber die hier hellen, dort schwarzen Fühler ").

a) Die Galtungsmerkmale von ovnogyua (Trichosoma B.) sind nicht stichlialtig.

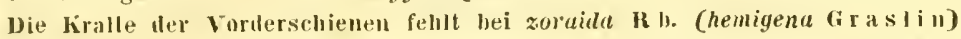
und das Weih ist nicht immer verkümmert, wovon mich eint bei Tarsus in Karananien vorkommende Art, welche mir Herr E. Beldier de la chaviguerie in Paris kürslich in drei Exemplaren mitheilte und ich nach ilm beneme, ïberzengt. Diese hat ein vollkommen geflignltes IVeib, aber atuch die Katle der Vorter- und boss Fudspornen der Hintersihienen.

Arctia Bellieri m. Etwas kleiner als maculosa, Vorderflügel mehr gerunlet, wie bei Imblusa. Der schnetterling scheint sehr zu variiren, Kopf, Brust, Mhorax und Beine sind bei meinem Männchen einfärlig gellgrau, bei den zwei Weibchen dumkler, brangrau. Der Ilinterleib ist anliegend beschuppt, oben beim Manme lleischfarb, beim IVeibe schön roth mit ciner Reihe s.liwarzer Flecken über den Rürken und groben schwarzen Puncten in deu seiten, unten schwar\%. Die Vorderschenkel sind leblaft carmoisin mit einer langen starken Kralle am Eule, die Mitlel- und IInterschenkel bleichroth, die Schienen und Füsse mit der Brust gleichgefärbt; die IInterschienen haben nut Endspornen. Die Fühler haben bei meinem (im Ganzen weit heller gefärbten) Männchen einen luelgelblichen Schaft mnd \%wei Reihen gleich langer regelmassiger lammzilme bis zur spil\%e, beim Weibe simul sie dunkler umb haben kurze scharfe sigezälne. Bie Vordertïgel des Mäuchens sind schmutzig graubram mit trïb lelıufarbigen Querbantern, welche die Grumbarbe fast ganz verdringen. An der Basis ist diese Querzeiclumug ganz verworren und undentlich; es lasst sich nur ein Vartiger mit semer spilze answarts gerichteter Zacken vou lex Farbe des Flïgelgrundes, wetcher auf den Rippen hell durchschnilten ist md einen „unklen Punct an der Flügelbasis einschtiesst, erkemsu. Dentlich sind die folgenden zwei Querbinter, von denen das eine mit semer Imensejte an die Querrippe der Hittelzelle anstösst (in dieser selbst sleht llahe vor der Bimde ein kleiner lelumgelfer Fleck) das andere lurch die Mitte des ansseren Flïgelrammes zieht. Der Samm und tie Fransen sind elsenfalls lehmgelb und diese Farbe macht auf den Rippen splitterarlige Flecke nach imen; die bramne Grundfarbe ter Flugel awischen bejden Binden erscheint daher als eine Reihe ahgesetater Flecke. Die Ilinlerflugel sind bleichroll, latngs des Imnenrandes etwas dumkler, mit einem srowarzgratlen flech auf der Quterippe, einem gleichfarbigen Bande dahinter, das am Vorderwinkel hegimt, munterbrochen his zu riple 2 zieht und nicht mit seiner gangen lange an len saum anstöst, und einemgleichfarbigen Flerk am lmemwinkel. Unten ist dieselbe Zeichmmg, wie oben, nur bleicher vorhanden.

Von meinen zwei Wejbchen bat das eime kaffehhamne Vorber- und memnigrotle Hinterfligel, das andere graubrame Forder- nut carmuisiorotue llinterthgel. Fon der lichten Vacichung der Vordertïgn finden sich bei erslerem mo 3 abgerissente Flecke der ersten Querbimle mal die zweite Bimds,

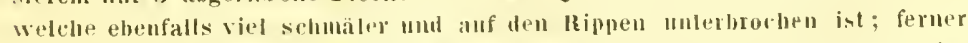
einige gan\% kleine gelbliche Floken am samme auf den Riplen. Das zweite Exemplar lad von der jussern guerbinte nur wenige spurto, dagegen als

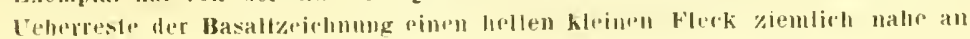




\section{Noctuina.}

Simey"re Tr.

Dentinosa F r c y e r. Raupe häufig in grossen Nestern an Euphorbien.

\section{Acrongete T r.}

\section{Rumicis L.}

\section{Hovgoptrila 'T r.}

Labecula m. Tafel 2, Figur 10. Männchen. Ich erhiclt nur diess eiue Stiick; es wurde im Sommer, schon etwas geflogen, an einem Felsen ge-funden. Grösse, Flïgelschnilt und Beschuppnng wie bei lupula, Fühler mit eben so langen Wimpern. Körper grau, Hinterleib anf dem ersten und zweiten Segmente nur mit schwachen Spuren von Rïckenschöpfen, (do;) mögen diese abgerieben seiı), Palpen aufwärls gekriimmt, etwas vorstclıend; Beine kräftig, Schenkel und Schienen längshaarig. Vorderflügel matt graubraun. Zeichnungsanlagen wie bei lupula, die beiden IIakeln aber fein lichtgrau umzogen, das Millelfeld mit einem grossen bleichgelben Fleck unter deu Mlakeln, die änssere Wellenlinie heller. Hinterliugel aschgran, saumwärts dunkler, mit dunklem Mittelpunct und helleren Fransen. Unterseite grau; Vorderllügel mit Andeutung der Makeln, Hinterlliigel mit Mittelpunct.

\section{Spincticerops B.}

Exsiccata m. Tafel 2, Figur 12, Mann. Ich erhielt nur das abgebildete Männchen. Dieses ist $1 / 3$ kleiner als dilucida und noch schlanker; die Vorderflïgel sind beträchtlich schmäler, als bei dieser Art, sonst aber nebst den Ilinterfïgeln eben so geformt. Die Zeichunug ist gegen die verwandten Arten etwas fremdartig und erinnert einigermassen an Charadrina, novon aber schon die gleiclıstarke Rippe 5 del Hinterflïgel den Sclumetterling entfernt. Körper und Beine grau, sehr lang und schlank, ersterer den Innenwinkel der Hinterfligel überragend und etwas flach gedrïckt, letztere sehr spärlich behaart, die llinterschienen fast doppelt so lang, als die Schenkel mit zwei Paar langen Spornen, der llinterfuss kaum halb so lang, als die Schiene. Zunge spiral, Palpen anfwärts gekriimmt, das erste und zweite Glied dicht, lang und schneidig beschuppt, das dritte am Scheitel empor ragend, schueilig, die Bescluppung kurz und anliegend. Halskragen und Rücken glatt gestrichen, Hinterleib ohne Schöpfc. Fühler fein, mit

der Wurzel und einen grösseren mehen ihm, gegen die erste Mitfeibinle zu; alle helle Zeichmmg ist hei diesem Exemplare schwarlich umzogen. Die Zeichunng der Hinterfliggel stimmi hei beiden Exemplaren mit der des Mannes, doch ist sie lier dunkler. Unten führen alle Flugel dieselbe Zeichnung wie oben, mur sind die Binden der Vorderfügel so lebhaft roth, wie die Hinterflugel und der Flugelgrumd ist fast siduwarz. 
langen, dümmen, weit voll eiunder stehenden IVimpern. Vorderflïgel hellgrau mit elwas gelblichem Stich, am Aussenrand dunkler, fast schwarzgrau, die in diesem lunklen Grunde stehende lichte Wellenlinie undentlich, verwaschen, in ihrer Mitte etwas nach aussen vorspringeud. Basal- und Miltellinien, so wie der Mittelschatten fehlen gänzlich und es findet sich an Zeichnung mur die sehr kleine, licht holzgelbe, dunkler gekernte runde Makel und die weit von ihr entlernte ehenfalls sehr kleine Nierenmakel, welche weiss ist und inmen an Oher- und Unterseite einen schwarzen Punet trägt; ferner ein fciner ästiger schwarzer Längssıriclı unter den Makeln, welcher von der Basis bis zur Gegend der lunden Makel reicht und schwarze Aısfüllung zwischen beiden Makelı. Die Hinterflïgel siud weissgrau mit einem breiten schwarzgranen, nach innen verwaschenen und vor dem Innenrande verlöschenden Randhande, dunkler bezeichneten Rippen und Zellenschlusse. Unten sind alle Flïgel weiss mit breilem schwarzen, nicht ganz zum Innenrande reichenlen Randbande und hellgrauen Fransen; die vorderen noch mil zwei schwarzen Puncten auf den Enden der Querrippe, die hiuteren nur mit einem, auf dem oberen Ende derselben.

Triplectenes $\mathrm{T} \mathrm{r}$.

Pronuba L. und Var. innuba Hb.

\section{Agrotis T r.}

Puta II b.

Trux II b.

Suffusa S. V.

\section{Erateren tir.}

Chenopodii S. V.

Srriptura Freyer. Ein verkriuppeltes Stück entwickelte sich bei mir aus einer mitgebrachten Puppe im .länner.

Relina Freyer. Die Raupe vom November bis zum Februar unter Steinen. Sie ist röthlichbram mit einem schwachen Absatz auf dem letzlen Gelenke. Das Rückenschiff ist breit aschgrau, beiderseits schwarz eingefasst. Auf dem ersten Gelenke slehen zwei grosse schwarze Puncle neben einander, anf dem zweiten zwei kleinere; von ihnen laufen die beiden Riickenlinien aus; und auf dem vortelzten und letzten Segmente sind diese ebenlalls punclartig verdickt. Die Raupe nährt sich von verschiedenen niederen Pllanzen und liefert deı Schmetterling 4 Wochen nach der Verpuppung.

Pretogopleore Tr.

Meticulosa L.

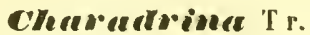

Exigua II b. Ziemlich vicle Exemplare erhalten.

Latebrosa 11. Tafel 2, Figur 11. IVeibehen. MIt exıgua velwandt, Vorderflügel aber kïrzer und breiter, ungefähr wie bei morpheus, Ilinter- 
leib ebenfalls mit einem horizontalen Schuppenkamm auf dem ersten Segmeute. Stirne glatt beschuppt, Thorax glatt gestrichen, Palpen anfwärts und etwas vorstehent, nit kurzem stumpfen Endgliede. Zunge spiral, Fühler beim Manne mit schwach vortretenden Ecken und langen dünnen Wimpern, beim Weibe kurz bewimpert. Zeichnung in beiden Geschlechtern gleich. Thorax und Vorderflügel erdbranu, mehr oder weniger ins Graue ziehend, glanzlos; die halhe Querlinie an der Wurzel kaum angedentet, die beiden Mittellinien dentlich und doppelt, innen dunkJer als anssen, wie bei exigna angelegt. Beide Makeln heller als der Grund, fein schwärzlich umzogen, wie bei exigua geformt; die Nierenmakel ist dunkJer gekernt, die Zapfenmakel fehlt. Der Mittelschatten ist kanm angedeutet. Die lichte Wellenlinie ist weit verloschener, als bei exigna und hat an ihrer Innenseite zuweilen einige dunkJe Pfeilstriche. Alle Linien und der Mittelschatten entspringen ans dunklen Vorderrandflecken und zwei lichte Puncte stehen noch an Vorlerrande zwischen der äusseren llittel- und lichten Wellenlinie. Die Ilinterflingel sind nebst den Fransen schneeweiss mit feiner dunkler Saumlinie. Unten sind die Vordertlïgel aschgran, die hintern weiss, am Vorderrande gran bestäubt, zeichnungslos. Die Ranpen wurden zngleich mit denen von retina gefunden, aber nicht uäher heachtet. Ich erhielt nur 8 Schmetterlinge. Die Flïgelform unterscheidet latebrosa leicht von exigna, die langen Wimpern der männlichen Fühler und der Schuppenkamm des IIinterleihes von den übrigen Charadrinen.

Cerestis $\mathrm{T} r$.

Mansueta H.-Sch. Nur zwei Stïcke.

\section{Cleophereen B.}

Antirrhini II b. So licht lılaugrau gefürbt, wie linariae, alle Zeichmung viel schärfer als gewöhnlich.

\section{Ceccellice Tr.}

Chamomillae S. V. nebst Var. calendulae $\mathrm{T} \mathrm{r}$, und chrysanthemi II b. Plosiate $\mathrm{T} r$.

Chalsylis H b. Raupe im Ilerbst auf Salbey, Schmetterling schon im Februar.

Gamma L.

Circumflexa L. (graphica HI.-Sch.)

$\mathrm{Ni} \mathrm{Hb}$.

Heliotheis 'Tr.

Pelligera s. V. Darunter auch zwei Stücke der Var. mbigera II.-Sch. Armigera II b.

\section{Alenstien T r.}

I'rania fipeser. Nur eill schlechtes Sliicli. 
Cestocentes $5 \mathrm{c}$ li $\mathrm{k}$.

Ilymenuea s. V.

Separala fircyer. Circa 20 Slïcke im Inli in gelegten dïrren Eichbïschen gefangen. Der Schmetterling ist vielleicht doch nur eine diister gefïble Varichit von disjuncta.

Enlychea Tr. Jïn Pärchen an Eichstimmen.

Nymphagoga 11 b. Mehrere sehr grosse Exemplare zugleich mit separata gefangen.

\section{Dpreiersie Tr.}

Tirrhaea F a b. Ein Stïck an einem Johannisbrothan sitzend gefunden. Illumaris $11 \mathrm{~b}$.

Algira L.

Geometrica F a b.

Slolidu F a b.

Zertoes $\mathrm{R}$ b.

Insularis R b. (Nullyi Freyer.) In Mehrzahl im Mai und Juni au trockenen Berglehneı; kleiner, vicl dunkler und schärfer gezeichnet, als gewöhnlich.

\section{Therdpocturses m.}

Oslrina II b. mil ihren Varietäten.

Parva II b.

Phoenissa m. Tafel 2, Figur 13, Männchen. Grösse und Flïgelschnitt von parva. Kops, Thorax und Hinterleib gelblichweiss. Vorderfluge! in zwei Qnerfelder getheill. Das innere ist elwas kleiner, als das änssere, bleich strolıgelb, am Ende in schräger Richtung nach innen gerade abgeschnillen und daselhst olivgrïn begrenzt, welche Farbe in das Gelb sanft vertrieben ist. Das äussere ist violett-rosa; die Fliigelspitze ist durch einen bräunlichen, innen verloschenen Schrägwisch gelheilt; ober dem Innenwinkel und zwar nahe vor dem Saume sleht noch ein mehr oder weniger deutlicher, gelblicher, aussen braun beschatleter länglicher Fleck. Die Fransen sind gelb. Dic Hinterlingel sind lichtgrau, nach aussen etwas dunkler, mit helleren Fransen. Die Unterseite ist einfärbig grau, ohne Zeichnungr; die Vorderflügel sind nach aussen etwas dunkler, als die hinteren. Es whrden nur wenige Stiicke im Sommer an trockenen Berglehnen gefangen.

Psilogrumma m. Tafel 2, Figul 14, Weibchen. Mit polygramma velwandt, aber elwas grösser, fast wie glurea. Körperlheile wie hei allen verwandten Arlen geformt, Kopf, Rïclien, llinterleil unl Vorderflügel kreidigweiss, glanzlos. Die Zeichmung der letzteren besteht in zwei verloschenen schwar\%en Puncten, welche dic Hakelu vertrelen und wic bei polygramma gestell sind und drei zarten olivbraunen, beiderseits heller begrenzlen rom Volderrande schräg nach aussen gewendelen, sodann winklich gebro- 
chenen schräg einwärts ziehenden Linien. Die innere derselben zieht liber den ersten schwarzen Punct und ist sehr verloschen; die äusseren zwei sind am schärl'sten, ziehen ziemlich weit hinter dem ersten Punct, parallel und sehr nahe an einander; hinter ihnen wird der Raum bis zum Saume dunkler, mehr bläulichgrau; von der Flïgelspilze zieht ein heller Wisch in den Winkel der äussern Querlinien, vor ihm steht ein schwärzlicher, puncturtiger Fleck, am Vorderrande drei licht olivbraune Strichelchen und parallel mit dem Saume, gegen den Innenwinkel zu noch eine weissgraue verlosehene Linie. Die Sanmlinie ist matl olivbraun. Die Fransen sind breit, der Länge nach gellıeilt, zur inneren Iälfte olivfarb, einwärts heller verwaschen, zur äussern lichıgrau, von einer hellen Längslinie durchschnitlen. Die Ilinterflügel sind sammt den Fransen hellgrau und haben gegen den Innenwinkel zu Spuren der Fortsetzung der Linien der Vorderllügel. Unten sind alle Flügel bräunlichgrau, zeichnungslos. Ich erhielt mur diess eine Strick.

\section{IIypene T r.}

Revolutalis $\mathrm{Z}$ e $\mathrm{ll}$ e r. (Lepidoptera microptera, quae J. A. Wahlberg in Caffrornm terra collegit, Stochholm 1852, pag. 10.) Tafel 3, Figur 1, Männchen. Nur wenige Stüclie; meist verllogen. Ilerr Professor Zeller erhielt nur das Männchen vom Cap; das Weibehen ist wie das von autiqualis gebildet.

Obsilalis $1 \mathrm{l} \mathrm{b}$.

Lividalis $\mathrm{HI}$.

Herminies $\mathrm{T} \mathrm{r}$.

Crinalis $\mathrm{T} \mathrm{r}$.

Riveala Gin e il.

Sericealis S. V.

\section{Geometroidae.}

Phoporesmure $B$.

Neriatia II.-Sch. Nur ein Männchen.

Eucrostis IIb.

Indigenata de Villers.

Beryllaria il a $\mathrm{n} \mathrm{n}$.

Nemerial H b.

Cloraria II b.

Acialudien $\mathrm{Tr}$.

Scutulata S. V.

Comparia II.-Sch. 
Reversala Ti.

Polilata it b.

Filicala Il b.

Aridala $\mathrm{Z}$.

Rufillaria H].-Seh.

Inclinula m. Tafel 3, Fignr 2, Mäuncheı. Der Schmetlerling gehört in meine Unterabtheilung $\mathrm{A} b 28$, deren Arleu Rippe 6 und 7 der Ilinternïgel gestielt, im inännlichen Geschlechte nngespornte verkümmerte Ilinterheine und lang und dünn gewimperte Fühler haben. Etwas kleiner, als muricala $\mathrm{H}$ uf $\mathrm{n}$ a gel (auroraria S. V.), Fliigelschnitt wie bei dieser Art. Körper schmulzig braungelb, Palpen ungemein kurz und schwach, uur bis zur Stirn reichend, Zunge spiral. Beine anliegend beschuppt, die hinteren beim Manne sehr linrz, ihr Fuss elwa halb so lang als die Schicne, beim Weibe wenig lïrzer, als die milteren, mit Endspornen und vollkommenem Fusse. Fühler heim Manne mit abgeselzten Gliedern und langen, dünn gestellten Wimpern. Vorderfügel schmutzig braungelb. Die Zeichnung besteht in etwas dumkleren Querlinien und lat in ihrer Anlage (den rothen Vorderrand abgerechnet) einige Aehnlichkeit mit osseala, nur ist sie viel unbestimmter und verflossener. Die am schärfsten gezeichneten Slücke haben die beiden Mittellinien deutlich, doch nicht scharf, ein kleines Feld an der Wurzel (sehr verloschen) und das von der liehten Wellenlinie durchzogene Saumfeld dunkler braungelb; dieses ist dentlicher als bei osseata, schmäler und innen schärfer begrenzt, als aussel. Das Hittelfeld hat meist, doeh nicht immer einen sclwärzlichen Hittelpunct anl der Querrippe, worïber ein breiter, bräunlicher Mitlelschatten läuft; hiuler diesem ist der Raum bis zur äussern Mittellinie stets viel heller, als die ïbrige Flügelfïche. Die Hinterfligel haben rom Hittelschatten his zum Saume die Fortsetzung her Vorderfligelzeichnung, sie ist aber nur am lnnenrande deullich, wach vorne verloschen. Die Fransen sind breit, ganzrandig, mit der Flïgelfarbe gleich; die Sa!nmlinie ist nur wenig dunkler. Unten sind die Fliigel gelbbraun; saumwärts haben sie die Zeichnung del Oberseite angedentet. Das WVeib ist gewöhulich etwas schärfer gezeichnet, als der Manı. Es wurden rirca 20 Stiicke gesammelt.

Turbidaria H b.

Immulata L.

Coenosuria m. Tafel 3, Figur 3, Mäuchen. Hat nach HerrichSehäffer's Abbildıng einige Aebnlichlieit mit der mir unbekannten luridata $\mathrm{Z}$ eller (aus Rhodus), Herr Professor $\mathrm{Z}$ elle r besläligte mir aber die Verschiedenheit meiner Art. Noch näher stcht ilı in Zeichnung und zum Theil anch Färbung falsaria II.-Sch. Figur $464^{*}$ ) (463 diirlte eine

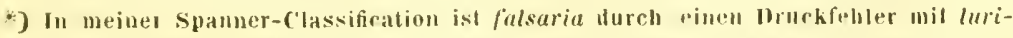
data Zeller zusammengeklammert, wälend sie als eigene Art aufgefulut sein soll. 
lunkle Varietait von confinaria scin, wie ich sie seither auch aus Tirol erhielt, wenn nicht etwa die Billung der llinterbeine differirt), die ich aus Andalusien brachte. Von diesen hat aber das Weibchen - das Männchen kemne ich nicht - bloss Endspornen der Hinterbeine, coenosaria aber im weiblichen Geschlechte Mittel- und Endspornen, im mänılichen, kurze ungespornte Hinterbeine. Grösse $1 / 3$ unter immutala; von den fünf Exemplaren die ich besitze, sind zwei elwas ansehnlicher, als das abgebildete. Körper, Beine und Fühler schmulziggelb, Zunge spiral, Palpen aufwärts gebogen, anliegend beschuppt, etwas iber die Stirue vorstelend, Stime schwarzbrann; Hinterbeine beim Manne kurz, Schienen ungespornt, mit einem weisslichen bis zur Milte des ersten Tarsengliedes reiclıenden Haarpinsel an der Innenseite, Fuss fast so lang, als die Schiene; beim Weibe mit Mittel- und Endsporuen. Fühler beim llanne mit sehr schwach vortretenlen Ecken und langen, dinn gestellten Wimpern, beim Weibe nackt. Die Grundfarhe del Flïgel ist ein malles, staubiges, mil l'einen schwärzlichen Atomen hestreutes Ockergelb. Die Vorderflïgel haben die beiden Mittellinien und den Miltelschalten deutlich, bei sehr reinen und lebhaft gezeichneten Exemplaren zimmtroth gefärbl; bei matt gezeichneten oder geflogenen Stücken fehlt dieser zimmtrothe Anfug und die Zeichnung erscheint dadurch mehr graubraun. Alle Zeiclunung entspringt ans dickeren, etwas schärfer marquirten Vorderraudsflecken nud besteht nicht ans scharfen Linien, sondern ist nur aus angelıäuften Atomen gebildet. Beide Mittellinien sind am Vorderrande nach aussen gewendet, ziehen aber dann parallel mit dem Saume; die äussere besteht zum grössten Theil aus schwachen, auswïrts gekehrten und aul den Rippen etwas dunkler marquirten Halbmonden. Der Mittelpunct ist ein wenig dunkler, als die Querlinien, malt und unbestimml (nur bei einem Exemplare

Ich uHhme hier noch Veranlassung zu berichten, dass hinter lotaria:

$$
\begin{aligned}
& \text { o Tempestaria H.-Soli. } \\
& \text { (Ablutaria B. H.-Sch. 38z-83. } \\
& \text { - Rufinctaria G u e } \mathbf{e} \text { e in lit. } \\
& \text { Muscosaria L. e ll. in lit. } \\
& \text { - }\left\{\begin{array}{l}
\text { V. probaria Ma } \mathbf{1} \text { in lit. } \\
\text { Salicaria H.-Sch. 529. }
\end{array}\right.
\end{aligned}
$$

nint+r tristaria:

$$
\begin{aligned}
& \text { SBrulleata D } \mathbf{~ p . ~} \\
& \text { Decrepitata B e ll e m:a } ॥ \text { \%. }
\end{aligned}
$$

himter consiguata:

Irriguata $\mathrm{H} \mathrm{b}$.

einzuschalten, bei ambustuta, gesticularia unil cognata die o zu streichen ist, serotiuaria und tibialala dagegen als österreichisch ein o \%u erlatten haben, zu punctata als Synonym: Nemoraria Fre yer 605, \#u sparsata: melanoperva Graslin (Amalen 1848) gehört, statt holosericata: hotosericearia, statt fulginaria: fuliginaria, statt effractiaria: effractariu, statl tritinearia: trilinearia zu lesen ist und das Geäder meiner Figur 22 ans Versehen pag.69 bei Phasiane statt pag. 70 bei Eubotia ritirt wurle. 
etwas deullicher). Der Vittelschalten steht bei allen meinen Stücken der inneren Mittellinie viel nihher, als der änsseren, willrend er bei den verwandten Arten mitlen zwischen beiden zicht; er entspringt gerade ober dem Puncl, zieht um lenselhen aussen herum nnd setzl sich unter ihm zum Innenrande forl; zuweilen fehlen die wenigendunklen Atome, welche diesen Bug bilden und dann scheint der Schatlen (wie bei dem abgebildeten Exemplare) gerade iiber den Punct zu laulen. Die lichte Wellenlinie ist ganz nnbestimmt, nur an ilırer Innenseile dnrch einige dnuklere Wolkenllecke (wie bei immulata) begrenzl, nach anssen aber ganz verwaschen. Die Hinterfligel (auf welchen Rippe 6 und 7 ans einem Puncl entspringt) haben deutlichen schwärzlichen Mittelpunct, vor ihm ziehenden starken Millelschallen, Fortsetıung der äusseren Mittellinie, die hier ebenfalls auf den Rippen schärfer marquirt ist und die lichle, an ilırer lnnenseile dunkler gewölkle Wellenlinie. Die Sanmlinie bestcht auf allen Flitgeln aus abgesetzten grolien schwärlichen Strichen; die Fransen sind mit der Flügelfache gleichlarbig. Die Unterseite ist gelblichgran, zeichunngelos.

Flacciduria $\mathrm{Z}$.

Imitaria II l.

Zoneosonere m.

Prpillaria H b.

Pellomice D " p.

Calabra Pelagua. Var. tabidaria Z e 11 e l'

Nrecenters $\mathrm{C} u \mathrm{r}$ is.

Aestimaria II b.

\section{Nyeluiodes m.}

Lividariu Hh. Glanzhoser und $1 / 3$ kleiner, als die lianzöschen.

\section{Symopsiat H b.}

Deliciosuria m. Tafel 3, Figur 4, Männchen. Diese Art bildel mit ier in diesen Schriften beschriebenen sibirischen phaeolencaria eine eigene Unterablheilung, deren Arten nur Endspornen der Huterbeine baben; die Zeichnung ist elwas fremdartig, doch weisen das Geäder, die fast fehleude Zunge und der Mangel eines kahlen Fleckens an der Basis der mänulichen Vordertlügel dem Schmetterlinge lier seinen Platz an. Ich erhielt nur ein Pälchen. Das Mänuchen ist $u$ m 1/3, das Weibchen 1/s kleiner, als gewöhıliche mänuliche Fxemplare vou sociaria; die Fliigelform ist dieselbe bis auf die Spitze der Vorderflïgel, welche hier scharl, dort etwas gerundel ist. Das Weilichen ist durch den Mangel der Hafthorste ansgezeichnel, das Mannchen hesitzl sie. Kürper weiss, Thorax slark behaart, hinten mil getheiltem Schopfchen, weiss und branu gemischt. Stirne anliegend beschuppt, Palpen schr schwach und kur\%. kaum bis zur Slirn reichend, Zunge ganz 
verkümmert; Beine anliegend beschuppt, Hiıterschienen dünn und schwach, in beiden Geschlechtern bloss mit Endspornen. Fühler weisslich bestäubt, beim Manue mit langen regelmässig gestellten und abwärts stehenden Kammzähnen, bis zur Spitze, beim Weibe ebenfalls gekämmt, die Kämme nur wenig kürzer. Flïgel schneeweiss. Vorderflügel mit kaffehbraumem schmalen, durch eine grobe schwarzbranne Linie eingesäumten Wurzelfelde, das vom Vorderrande schräg nach aussen zieht und zivischen Rippe 2 und 1 und auf 1 selbst scharfo Zacken nach aussen macht. Die äussere Mittellinie ist ungemein weit saunwärts gestellt, doppelt angelegt und sehr scharf. Sie zieht zur oberen Hälfte parallel mit dem Saume, krümmt sich danı einwärts und biegt sich vor ilırem Ende wieder nach anssen, dem Innenwinkel zu. Nahe an ihr, am Vorder- und Innenrande an sie anstossend, zieht der Mittelschatten; er ist matthraun verwaschen, nur in der Gegend des Zellenschlusses schärfer marquirt; sonst hat das Mittelfeld keine Zeichnung. Das Saumfeld ist schmal, weiss; die äussere Mittellinie ist hier am Vorderrande durch einen bräunlichen Wisch, am Inneuwinkel durch einen tiefbrauneu, auf deu Rippen nach aussen vortretendem Schatten begrenzl; ein verloschener schmutzigbrauner Streif zieht noch vor dem Saume. Die Innenrandsrippe und die aus der Mittelzelle entspringenden Rippen sind weiss, von feinen bräunlichen Schuppen umgeben, besonders beim Weibe, wodurch sie verdickt und erlaben erscheinen. Die Hinterllügel sind schneeweiss mit schwachem Mittelpunct und einer feinen dunkelbranen Linie mitten zwischen ihm und dem Saume, welc'se sich innen mehr dem lnnenwinkel zuwendet und daselbst schärfer marquirt ist. Die Saumlinie aller Flügel ist schwarzbraun, zusammenhängend; die Fransen sind auf den Vorderflügeln hell und dunkelbraun, auf den hinteren weiss und schmutzighraun gescheckl. Unten sind die Flügel weiss; die vorderen längs des Vorderrandes gran, mit matter Andeutung der äussern Mittellinie und der dahinter stehenden Zeichnnng, die hintern wie oben gezeichnet, nur matter.

\section{Cropothos Tr.}

Stevemaria B.

Surtala Tr.

Poggearia m. Tafel 3, Figur 5, Hünnchen. Grösse und Flügelform von obscurala, Fransen der Vorderftügel aber vollkommen ganzrandig, die der Hinterllügel äusserst seieht wellenrandig. Körper und Beine anliegend beschuppl, Stirue vertical, Palpen nur wenig darüber vorstehend, (wie bei obscurata). Zunge spiral, Fühler horstenförmig, beim Manne dick mit ungemein kurzen dichten Wimpern, Ilinterschienen ${ }^{2}$ / länger als ihre Schenkel, hinter der Mitte an dicksten, mit Mittel- und Endspornen; Fuss kürzer als die Schiene. Fliigel sammt den Fransen glanzlos staubgrau, an Aussenrande etwas dunkler, die ganze Fläclıe mit feinen schwärzlichen Atomen bestreut. Alle Flugel mit sehwachem Mlltelpunct, dahinter ziehendem schwarhem, am Vorderrande etwas schärfer marquirtem Mittelschatlen und den 
beiden Mittellinien. Diese sind weit von einander entfernt; die innere ist bogenförmig, nuhe an der Busis und wenig deutlich; die äussere zieht ungefähr in der Mitte zwischen Mitlelpunet und Saum, besteht aus abgesetzten groben bräunlichschwarzen Strichen, macht auf den Vorderflïgeln am Anfange einen schwachen Vorsprung nach aussen, und zicht dann parallel mit den Saume; anf den hinteren ist in der Mitte ihre Entfernung vom Saume etwas grösser, als am Vorder- und Innenrande; sonst findet sich keine Zeichnung. Die Unterseite ist dunkler, die schwarzen Alome sind gröber und nıehr gehäuft, die äussere Mitlellinie ist bloss aul den Rippen angedeulet, die Mittelpmete sind schwach. Das Weihchen hat dieselbe Grösse und Fltigelform, Mittelpunel und Querlinien sind aber ganz matt und verloschen. Auch beim Männchen ist die Zeichnung nicht immer so scharf, wie bei dem abgebildeten Exemplare und versehwinden die Querlinien auf Ober- und Unterseite zuweilen gänzlich. Zwölf Männchen, ein Weibehen gesammelı.

\section{Selidosemat H b.}

Plumaria S. V. Grundfarbe viel bleicher, als bei den hiesigen; alle Randzeichnung nach innen scharf abgegrenzt und daselbst dunkler beschattet.

\section{Eubolia B.}

Pumicaria m. Tafel 3, Figur 6, Mann. Ich erhielt nur 3 Männchen, das Weibchen kenne ich nicht. Etwas kleiner als murinaria, derselbe Flïgelschnitt und dieselbe Rippenbildung, das Männchen ebenfalls mit einem kahlen Grülıchen untell an der Vorderflügelbasis. Kürper grau, Palpen in Kopfeslänge vorstehend, hängend, Zunge spiral, Stirne anliegend beschuppt, Fühler etwas lichter grau, als der Körper, länger als bei murinaria, mit langen, dünnell, vorwärts gestellten Kammzähnen, bis zu $3 / \%$ ihrer Länge und nackter Spitze; Beine dümn, anliegend beschuppt, die Hinterschienen mit 2 Par Spornen, das Mittelpaar hinter ${ }^{2} 3$ der Schienenlänge; der Hinterfuss halb so lang, als die Schiene. Die Flügel sind staubig grau mit feinen, schmutzighratuen Atomen bestreut. Die vorderen haben schwacheu Mittelpunct, gerade darüber ziehenden schwachen, aus gehäuften bräunlichen Atomen bestehenden Mittelsehatten, die beiden Mittellinien, jede gleichweit vom Mittelschatten entfernt und ungefähr wie bei murinaria angelegt, die äussere aber nieht so gerade, sondern mehr ans abgesetzten groben Strichen bestehent. Die hinteren haben schwache Millelpuncte und Fortsetzung der äusseren Mittellinie. Die Sanmlinie aller Flïgel besteht aus grohen punctartigen Strichen; die Fransen sind ganzrandig, mit dem Fliigelgrunde gleichtärbig. Die Uuterseite zieht mehr ins Lelungelbe, ist mit schmutzighraunen Atomen bedeckl, hat schwachen Mittelpunct und dunklere Saumstriche.

Perviaria m. Tafel 3, Figur 7, Hännelıen. Nur das eine Stiick erhalten. Im Bau der Körpertheile und Flügelform ganz nil voriger Art übereinstimmend, die Fühler eben so lang, mit eben so geformten Kammzähnen und nackter Spitze, die Hinterheine un mit dickeren Schienen und kiirzerem 
Fusse. Thorax grau, Stirn, Palpen und Hinterleib lehmgelb, Fühler weiss und schwarzgrau beschuppt. Flügel aschgrau. Von den beiden Mittellinien der Vorderflügel ist die innere ganz verloschen, die äussere gerade, bräınlich, inuen scharf durch ein schmutzigweisses bis zum Mittelschatten reichendes Band begrenzt. Mittelschatten breit, braungrau, an seiner Innenseite in die Grundfarbe verwaschen, an der äusseren mit einigen duukleren Schuppen in dem weissen Bande. Mittelfleck nur schwach angedeutet. Saumfeld wie bei murinaria, mit verwaschenen dunkler wolkigen Stellen an der Aussenseite der Mitlellinie nnd gauz undentlichen Spuren einer lichten Wellenlinie. Saumlinie schwarz, punctirt; Vorderrand hell und dunkel gesprenkelt; Franseı graı, ganzrandig. Die Hinterflügel haben die erste Querlinje ausgenommen - dieselbe Zeichnung wie die vorderen, im Saumfelde, ungefähr bei der Milte des Aussenrandes und gleichweit von ihm und der äusseren Mittellinie entferul, einen schmulzig weissen verloschenen runden Wisch, zusammenhängende Saumlinie und gelblichweisse ganzrandige Fınsen. Die Unterseite fülırt dieselbe Zeichnung, wie oben, mur matter und auf mehr bräunlichem Grunde und es haben lier anch die Vorderllügel einen lichten IVisch an derselben Stelle. wie die hinteren.

Apotresta H.-Sch.

Ononaria Fuess I y. Sehı kleine Exemplare.

Sacraria L.

Steryert H.-Sch.

\section{ostreotithere $\mathrm{Hb}$ b.}

Cervinata S. V.

\section{Cielavire Tr.}

Ablutaria B.

Schneideraria m. Tafel 3, Figur 8, Männchen. Ueber 30 Stücke ॥॥ Gesellschaft von ablutaria im April und Mai an schatligen Felsen an Hundsllusse gefangen. Etwas kleiner als tophaceata, dieselbe Fligelform; in Zeiclıung dieser Art - die verschiedene Färbung abgerechnet - sehr älılich, den gekämmlen Fühlerı zufolge aber mehr mit ablutaria und Podevinaria verwandt. Palpen schwach, wenig über die Stirn vorstehend, hangend. Fühler beim Hanne mit ziemlich Iangen, etwas vorwärts gestellten Kammzähneı, an der Spitze bloss sägezähnig, beim Weibe nit kurzeı Sägezähnen; Beine dünn, anliegend beschuppt, die hinteren mit 2 Paar spornen. Zeichnung der Vorderflïgel genau wie bei tophaceata, der Flügelgrund aber bräunlich ockergelb, die Hittelbinde und sonstigen dunklen Stellen staubig kohlengrau, die Fransen schmutzig weiss und grangescheckt. Hinterflügel ebenfalls wie bei tophaceata, das lichte Querband aber anl unklerem Grunde und dadurch mehr hervorgehoben, mehr oder weniger deutlich ockergelb angeflogen, die Fransen sebr undeutlich gescheckt. Uilerseite mit schwachem Mittelpuucte, bis zur äusseren Mittellinie aschgran, dahinter dieselbe Zeichnnng, wie obeu, aber lichter und matter. 
Filuviata il h.

Cerussaria m. Taldel 3, Figur 9, Weihchen. Lis wurle nur ein Paar gefunden. Grösse und Flïgelschuilt von albuluta. Palpen hängend, fast nicht ïber die Stirne vorstehend, Zunge spiral, Beine glatt besehuppt, die hintern mit 2 Paar Spornen, Fühler beim Manne sehr dieht und kurz bewimperl; Ilinterleib weiss mit feinen schwarzen Puncten auf der Mitte der Oberseile. Fligel zart seidenartig heseluppt, gelblichweiss, die vorderen am Vorderrande löunnlichgelb (dieselbe Farbe zicht sich anch ïber den Riicken fort) mit mehreren olivbrannen Strichelchen, aus welehen vier Querlinien entspringen und sehr kleinem olivbrannen Wurzelfelde. Die Querlinien sind parweise genahert und so gestellt, dass im Mittelraume der Flügel ein elwas breiteres weisses Feld bleibt, als vor und hinter ihnen. Sie bestehen aus schwachen undeutlichen Bogen, die auf den Rippen dureh sehwärzliche Puncte anfgeblinkt sind und die äussere Linie des zweiten Paares ist schwäelıer als die innere (beim Männchen ist sie sehr malt und auch die zweite Linie des imeren Paares nielit so seharf, wie bei dem abgebildeten Weibchen). Auf den Ilinterflïgeh setzen sich beide Paare fort, aher viel selıwächer und sind da nur am Innenrande deullich, nach vorne verloschen. Mittelpuncte und Saumlinie fehlen; die Fransen siud breit, ganzrandig, mit dem Fliigelgrunde gleieh gefärbl. Unten haben alle Fliigel sehwache Mittelpuncle, die vorderen hinter demselben bis zum Saune die

Zeichnung der Oberseite, aber matter und auf aschgrauem Grunde.

Permixtaria II.-Sch. Grosse Exemplare.

Eepithecin Cultis.

Pumiluta $\mathrm{Hb}$.

Centuureata S. V.

\section{Pyralidoidae.}

Agtosse L a l.

Pinguinalis L. Zwei Exemplare, durch licht lehmgelbe Grundfarbe ansgezeielsnet.

\section{Asopire Tr.}

Farinalis L.

Subustalis m. Tafel 3, Figur 10. Nur ein Mämnehen. Um dem einzelnen Stiicke kein eigenes Genus bilden zu miissen, führe ich es bei Asopia auf, es unterscheidet sich aber davon durch die deutlichen 0eelleu: von der Gattung Pyralis (im Herrieh-Schäffer'sehen Sinne) entlernen es die versehiedenen Palpen und die Fliigelform, von Botys die Rippenbildurg der llinterliigel; (es bildet nemlich wie bei Asopia Rippe $;$ den Vorderrand der Hittelzelle und \& zieht ober ihr, last aul' ilst anl'liegend, frei aus der 
Wurzel, während bei Botys 8 aus $g$ entspringt*). Grösse von rubidalis, Fligel ein klein wenig schmäler, die Spitze der vorderen etwas melır vorgezogen. Körper thongelb, Stirne anliegend beschuppt, Palpen horizontal, cylindrisch mit wenig abstehender Beschuppung und kurzem, stumpfen Endgliede kaum in Kopfeslänge vorstehend; Nebenpalpen etwa bis zı ilırer halben Länge reichend, ebenfalls horizontal, sehr dünn und schwach, Zunge spiral, Beine anliegend beschuppt, von gewölılichen Dimensionen (nämlich nicht auffallend verlängert oder verdïnnt), Fühler borstenförmig mit sehr feinen und nicht gar dicht gestellten Wimpern, die etwas länger, als der Durchmesser des Schafts. Ocellen in einiger Entfernung hinter der Fühlerbasis, gerade ober dem senkrechten Durchmesser des Auges. Die Fligel sind glanzlos und haben die Farbe gebrannten Thones; sie sind mit feinen rothbraunen Atomen bestrent, besonders an den Aussenriuderu, und erlalten ladurch eine zimmtartige Färbung ; alle Fransen sind ganzrandig, brandbraun, mit einzeln eingemengten grauen Schuppen. Die Vorderflügel haben zwei lıleiche, an ihrer Innenseite schmal und schwach bräunlich beschattete Querlinien, die innere im ersten Drittel der Flügellänge sehr schwach answärls gebogen, die äussere hinter dem zweiten Drittel, fast parallel mit dem Saume, nur am Vorderrande etwas weiter davon entfernt. Das Mittelfeld ist nicht dunkler, als die Grundfarbe, mit eincm bräunlichen Punct auf der Querrippe und tief chocoladebraun gestrichellem Vorderrande. Die Hinterllügel siud zeichnungslos, nur - wie schon erwähnt - gegen den Rand zu dunkler. Die Unterseite ist elwas lehhafter gefärbt, als die obere und mit groben rothlichen Atomen bestreut, die gegen den Innenrand zu spärlicher werden. Die Vorderflügel lıahen einen undentlichen Hittelfleck und die äussere Querlinie, die sich auch über die Hinterflïgel bleich fortsetzt, ulunkler gestrichelten Vorlerrand von der Basis bis zur genamuten Querlinie (oben blos zwischen beiden Mittellinien) und dunkelbraune Fransen.

$\Rightarrow$ II errich-schäfor thrilt die nach Iostremung vou Herminia, Iypena, Hercyna Abtheilung A (Nola $\mathbf{L}_{4}$ ea $\mathrm{ch}=$ Boeselia II.-S.h.) Helia calvarialis unn Bivula sericealis verhleibenden Treits chkeschen Pyraliden in zwei Zünfte: Pyraliden (Genus Aglossa, Hypsopygia, Hypotia, Asopia und Pyralis) mit frei aus der Wurzel entspringende Rippe \& der Hinterflügel und Crambiden alle ïbrigen pyratiden-Gattungen, fermer alle Phycidesn, die Arten des Genus Chilo, Scirpophaga, Crambns, Eudorea und die Gallerien, bei welchen Rippe 7 den Vorderraut der Nittelzelle bitdet, sich bis zum saume fortsetzt unt Rippe 8 erst vor diesem aus 7 entspringt (mit 8 auf einem stiele steht). Dieser (haracter scheint constant zu bleiben (zur Errichtung einer eigenen Zunft scheint er mir aher nicht genügend); II er rich-Sc hi ffer gibt aher hei scirpophaga - llie er stoch zu seinen Crambiden zahlt, auf pag. 6 und 52 "frei aus der Wurzel entspringende Hippe 8 der Ilinterfligel" an, was seiner angefürten Eintheilung eben so gerate widerspricht, wie ler Wirklichkeit, demn 7 und 8 simu verhunden, und 8 entspringt erat nahe vor dem saume alls 7 . 
Pyoratis L.

Netricalis $11 \mathrm{~b}$.

\section{Crambites II.-Sch. \\ rercysed Tr.}

Floralis Hb.

\section{Hotys T r.}

Punicealis S. V.

Purpuralis L. Das Gelb reichlicher, das Roth blässer, als bei den hiesigen Exemplaren.

Cruentulis H b. Zuträge (Bourjotulis Du p.) Selır häufig.

Unionalis $\mathrm{H} \mathrm{b}$.

Ruficostalis m. Tafel 3, Figur 4, Mann. Etwas kleiner als hyalinalis, derselbe Habitus und Flügelschuit, dieselbe Bildung der Körpertheile. Bleich beingelb. Vorderfliigel mit blass ziegelrothem Streif am Vorderrande, der sich auch üher den Ilalskragen und einen Theil des Rïckens fortsetzt und hinter der Mitte der Flügellänge verlischt. Zeichnungsanlage wie bei hyalinalis, aber viel bleicher. Vorderflïgel mit einem kleinen makelartigen lileck auf der Querrippe und einen punctartigen vor jhm in der Miltelzelle; beide kleiner, bleicher und näher an einander stehend, als bei hyalinalis, von zwei bleichgrauen Querlinien eingefasst, von denen die innere wie bei hyalinalis zieht, die äussere aber am Vorder- und Innenrande gleich weit rom Saume entfernt ist und in der Mitte einen starken Bogen nach aussen macht (bei hyalinalis beginnt sie am Vorderrande hei $2 / 3$ der Flügellänge, ist im obern Drittel ihrer Länge auswärts gebogen, und zielıt dann zur Mitte des Innenrandes). Hinterflitgel mil einem bleichgranen Fleck auf der Querrippe und einer gleichfärbigen geschwungenen, wie bei hyalinalis angelegten Querlinie dahinter. Samm aller Flügel bleiclıgrau, nach inuen verwaschen, Fransen ganzrandig, mil der Grundfarbe gleich. Dic Unterseite ist beingelb, zcichnungslos; nur die Zeichnung der Oberscite schimmert malt durch. Ich erhielt nur wenige Stücke.

Aurantiacalis F. R.

Polygonalis II b. In Hlenge gefangen und gezogen. Raupe auf Spartium.

Sanguinalis $\mathbf{L}$.

Ferrugalis II $\mathbf{b}$.

Pentadalis m. Talel 3, Figur 13, Weib. Der Argillacealis Z ell e ${ }^{\circ}$ am näclssten, die Vorderllïgel aber länger und schmäler und ohne Querlinien. Grösse von Argillaceulis. Körper schlank, anliegend heschuppl; Beiıe vou deı gewöhnlichen Dimensionen. Ocellen vorhanden. Zunge spiral, Kopf flach, Palpen fast in doppelter Länge larüber vorstehenl, liorizontal, unten. abstehend beschuppt; Nebenpalpen his zu ilırer halben läıge reichend und auf sic aufliegend. Fühler von luaber Volderraudsläuge, borslenlörmig. 
ziemlich dick, beim Manne mit sekl kurzen dichten Wimpern. Thorax nach vorne verlängert, sehr flach, so dass der llalskragen list lıorizontal daraul anfliegt; seine Beschuppun glatt gestrichen. Ilinterleib etwas flach gedrïckl, in heiden Geschlechtern spitz zulaufend, len Innenwinkel der Ilinterflïgel wenig ïberragend. Vorłerflügel mehr als zweimal so lang, als breit mit fast rechtwinkeliger Spitze und gegen den Innenwiukel zu bauchig ausgeschwungenem Saume; Hinterllügel am Vorderrande 1/3 länger als am lunenrande, mil slumpfeckigem Vorder- und stark gerundetem Innenwiukel und von der Spitze his zur Milte des Flügels eingezogenem Saume. Dic Vorderllägel sind glanzlos aschgrau. Zwei dunkle Stellen in der Mittelzelle, die eine hinter der Mitle derselben, die andere auf dem Zellenschlusse, denten die beiden Makeln an; sie sind ohne alle deutliche Begrenzung und vou der äusseren zieht ein verloschener dunkler grauer Schattenstreif zum Inuenrande. Die aus der Mittelzelle entspringenden Rippen sind schwarz beschuppt und der Grumd un sie ist etwas lieller gran, als die Flügelläche; die Zeichnung erscheint daher strahlenartig hervorgehoben, was um so melur vortritt, als auch die Rippen ungewöhnlich stark in die Flügellläche einschneiden und diese daher saumwärts faltig wird. Der Flügelgrumd ist nahe vor dem Aussenrande dunkler griu; diese dunkle Farbe ist einwarts verwaschen, und reicht aussen niclıt ganz bis an den Saum, soudern es bleibt zwischen diesem und der Saumlinie ein schmaler elwas hellerer Rand. Der Vorlerrand hat eine schmale weissgrane Kante; zwischen der Mitte und der Spitze des Flügels stehen auf ihm in gleicher Entfermung fünf sammtschwarze Fleckchen, von denen das innerste nicht immer dentlich vorhanden. Die Saumliuie ist schwärzlich. Die Fransen sind breit, ganzrandig, zur inneren Hälfte aschgrau, zur äusseren bräınlich, von den Rippen heller durchschuitten. Die llinterfliigel sind lichtgrau, am Rande elwas dunkler, mit helleren, weissgrauen breiten Fransen. Uuten sind alle Flügel weisserau; die vorleren mit deı fünf schwarzen Vorderrandstrichelchen, Spur der äusseren Makel, des Querstreifs und der Randzeichnnng; die hinteren mit dunklerer Saumlinie und einem aus gehänften groben Atomen gebildeten verwischten schwärzlichen Fleck am Vorderlande; er steht an der Stelle, wo lippe 8 ans $;$ entspringt. Der Bauch ist weissgran mit zwei einen schwärzlichen Iängslinien ïher die Mitte. Es wurden ïber 20 Stïcke gesammelt.

Interpunclalis IIb.

Pustulalis IIb.

Rupicapralis m. Tafel 3, Figur 12, Weib. Ein Männclıen und zwei Weibchen gesammelt. Grösse ınd Flügelschnitt von praetextalis. Palpen anliegend beschuppt, horizontal in Kopleslänge vorstelıend, Nebenpalpen daraul" anlliegend, bis zur halben Palpenlänge reichend.. Beine anliegend beschupt; Fühler borstenförmig, beim Manne mit selır kurzen dichten Wimpern. Die Vorlerlïgel sind sehr dicht beschuppt, wenig glänzend, stauhig ockergelb, gegen den Saum zu alluälig zu einem malten Graubraun 
verdunkelt, von welchem die schmntzigweissen fransen eigenthimlich ab. stechen. Zwei bleichgraue matte Querlinien zichen uber das mittlere Flügeldrittel; beide sind bald nach ihrem Ursprunge ein klein wenig sanmwärts geschwungen, soust gerade; auf der Querrippe steht ein verloschener grauer Strich. Die Hinterllugel sind elwas bleicher als die vorderen, an saume mehr aschgran, laben ganz matte verloschene Fortselzung der änsseren Querlinie der Vorderflügel und weissgrane Fransen. Unten sind dic Vorderflügel bleich ockergell, die hinteren weiss, am Saume grau, alle mit Mittelpmucten und der äusseren Bogenlinie. Die Zeichnnng ist hier schärfer, als oben; die Fransen sind trüb weiss.

\section{Ebuler Gu e u.}

Catalaunalis D up. Ziemlich viele Exemplare. Assez courtes, wie Herr Gu enée (Suites à Buffon tom. $s$, pag. 35z) sagt, kann ich die Fühler nicht finden, denn sie reichen fast bis zur Flïgelspitze. Die iibrigen in seiner Gattung Ebulea vereinigten Arten als crocealis, fimbrialalis, rubricalis, rubiginalis, verbascalis und stachydalis haben wohl sehr wenig Verwandtschaft mit catalaunalis.

\section{Cysucala if b.}

Dentalis S. V.

stenopteryx Guен.

Hybridalis $\mathrm{Hl}$ b.

Gremire G II e ll.

Suppandalis Hb.

Carnealis $\mathrm{T} \mathrm{r}$.

Punctalis S. V.

Brugieralis D $\mathrm{P}$.

\section{Duposecheliat $Z$.}

Fovealis $\%$.

Nymepheela H H.

Undalis G o e $\mathrm{t} \mathrm{z}$.

Potamogalis Tr.

Thyridialis m. Tafel 4, Figur 2, Weib. Nur in dem einzelnen Exemplare erbeutet. Ein Dritlel kleiner als nivealis; Körper und Beine nicht so lang, wie bei den übrigen Nymphulen, mehr wie bei Botys, den anfgebogenen Palpen nach aber hierher gehörig, Körper graubrann; Hinterleib den Afterwinkel nur wenig üherragend, mil helleren Ilinterrändern der Segmente. Palpen sichelförmig anfsteigend. Endglied anliegend beschuppt und spitz, Zunge spiral, Beine gelblich, anliegend beschuppt, nicht unverhältnissmässig lang, die hinteren mit 2 Paar Spornen. 
ihr Fuss nicht gauz so lang, als die Schiene. Fühler von gewöhnlicher Länge, borstenförmig. Die Flügel sind goldbraun, diese Farbe ist aber durch dunkler braune Atome stelleuweise ganz verdeckt. Zwei weisse Querlinien ziehen über das mittlere Drittel der Volderfligel, eine weniger deutliche uahe an der Basis. Die beiden Mittellinien sind am Vorder- und Innenrand fleckenartig erweitert. Die innere ist schwach auswärts gebogen : die äussere macht wie bei nivealis einen fast halbkreisförmigen Bogen vom Vorderrande zur Flïgelmitte, einen minder starken von da zur Mitte des Innenrandes; jeder Bogen schliesst eine runde weisse Nakel ein und zwei kleine weisse Fleckchen stehen noch parallel neben der oberen Makel in der Mittelzelle. Am Saume lauft ein lichtgoldbraunes gleichbreites schmales Band; dasselbe ist an seiner Inneuseite durch eine dunkelbranne Linie begrenzt, diese einwärts wieder durch weisse, nicht ganz zusamınenlıängende Striche aufgehlinkt. Auf den Hinterflügeln setzen sich alle drei Querlinien und das Saumband fort; von den zwei grossen weissen Makeln ist aber uur die obere deutlich, die untere bis auf wenige Spuren verschwunden. Die Fransen sind breit, ganzrandig und eigenthümlich bezeichnet; sie sind durch eine Längslinie getheilt; ihre innere Seite ist schwarzbraun, ihre äussere hellgrau mit weissen Schuppen gemengt; das Spitzcheu der Vorderflügel und ein mit der oberen runden Makel parallel gestellter Wisch der Vorderund lfinterflügel sind rein weiss. Die Unterseite ist eben so bezeichnet, wie die obere, nur ist hier Alles matter gefärbt.

\section{Zinectiencire Z.}

Recuroalis $\mathrm{Fab}$.

Ancylonsies H.-Sch.

Pectinatella Z.

Tentaculella $\mathrm{H}$ b.

\section{Curambues $\mathrm{Fab}$.}

Tersellus m. Tafel 4, Figur 6, Mann. Nur diess Eine Exemplar erhalten. Grösse und Habitus von inquinatellus. Palpen und Nebenpalpen wie bei dieser Art, die Fühlerglieder aber unten in scharfen Vierecken vortretend, jedes Viereck mit feinen ziemlich laugen Wimpern. Vorderflügel lichtaschgrau, Vorderrand und Rippen mehr gelblich, ausser schwarzeu Puncten auf dem Saume und Spuren einer durch schwärzliche Atome grebildeten Querlinie, welclie den Raum zwischen der Querrippe und dem Saume durchziehen und parallel mit letzteren stehen, ohne Zeichnung. Fransen ehenfalls zrau, glanzlos. Hinterflügel sammt den Fransen weissgrau, uur am Vorderwinkel und Aussenraude dunkler angeflogen. Die Unterseite ist asclgraı ; die Hiulerflügel sind zur inneren Iällte und auf den Fransen weıssgrau.

Desertellus m. Tafel 4, Figur 7, Mann. Grösse und Flügelschnitt des Manues von festivellus Her i i h-S $\mathrm{chäf}$ e $r$, die Spitze der Vorderflïgel aber melır vortretend, das Weib noch nelır gespitzt und so schınalliüglich, 
wie der Mlann von poliellus. Die Palpen und Fühler sind wie bei allen verwandten Arten gebildet. Die Vorderflïgel sind gewölnlich sehmutzig aschgrall mit sehr feinen dunkleren Atomen bestreut, doch variiren sie auch in gelblichgran (hesonders beim Weibe) oder weissgran und sind die dunkleren Atome zuweilen selır spärlich vorhanden. Die Zeichnming besteht aus einer aus zwei grobstrichigen bräınlichschwarzen Qucrlinien gebildeten Mittelbinde, welche am Vorderrande sehr verloschen ist und im ersten Drittel der Flïgellänge einen spitzen Winkel nach anssen macht; heide Linien sind weiter von einander entfernt, als bei fascelimellus und an ihrer Innenseite durch gehäufte dunklere Atome verdickt. Die Saumlinie ist schwarz punclirt. Die Fransen sind einfärbig grau glanzlos. Die äussere Linie verlischt oft bis auf wenige Spuren. Die Hinterfliggel sind ascligrau, haben einen verloschenen dunkleren Bogensireif vor dem Aussenrande, helleren Discus und hellere Fransen. Die Unterseite ist einfärbig aschgrau mit feiner dunklerer Saumlinie; die Vorderflïgel sind an der Spitze und längs des Saumes, die hinteren an der Innenseite etwas heller. Das Weih hat viel schmïlere Vorderflügel mit längerer und schärferer Spitze und ist blässer und matter gezeichnet. Es wurde diese Art in Mehrzahl, aher meist in verflogenen Exemplaren gefangen.

Inquinatellus S. V. Bleieher als die hiesigen; die Vorderflügel viel reiner strohgelb, die dunklen Atome und die Querlinien des Mänuchens selir spärlich orler ganz fehlend.

Cassentiniellus $\mathrm{Z}$.

\section{Evoneme II b.}

Cyrilli Costa.

Vinculella $\mathrm{Z}$.

Anapiella Z.

\section{Eecalosect in ris.}

Ingratella Z.

\section{Anerastive $\%$}

Venosa Z. Nur wenige Stïcke.

Ichorella m. Tafel 3. Figur 8, Männehen. Halls so gross, als punctella, derselbe Fliigelschnitt. Trüb strohgelb. Stirn einen stumpfen Kegel hildend, Zunge scluwach, Beine anliegend beschuppt, die llinterschienen ziemlich stark mit zwei Paar Spornen. Palpen dicht beschuppt, in mehr als doppelter Kopfes]änge vorstehend, mit zugespitzlem Endgliede; Nebenpalpen kaum bis zum Stirnkegel reichend, schwach, fadenförmig. Fïhler zurück gebogen mit sehr kurzen dichten Wimpern. Ocellen scheinen zu fehlen, doch kann ieh die betrelfende Stelle nicht genan tuntersuchen, da die Fühler darauf aufliegen. Vorderflügel glanzlos, zur oberen IIälfte matt strohgelb, zur unteren (rom Innenrande der Mittelzelle an, bis zum Innen- 
rande des Flügels) blass fleisehfarb, die Fransen durchans strohgelb. llinterflïgel (olıne Rippe 5) sammt den Fransen einfärbig gelbliclıgrau. Unterseite gelblichgrau, die Vorderllügel mit schunaler lichterer Kante. 'Ich erhielt nur diess Eine Stïck.

\section{Semenia H.-Sch.}

Punctella Tr.

Ephestio Gn enée.

Oblitella Z.

\section{Homoeosoma Curtis.}

Binaevella II b.

\section{Mryelois Z.}

Cirrigerella $\mathrm{Z} \mathrm{k}$.

Biflexella m. Tafel 4, Figur 10, Weihchen. Ich erhiell nur diess eine Exemplar; ob die Art bei Myelois richtig stelı, muss erst die Entdeckung des Hännchens zeigen. Grösse und Flügelschnitl von Pempelia subornatella. Körper und Beine anliegend beschuppt, Hinterschienen mit zwei Paar anliegenden Spornen, Stirne nur sehr wenig blasig erhaben, Palpen weit darüber hinauf stehend, sichelförmig, das erste und zweite Glied dicht, das dritte fein nud anliegend beschuppt, dieses kurz und stumpf zugespitzt. Nebenpalpen kann ich keine auffinden. Ocelten klein, Zunge stark, Fülılor borstenförmig; Hinterleib mit kurzem, etwas vorstehenden Legestaeliel. Vorderflingel sammt den Fransen licht graubraun, Vorderrand und zwei dicke Querlinien weisslichgelb. Von letztereu zieht die erste im inneren Drittel des Flïgels, ist schräge naeh aussen gerichtet und beiderseits ganz matt begrenzt; die äussere steht verlältnissmässig nahe am Saume (etwa im äusseren Fünftel des Flügels) machı vom Vorderrande zur Mitte der Flügelbreite einen spitzen Zahn, von da eimen schwachen Bogen zum Innenraude und ist an ihrer lunenseite etwas dunkler besehattel. Miltelzeichen sind keine vorhanden. Die Hinterflügel (ohne Rippe 5) sind licht aschgrau, die Fransen ebenfalls, letztere hahen aber an ihrer Innenseite eine schmale dunkel bleifarbe Theilungslinie, welche wie eine dicke Saumlinie aussieht. Die Unterseite ist einfärbig weissgran.

Convexella m. Tafel 4, Figur 9. Ebenfalls nur ein Weibchen. Grösse und Flügelschnitt der vorigen Art. Zunge spiral, Palpen sieltelförmig. Nebenpalpen sehr kurz, fadenförmig, Stirne nicht kegelartig vorspringend, Fülıler borstenförmig. Vorderflïgel semmelfarb, am Vorderrande heller, mehr weisslichgelb. Eine answarts gehogene Linic lauft sehräg von 1/3 des Vorderzur Mitte des Innenrandes; sie ist an ihrer Innenseite scharf dunkelbraun begrenzt und das Braun ist wurzelwärts in die Grundfarbe vertrieben, an ihrer Aussenseite verwaschen hellgelb. Auf der Querrippe steht eine hellgelbe, unten schwarz gekernte Makcl und nahe vor dem Samme zieht eine 
loellgelle boillerseits unden!lich hegrenzte Querlinic; an der Flïgelspitae und längs des situmes stehen schwärblichgrane Schuppen, im Wurzelfelde befindet sich eine hellere gelbe Stelle. Dic Querlinien und sonstigen heller gelben Stellen sind matt glänzend, die ïbrige Fläclıe aber ist glanzlos, die Zeichunng sicht daher wie erhaben aus. Die Hinterllügel sind hell gelbgrau, ihre Iransen gleichfärbig, die der Vorderflïgel lichtgrau. Die Unterseite ist einfäbig gelblich weiss.

Ancytosis $\mathrm{Z}$.

Rhodochrella II.-Sch.

Neproprengr. 7.

Poleriella \%.

Pempetia 7.

Curnella L.

\section{Tortricina.}

Erenere H.-Sch. *).

Siliquanu II.-Sch Nur wenige Stücke auf dem Libanon gefangen.

\section{Coceyse $\mathrm{Tr}$.}

Scabidulana m. Tafel 4, Figur 3. Ein Weibchen. Doppelt so gross, als zephyrana, wie ein mittleres Buoliana Weib, auch derselbe Flügelschnitl, die lippen der Hinterflïgel aher wie bei zephyrana, eben so die Bildung der Körpertleile. Kopf und Rücken sind licht rostbraun, der Hinterleib ist grau. Die Vorderllïgel sind glanzlos strolıgelb mit licht rostbraunen Atomen bestreul, welche zu zwei zerfaserten Querbinden derart zusammenfliesseı, dass der Flïgel in fünf ziemlich gleiche Felder getheilt wird; über das zweite und vierte Feld zielıen dic rostbrauen Bänder und ibre Fasern laufen in die gelben Felder aus. Die ganze Flägelfäche ist mil metallglänzenden Schïppchen und Querstrichelchen bestreul; in den rostbrannen Feldern ist diese Metallfarbe anfallend dick anfgetragen und dunkel bleigrau, in den ïbrigen Feldern schwächer und licht silberfarb. Auf den Fransen und längs des Aussenrandes sind die Flïgel einfärbig strohgelb. Die Hinterfligel sind dunkelgrau; ihre Frausen lichter, durch eine schmale helle Längslinie getheilt. Die Unterseite ist dunkelgran mit helleren Fransen und lichter

*) Ich zälıle diese Gattung bei den Tortriciden auf, da man sie gewöhủich bei diesen auffuht ; sie ist aber wohl richtiger mit de Lithosiden und Cheloniden in eine \%unft \%u vereinigen. 
gestricheltem Vorderrande der Vorderflïgel. G II e né e führt in seinem Microlepidopteren-Calaloge (Paris 1845) pag.63 zwei mir unbekannte neue mit zephyrana verwandte Arten auf: Maritimana aus der Gegend von Vannes im westlichen Frankreich und virginiana ans Chateâudun. Die erstere soll spitzere Vorderflügel mit gescheckten Fransen und weissgefranste Hinterflügel haben, die zweite soll noch kleiner als zephyrana sein und ganz weisse Hinterfliggel becitzen; beide sollen üherdiess noch bleicher als sephyrana sein, meine scabidulana kann also nicht zu ilmen gehören. Margarotana D u p. kenne ich nur nach Her r ich-S chäf fer's Abbildung und Beschreibung, soll aber ebenfalls gescheckte Fransen lıaben. Zephyrana isı viel kleiner, licht schwefelgelb mit grünlichgrauer Zeichnung und die Netallfarbe ist durchaus gleichlärhig, matt und gleich dick aufgetragen.

\section{Cochylis Tr.}

Tischerana $\mathrm{T}$ r.

Smeathmanniana Fab.

\section{Prectreochrou Steph.}

Gloriosana H.-Sch. Das Weiss reichlicher als bei den ungarischen ixemplaren; die Hinterfliigel lichter grau.

\section{Hetisuir G n e née.}

Thurificana m. Tafel 2, Figur +, Weib. Anf Cypern und bei Beirut II ziemlicher Menge erbeutet. Der Bnoliana sehr nahe; Rippen, Fithler, Palpen und Beine wie bei dieser Art. Die auf Cypern gesammelten Exemplare kaum so gross als resinana, die Beiruter grösser, hesonders die Weibchen, aber alle kleiner, als Buoliana. Die Zeichnung der Vorderflügel ist ler von Buoliana sehr ähnlich, un finde ich das Gelb nnd Rothbraun hier schärfer geschieden (bei Buoliana in einander verwaschen) ersteres viel heller, beingelb, letzteres dınkler, hesonders am Vorderrande, der daher schärfer gestrichelt erscheint, und im llittelranme, wo es schärfer abstehende wolkige Flecke bildet. Die metallglänzenden Querbänder sind breiter, nicht so bleilarb, sondern weisslichgelb, nur im Mittelraume des Flïgels mit wenigem matt bleilarben Schimmer. Längs des Aussenrandes sind die Flügel heller als im Mitlelranme (bei meinen Exemplaren von Buoliana reicht die rothbraune Farbe bis zur Sammlinie, was aber vielleicht variiren kann), die Fransen sind mit der Saumlinie gleichfarhig, beingelb. Die Hinlerfiigel sind beim Manne gelblichweiss oder nur wenig ins Graue ziehend, beim Weibe lichtgrat, ihre Fransen viel heller, denen der Vorderllïgel gleichfarbig; die hei Buoliana vorhandene dunkelgrane Theilungslinie fehlt hier und auch der Saum ist meist elwas heller gerandet, wodurch die Fliigel ein viel breitfransigeres Anssehen erhalten, als bei Buoliana. Unten 
sind die Flïgel gelhlichgran mit helleren liransen und roth angellogenen Vorderrändern: die vorderen haben einige hellere Strichelchen gegen die Spilze z.ı. Der Selumelterling unterseheidet sich in der Natur leichter von Buoliana, als diess mit Worten zu geben ist, ich halte es aher doch nicht für gauz unmöglich, lass er mur eine südliche Abänderung vou Buoliana sein kö̈ne, da ich anch hier schon hellere (in Grösse aber nicht verschiedene) Varietäten dieser Art bei Mödling fand. Der englischen pinicolana Do uh le da y (non Il er r i ch- S e hif f e r) steht thurificana ebenfalls nahe; pinicolana hat aher spitzere Vorderllïgel, las Rothbraun ist so dunkel, wie die dunkelsten Stellen hei thurificana, auf der ganzen Flügelfiiche bis zum Saume gleichmässig vertheilt, nur an Innenrande etwas heller, die Ifinterflügel haben eine graue Theilungslinie und der Thorax ist bei dieser Art rolhbraun, hei thurificana nebst den Kopfe bleichgelh.

\section{Graphotitber Tr.}

Effusana m. Tafel 4, Figur 5, Mäunchen. Ieh erhielt nur ; Stiicke. Nahe an gallicolana, dieselhe Grösse und gleicher Flïgelschnitt, nur ist der Saum auf Vorder- und Ilinterflügeln unter der Spitze etwas stärker eingehogin. Die lírudfarhe der Vorderflïgel ist ein sammtartiges Schwarzbraun. Aaf der Mitte des Innenrandes sitzt wie bei gallicolma ein grosser unregehmässiger weisser Fleck anf; er ist eben so breit, aber höler, als bei dieser Art (höher als breit) und von einer oder zwei schwärzlichen Queradern durchzogen, welehe am Innenrande deutlich sind und nach oben verlöschen. Am Vorderrande stehen gewöhnlich 5 Paar weisse Häkchen. Das erste Paar ist aber zuweilen sehr verlosehen, die übrigen manchmal nur einfach (nimlich stalt je einem Paare nur ein einzeines IIäkchen) vorhanden. Alle setzen sich in violett-bleifarben strichartigen Linien fort. Die erste stösst auf den weissen Fleck auf; die zweite beschreibt hinter demselben einen Bogen und läuft nahe vor dem Innenwinkel aus, die dritte bildet nur ein liurzes Strichelchen, die vierte und fünfte stossen in eine Linie zusammen und setzen sich längs des Saumes bis zum Innenwinkel forl: au ilhrer Aussenseite befindet sich an der Stelle, wo der Saum einen Einbug. macht, ein aus lichteren Schüppchen gebildeter Wisch. Die hinter dem weissen Flecke und die am Saume ziehende Bleilinie schliessen drei ungeführ im millleren Drittel der Fligelbreite über einander stehende sammschwarze längliche Puncle ein nud ober diesen ziehen sich manchmal nock spärliche schwarze Schüppehen bis zum dritten IIäkchenpaare fort. Die Fransen sind braungran. Die llinterlligel sind schwärzlichbraungrau, an der Basis zuweilen etwas beller und hahen lichtere von einerdunklen Theilungslinie durchyogene Fransen. Die Unterseite ist schwarzgrau; die Vorderrandstriehelchen der Vorderflügel sind hier matt und gelblich, die Ilinterflugel zuweilen gegen die Spitze zu anch etwas heller gestrichelt: sonst findet sich keine Zeichnung. 


\section{Tineina}

\section{Atyeleire L in t. *).}

Nana Tr. Tafel 4, Figur 11, Weibchen. Im Juni an dïrren Stellen im Grase fliegend gefunden. Unter nngefähr 30 Männchen erhielt ich auch zwei Weilıchen. Diese haben borstenförmige Fühler, zugespitzten Hinterleib

*) Fortgeselzte Untersuchungen haben mich iiberzengt, dass IIerr Herric hSch affer Recht hat, die Galtungen Atychia und Typhonia zu den Tineen zu ziehen, denn so viel Eigenthümliches jede dieser Gattungen auch hat, so blcibt doch nicht ein einziges Merkmal, las sich nicht anch bei den Tineen fände. Jeurn llerich-schäffer möchte ich ïbrigens in Antwort auf seine urbenbei gesagt in einem solchen Tone ahgefasste Anmerkung (bei Atychialass ich mich gerne bescheiden will, einen "verschiedenen standpunct" ein) zmmelmen, darauf aufmerksam machen, lass er selbst die Typhonien zu den Bombyuden zähle, dem er hat sie auf Tafel 15 und 20 milten untr Fuprepien und psychen abgebildet und die Tafeln tragen lije Ueberschrift: Bombycides; auch ilın habeu also erst spätere Un'ersuchungen der Tineen zuu Auffiulen ter richtigen stelle geleited.

Es ist mir nie eingefallen, eine schumgerale Reihenfolge deri Arten herstellen zu wollen, oder eine solche ïberlaupt fur möglich zo halten; ich bitte llern llerrich-Schäffer die Worte möglichst laturliell Reile $n f_{\text {olg }}$ e in meinem Infsatze zu beachten und dam weniger schull abzusprechen. Legt ibrigens Herr Herrich-Sch äfer wirklich so ganz wenig Gewitht auf lie Reilnenfolge, tass er sogar (Nycteolides pag. 143) so weit geht zu sagen: , ila ich mich hier, wie schon oft geschehen, gegen die Unmöglichkeit einer Reihenfolge der Familien in gerader binie auspreclien muss, so (also darum?) ist es auch einerlei (?), wo ich diese Familie einschalte" Cer hatte sie also eben so gut unter die 'Tagfalter setzen kömnen, comsequenter wäre es aher gewesen, sie - da sie kein positives Merkmal bielen - mil seinen Lithosiden und Cheloniden in einer Zunft zu vereinigen), so muss jhm lloch jede andere Reihenfolge ehen so gleichgillig sein, wie seine eigene und ihm nicht ausser dieser Alles für ,Unsin“ gelten.

IIerrn Herric h-S h äffer belieht es, mich inconsequent zunennen. Er sagt: „Wie inconsequent übrigens hier verfahren ist, beweisen Ilerrn L, ederer's eigene Worte: Den gomeinhin unter dem Namen Sphingiden begriffenen Arten kommen in der Mehrzalı keuten- oder spindelfömige Fühler zu; diese mussen also beisammen bleiben. - Eine Ausnahme in der Fühlerform machen die syntomiden, Heterogyniden, einige Sesien und procriden; diese hieten aber im Uebrigen Merkmale genug, die über ilıre stellung bei den sphingiden keinen Zweifel lassen. - Hatte es Herr I, d ere l doch der Mühe werth gefunden, diese Nerkmale anzugeben, ich wiode ler erste sein, der ihm dafür Dank sagt. So lauge er liess nicht gellan hat, kan ich nur glauben, dass tie von seinen ersten Sammlerjahten her ihm heigebrachle Ansichl von dem Wesen ter sogenannten sphingiden ihm zur fixen Idee geworden ist mul wie schwer soldhe Ileen zit widerlegen silul, weiss ich als Arzt nur zu gut," 
und schwärzlichgrane Flïgel; auf der vorderen stehen sich anf der Oberseite bei $1 / 3$ der Flügellänge zwej weisse Tropfen gegenüber, ller einc aแ Vordep-, der andere am Innenrande.

Die „fixe Idee* muss ich IJerrn Herrich-seh iffer anheim geben. denn ich kiml in meinen Worten keine Inconsequen\% finden; wenn z. 13. paranthrena andere Fühler hat, als die übrigen Sesien, und einige procriten in der Fuhlerform ebenfalls von den übrigen Zygaeniden abweichen, so wird

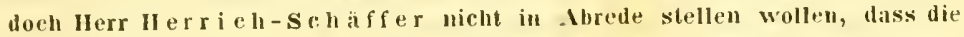
hetreffenden Thiere noch Merkmate genug lıben, die über ihre stellung keinen zweifel lassen.

Freilich finden sich bei Herrn Herrich-selhäfer andere consequenzen. Nicht aus Gelässigkeit, somlern nur damit Herr ll er r i c h-S chäffer nicht fermer von, nicht bewiesenen Vorwïfen" spreche, erlaube ich mir einige - denn zu allen haben diese Schriften keinen Raum - aus dem zweiten und dritten Bande anzufültren. Vorerst über die Classification:

Das Fehlen der Anhangzelle der Vordertingel wird pag. 425 zur Gründung der Unterzunft der Agleniden benutzt, bei ten Leptosiden. die nebenbei gesagt, so definirt werden ,Miltelkleine bis kleine Eulen, von ziemlich schlankem Körperbau, mit gleich geyeirhmeten Forder- unl llinterflugeln, erstere gewönlich olue die Eulenmakel: hat es nieht eimmal generische Bedentumg, denn es werden da in der Gattung Helia (pag. \$30) calcarialis (mit Anlang\%elle mul O(ellen) mohoscidata (ohne Anling\%elle mul ohne ocellen) velox, Dardomini, glarea und phlomidis - letztere ist nur Synomym von glarea und nicht eigene Art - Cohne Anhangzelle und mit ocellem) zusammengestellt.

Bei den Metoponiden, nach pag. 356 ,durch den ganz eigenthümliehrn lorimontal vorstelenden Stirnfortsat\% ausge\%eichnet" Iesen wir bei der Gitlung Segetia "Stirn gerumdet". Das ist sie auch in der That, wie stimmt aber diess mit dem Merkmahle ler Zumft zusammen?

Bei den Hadeniden, "deren Thorax wnd Hinterleib durch Ilaarschöpfe ausgezsichnet", begeguen wir nicht nur melıreren Arten, deren Hinterleib keine Srhöfe hat, z. B. siriptura Cihre Nachstrerwandte: anstralis steht bei den Xyliniden, Lmeburgensis, eine Varietat von Intulenta bei den orlhosiden, wahrend die stammart bei den Hadeniden aufgefihrt wird) sondern sogar tlis auf Thorax und Hinterleib gan\% glattschuppige (nicht behitarte) Noclua signalis.

Wie genan die Beschrenbungen und Citate behiudelt sind, davon folgende Beispiele:

Noct. nercosa lat nach pag. I79, fadenförmige“ Kammzähne der Füller, ein Paar heilen larunter ,gekeulte".

Bei Leuc. hesperica (pag. 237) finden wir zwei Beschreihnugen nach timander; jede gehört zu einer athern schon an den Fühtern verschiedener Art.

Bei Triph. Chardinyi funden wir anf pag. 327 dic Fuller beschrifluen, auf pag. 328 lesen wir "Chardinyi habe ich hinsichllich der Galtungsmerkmale nicht vergleichen komuen", ein Paar Zeilen darunter wird diese Art aber dorli

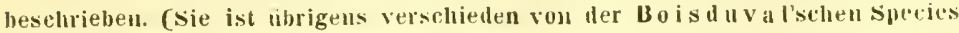
und vou Guenè c luperinoides genanul). 


\section{Nensotois Z.}

Istrianellus H.-Sch. Anfangs Mai in Weizenfeldern auf ScabiosenBlüllien zahlreich gefangen.

IIIfosiferct $\mathrm{Z}$. ?

Parcella m. Tafel 4, Figur 12, Mämnchen. Ich erhielt nur Ein Mànchen und zwei Weibchen; von denen ich eines abschuppte. Ich führe diese Art einstweilen bei Hapsifera auf, womit sie mir die meiste Uebereinstimmung zu hahen scheint und heschränke mich darauf, die Körpertheile und Rippenbildung genau zu beschreiben; jedenfalls gehört sie dem buschig behaarten Kopfe, der fehlenden Zunge und den getheilten Zellen nach eher in die Nähe von Euplocamus und bildet da wahrscheinlich eine eigene Gattung, als zu Hypsolophus, mit welcher Galtung der Schmetterling einige oberflächliche Aehnlichkeit zeigt. Mein Männchen ist etwas kleiner, als Hypsol. marginellus, mein Weibchen etwas grösser; im Habitus und F'lügelschnitt ähnelt parcella dieser Art, die dichte mehlige Beschuppung, die länglich eiförmigen Hinterflügel und ihre Fransen etc. stimmen aber besser

Auf pag. 344 wirl florigera $\mathbf{E}$ v. ganz richtig zu recussa $\mathbf{H}$ b. ge\%ogen, auf pag. 346 steht sie als eigene Art aufgefuilirt.

Auf pag. 43i kemt Herr He r rich-Sc ltäf er pusilla Ev. nichı, einige Zeileu darmiter beschreibt er sie, zieht dazu ganz richtig als Symonym concinnula B., fülırt aber auf pag. 437 concinnula B. als eigene Art auf uni citirt dazu seine Figur 256, die eine paralleta llarstellt.

Auf pig. 4\$0 begegnen wir einer dulmatina Le derer (ich benannte einst minuta 'T $\mathrm{r}$ e i $\mathrm{t} s \mathrm{e} h \mathrm{k}$ e so, da sie nicht die $H$ ii b $\mathrm{n}$ e r'sche Art ist, Guenée hat alser die Verschiedenheit schon fruher bemerkt und den Namen viridula vorgeschlagen) zu welcher gan\% irrig und olue Angabe eines Grundes elychrisi $\mathbf{R}$ a mb ur als Synouym gezogen wird; gleich darunter finden wir elyehrisi $\mathbf{R}$ b. als eigene Art antgeführt.

Wie gewissenhaft über las Vaterland berichtet wird, davon überzeugen wir uns bei Cossus paradoxa, die in der ersten Zeile naus Smyrna", in Jer letzlen "walıscheinlich aus Kleinasien" ist, odter bei Acidalia inustaria, wornach "las einzige Exemplar aus Italien", in den nachsten Zeiten aber "von Ma n n bei Baden nachst Wien" gefangin ist.

Wahrlich Herr II e r r c $\mathrm{h}-\mathrm{S}$ ch h f fer bleibt sich consequent und solche Consequenzen mögen sogar ibren Nutzen haben, da sie den blinden Glauben an Autorengewissenhaftigkeit benehmen und zn eigener Prüung antreiben; sehr verwahren aher muss ich mich, darin "gleichen Weg" mit Herrn II errich-s c häffer zu geher.

Zum Schlusse erlaube ich mir nur noch die Frage, ob liess eine Arheit "Hach welcher jede Art erkannt und in die ilır gebührende Gallung, (wie es unit der Begriulung ter Galtungen aussieht, davon geben die Noctuen auf jeder seite Kengniss) und Familie verwiesen werilen kant?. 
mit Euplocamns übercin. Die Fürbung ist ein lichtes Lehmgelb (nngefähr wie bei Hypsol. binotatellus Die Vorderfliggel haben uls Zeichumg unr grobe schwarze Alome längs den Rippen und am Sanme; im ersten und zweiten Drittel der Flügellänge stelien sie etwas mehr gehinft und erscheinen daher an diesen Stellen als grobnehlige Puncte. Anfgeworfene Schuppen (wic bei luridella) sind nicht vorhauden. Die llinterlliggel und die Unterseite ziehen mehr ins Graue und sind zeichnungslos. Der Kopf ist etwas buschig behaart Die Palpen stehen weit vor; das erste und zweite Glied sind dicht behaart und die Behaarung bildet nach vorne pinen lingen, spitzen und hangenden Bart, das dritte ist anliegend heschuppt mud steigt als langer dünner Stachel gerade auf. Zunge und Ocellen fehlen. Die Fühller sind gut von halber Vorderrandslänge, borslenförmig, beim Manne mit sehr kurzen dichten Wimpern; die Beine anliegend beschuppt, nur die Hinterschienen schwach längshaarig; ihre Spornen sind lang. Der Hinterleih ist heim Weibe zngespitzt und hat einen kurzen, etwas vorstehenden Legestachel. Die Mittelzelle der Vorderflügel ist durch Rippe 3 derart getheilt, dass der untere Theil un $1 / 3$ schmäler, als der obere ist. Die Theilungsrippe ist so stark, als die übrigen Rippen, die Innenrandsrippe der Mitlelzelle aher schwächer und nach innen zu unbestimnt; die Querrippe macht einen Bogen nach aussen und aus ihr ziehen in gleicher Entfernung von einander Rippe 3-7; Rippe 2 ist Fortsetzung des Innenrandes der Mittelzelle, 8 culspringt ans derem Vorderrande, beide in derselben Distanz wie 3 und 7 , 9 und 10 ebenfalls aus dem Vorderrande, erstere im zweiten, letztere im ersten Drittel desselben, 11 ist die Vorderrandsrippe. Die Hinterfligel haben eine durch lippe 5 in zwei ziemlich gleiche Hälften getheilte Mittelzelle. Rippe 2 entspringt aus $3 / 4$ ihres Innenrandes, 6 ist die Fortsetung ihres Vorderrandes, 7 ist ein ganz kurzer, erst dicht vor der Flïgelspitze aus 6 entspringender Ast, 2, 3 und 4 entspringen gesondert in gleicher Entfernung, 5 ist etwas näher an 4, als an 6, 8 frei. Die Querrippe maclit von 6 zu 5 einen eiuwärts gekehrten Bogen, dessen unteres Ende doppelt melır saumwärts reicht, als das obere, zwischen 5 und 3 ist sie derart naclı aussen winklich gebrochen, dass der Winkel auf Rippe 4 zu stehen kommt.

Iyprotophess Fa b.

Striatellus S. V.

Ancheincire $\mathrm{Z}$.

Sparella m. Tafel 5, Figur 1, Mänuchen. Ich erhielt nur 6 mäunliche Exemplare, das Weibchen kenne ich nicht. Grösse von aristella, Spitze der Vorderflügel aber melır lanzettförmig vorgezogen, die ülrigre Flügelform wie bei dieser Art; in Zeichnung mehr mit pyropella verwandt, in Bildung der Palpen aber von allen gellofligeligen Anchinien verschieden und darin mehr mit criella und labiosella iibereinstimmend. Kopf und Palpen sind kanariengelb, längs des Vorderrandes etwas dunkler schattirt, anf den lippen etwas lichter, die llinterfliigel dunkelaschgran mit lichteren, bräun- 
lichgrauen Fransen. Unten sind die Flügel aschgran, ihre Ränder und Fransen gelblichgrau. Die Zunge ist spiral, die Fühler sind borstenförmig, fein hewimpert, die Palpen $3 / \mathrm{s}$ so lang als der Hinterleib, elwas divergirend und horizontal vorstehend, die ersten zwei Glieder dicht bartig, beschuppt, die Beschuppung bildet oben und unten eine Schneide; das Endglied ist dünu und spitz, anliegend beschuppt, horizontal und ganz in der Behaarung des zweiten Gliedes versteckt; die Beine sind wie bei den übrigen verwandten Arten gebildet.

Largella m. Tafel 5, Figur 2. Nır zwei Männchen. Flïgelschnitt von monostictella, Grösse von pyropella. Fülıler mit etwas vortretenden Enden der Glieder und langen dünnen Wimpern, Zunge spiral, Palpen horizontal, dreimal so lang als der Kopf, die ersten zwei Glieder bartig beschuppt, oben und unten schneidig, das dritte dünn und anliegend beschuppt, horizontal; die Beschuppung des zweiten Gliedes reicht bis an sein Ende. Kopf, Rücken und Palpen sind licht semmelgelb, letztere an der Aussenseite brämnlich. Die Vorderflügel sind sammt den Fransen licht semmelhraun mit dunkler schattirtem Vorderrande und hahen zwei feine schwarze Puncte, den einen in der Mlitle des Flïgels, den andern mitten zwischen diesem und der Fliigelbasis, aber etwas tiefer gestellt. Die Hinterflügel sind liellgraı, ihre Fransen gelblicher; eben so die Unterseite, wo aber auch die Ründer und Spitzen der Flügel gelblich sind.

\section{Decophonic $\mathrm{L}$ a $\mathrm{t}$.}

Temperatella m. Tafel 5, Figur 8, Mämnchen. Nur zwei (männliche) Exemplare erhalten. Grösse von tinctella. Vorderflügel spitzer, Hinterflügel $\because ;$ schmäler. Kopf und Rücken bräunlichgelb. Vorderflügel glänzend grüılichgelb, auf der Querrippe abwärts geknickt, Fransen gleichfarbig. Hinterflügel aschgrau mit sehr langen etwas helleren Fransen. Unterseite aschgran, die Spitzen und Aussenränder der Flügel elwas heller. Fülıler mil am Ende etwas vortretenden Gliedern, die gegen die Spitze zu kaum dünner werden und fein bewimpert sind, Kopfhaare glatt anliegend, Zunge spiral, Palpen bräunlichgelb, dïnn und lang, anliegend beschuppt und sichclförmig aufwärts gelirummt, wie bei tinctella; Beine ebenfalls wie bei dieser Art. Die Vorderflügel haben eine einfache Hiltelzelle und 12 Rippen, 2, 3, 4, 5, 6, 7, 9 und 10 gesondert und in ziemlich gleicher Entfernnng, 8 ans $\%, 11$ aus der Mitte des Vorderrandes der Mittelzelle 12 frei. Auf den lliuterflügeln ist die Miltelzelle zwischen Ruppe 4 und 6 offen, 2, 3 und 4 ziehen gesondert in gleicher Entfernung, 5 und 6 entspringen aus einem Punct, 7 ist die Fortsetzung des Vorderrandes der Hittelzelle und 8 läuft ganz licht am Vorderrande. Der Rippeuhildung der Ilinterllügel nach, die aber je nach der filügelform bei den Tineen oft bei den nächstverwandten Arten bedeutenden Modificationen unterworfen scheint - dürfte sich für temperatella noch eine passendere Stelle als bei Oecophora und zivar eher Imter den letzleren Tineeen-Gallungen in der Nähe vou Elaclista finden. 


\section{Heucretis Tr.}

Inchusellu m. Talel s, Figur 3. Mann. Vier Exemplare; zwei Männchen, zwei Weibchen. Etwas grösser, als Knochella, derselbe Habitıs und Flügelschnitt, nur die Spitze der Vorderlligel etwas rumber. Kopf: Thorax und Palpen anliegend und glänzend beschuppt, letzlere diinn, sichelförmig aufgebogen (wie bei Knochella), Zunge spiral, lühler lıorstenförmig, llinterleil) und Beine violelt bronzefarben, die Hinterschienen dick, längsharig und mit zwei Paar Spormen. After beim Weibe unten vor der Spitze weisslichgelh gerandet. Die Vorlerlliigel sind nebst den Fransen violell, bronzefarb glänzend und haben im äusseren Driltel des Flügels eine mehr dom Innen- als Vorderrande genäherte (an derselben Stelle wie bei Knochella liefundiche und auch eben so geformte) weisslichgelbe Makel. Die llinterliügel sind dunkler und weniger glänzend als die vorderen, zeichnungslos. Die Unterseite ist einfärbig bronzebramn.

Desidella m. Tafel 5, Figur 4. Mann. Ein Männchen, zwei Weibchen. Hit acanthella Godart. (gallicinella Z e $11 \mathrm{er}$ ) verwandt, derselbe Habitus um» Flïgelschnitt, dieselbe Bildung der Körpertheiłe. Der Rücken und die Vorderfliigel sind kreidig weiss, glanzlos; der Hinterleil ist aschgrau, die Afterspitze zieht melır in's Gelhliche und ist (wie bei acanthella) beim Männchen mit einem langen Haarbiuschel besetzt, beim Weibchen kurz behaart. Die Zeichnung ist sehr einfach. sie besteht bei meinen zwei Weibchen nur ans einem gegen die Flügelspitze zu (an lerselben Stelle wie bei acanthella) befindlichen schwarzen Punct und einigen brüunlichen Schuppen an der Flügelspitze. Das Männchen hat vor diesem Fleck im zweiten Drittel des Fliigels zwei schmutzig lichtbranne Gegenflecke, eine ähnliche aber ganz verloschene Zeichnung in ersten Flïgeldrittel und schmutzig braune Schuppen an der Spitze und einem Theile des Saumes. Die Hinterflügel und Uıterseite sind einlärbig aschgrau. Das Geäder, - so weit es sich ohue Abschuppung ansnehmen lässt - scheint mil dem von acanthella zu stimmen.

\section{Apiletriar m.}

Luella m. Tafel 4, Figur 13, Mämnclien. Der Schmelterling hat in der Flügelform einige oberflàchliche Aehnlichkeit mit Ilapsifera und den kleineren Euplocamus-Arten, die einfachen llittelzellen und die Bildung der Palpen verweisen ihn aber in die Nähe von Carcina und Gelechia. Von ersterer Galtung differirt er durch die fehlende Zunge, von lelzterer durch die langen dicken liuhler, vou beiden überdiess durch verschiedene Flügelform; in beiden Galtungen ist allerdings noch viel Fremdartiges vereinigl, meine Gattung Apiletria wird aber auch nach dessen Souderung fortbestehen können. Kopf mil etwas wolligen zusammengestrichenen Haaren besetzt, Palpen sichelförmig aufgebogen, weit empor ragend, so lange, als der halbe Hinterleib; die ersten zwei Glieder sind dicht beschuppt und die Beschuppung steht auf der Oherseite etwas ab. Das dritte ist $2 / 3$ so lang als die heiden ersten $z, 1-$ 
sammen, auliegend beschuppt, sehr dünn und spitz. Nehenpalpen, Zunge und Ocellen fehlen. Fühler lang, bis $z u^{2 / 3}$ des Vorderrandes des Vorderflïgels reichend, djck, fast fadenförmig, beim Manne mit ahgeschnïrten Gliedern, die flicder unten in kurzen Sägezälınen vortretend; Beine anliegend beschuppt, nur die llinterschienen dicht läugsharig, mit 2 paar Spornen. Die Mittelzellen sind anf allen Fligeln cinfach. Auf den vorderen sind sie oben und unten gleich lang, durch cine hogenförmige Querrippe geschlossen; auf den hinteren zieht die Qnerrippe in schrägem Bogen von der Milte der Flügéllänge saumwärts, die obere Ecke ler Miltelzelle ist daher kïrzer, die untere vicl lïnger, erstere stumpf-, letztere spitzwinkelig. Die Vorderfliigel haben 12 Rippen, 2 und 3 aus einem Punct, 4 und 5 gesondert, letztere näher an 4, als an 6;6, 7,9 und 10 gesondert in gleicher Entfernung von einander, 8 ans $7, \mathbf{1 1}$ aus der Mitte des Vorderrandes der Mittelzelle, 12 frei. Auf den Hinterflïgeln eutspringen 3 und 4 ans einem Punct, 6 und 7 sind gestielt, 5 zieht näher an 4, als an 6, 8 frei. Die Färbung des Körpers und der Vorderfliigel ist glanzlos, ockergelb, beim Weibe viel lichter als beim Manne, semmelgelb. Gegen dic Ränder zn, auf den Rippen und den breiten ganzrandigen Fransen ist die Farhe dnnkler, mehr nmbrabran; ein bräunlicher matter Fleck steht auf ler Querrippe, ein undentlicher gleichförmiger Wisch zuweilen, doch nicht immer, in der Mitte der Mittelzelle, sonst findet sich keine Zeichnung. Die Hinterfliigel sind schwarzgran mit brciten bräunlichgranen Fransen. Die Unterseite ist schwärzlich oder bräunlichgran; die Spitzen und Rauder der Flügel sind heller, mehr gelblich. Ich erhielt mehrere Exemplare, die meistcn aber ohne Palpen, da diese sehr leicht ahbrechen.

Depuessurire Haw.

Comilella m. Tafel 5, Figur 5. Nur ein Weibchen. Grösse von alomella, Flügelform von depunctella, die Vorderllïgel nämlich mit stumpfwinkeliger spitze (hei atomella daselbst germulet). Körper und Beine sind fahlgelb, nur die Schienen aussen schwarzhraun, die Füh'er sind schwarzhraun, der IIinlerleib hat auf der Unterseite 4 Reihen schwarzer Puncte. Der Thorax mud lie Vorderflïgel sind gleichmässig licht ziegelroth, ihre Fransen dunkler, hesonders an der Spize, was aber bei weitem nicht so scharf absticht, wie bei depunctella. Auf den Rippen stehen - besonders gegen den Sam zu leine schwärzliche Schuppen, und in der llitlelzelle 3 erhabene schuppige l'uncte; der erste ist schwarz, weiss umzogen und steht in der Mitte der Zelle, die andern heiden sind weiss, und es steht der eine von ilnen nahe vor, der andere auf der Querrippe. Die Ilinterllügel sind hellgran mit lichteren gelblichgrauen Fransen und etwas dunkleren Rippen. Auf der Unterseile sind die Vorderflügel rölhlichgran mit rohbbramnen Fransen und schwärzlichen Schüppchen am Vorderrande; die hinteren gellgran, am Vorderrande und von der Spitze his zur dlitte des Sames ehenlalls mil schwärzlichen Atomen. Atomella hat cinige entfernte Aehnlichleit mit comitella, ibre Vorderllïgel sind aber gerundet, am Vorderrande viel heller, melır griin und 
donkler gestreichelt, wärend comitella hier dieselbe farbe wio anf tem ubrigen Fliigelranme nud keine Spur vou dunklen Strichelchen hat; die Saumlinie besteht aus sehwarzen Puncten, das Roth spielt mehr in`s Carmoisin und die Fransen sind nichi dunkler.

Thoracira m. Tafel 5, Fign' 6, Mïnnchen. Ehenfalls nur in einem Excmlare erbeutet. Sehr nahe all rhodochrella II.-Schr., dic Vorterfligel aber hleicher, mehr ledergelb, der Grund gleichmissig olme dınklere Alume und der ganze Thorax schwarz. Meine zwei Exemplare von rhodochrella (wovon

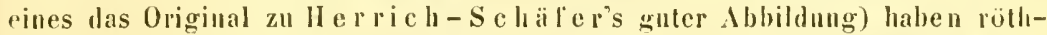
lichgelbe Vorderlligel mit dunkleren Alomen und der Riicken ist übre die llitte gelb, nur mit einzelnen schwarzen IIärchen gemischt. Bei der grossen Aehnlichlieit der Depressarien - Arten und dem Umstande, dass Ilerr M a meine Art unch bei Brussa in genauer Uebereinstimmung fand, möchte ich die Artrechte nicht bezweifeln.

\section{Gelectein Z.}

filurella D) up. Isegetella Z. "Isis" 184\%). Einige Ex(mplnre.

\section{CHonectis Tr.}

Lascivalis m. Tafel 5, Figur 7, Männchen. Nır dicss eine Exemplal. Grosse von allermulis; Fliigel kürzer, breiter mo runder, besonders die hillteren, deren Vorterwinkel ganz abgerundet ist. Körper und Fühler schwarza letztere an der Aussenseite hrännlichgelb, boıstenförmig mit sehr kurzen dichten Wimperı. Zunge spiral, PnIpen anfwärts gekrünml, elwas grobschuppig, oben schwarz, unten schwarz und gelb gemiseht, ilır Endglicl mit stumpfer Spitze. Nebenpalpen und Ocellen fehlen. Beire schwarz, Schienen und Füsse gelh geringelt, die Ilinterschienen kräftig mit 2 Paar Sporncn Vorlerllügel glanzlos, blänlichschwarz mit 3 aus groben nicht sehr gehänften russschwarzen Scluppen bestehenden Querbinden, welche von der Grundfarhe wenig abstechen, überhaupt nicht sehr deutlich sind, und in ziemlich gleicher Entfernung von einander ziehen, so dass sie die firundfarbe in 4 zicmlich gleiche Felder theilen, einer sehrverloschenen, ebenfalls russschwarzen Quelinie in dem letzten Felde nahe vor dem Samme und 3 hräunlichgelben VorderrandHecken, von denen der erste an der Anssenseite des ersten Querbandes stelıl und sehr verlosehen ist, der zweite an die Innenseite des dritten Querhandes slosst und keilförmig zulänft, der dritte punctformig ist, und sich nahe vor der Flügelspitze, da, wo die verloschene Querlinie vor dem Sanme beginnt, hefindet. Die Frausen sind ebenfalts russschwarz, an der Spitze und bei del Alitte schmal weiss gerandet. Die Hinterflïgel siub ranchhraun, gegen den Vorderrand zu und auf den Fransen grau; sie haben 2 matle bleichgelbe Querbänder, das innere bei $2 / 3$ der Flïgelbreite, das äussere diclıt vor dem samme, beigle nur an Innenwinkel deulich, schon vor der Fliggelmitle ver- 
Jöschend. Die Unterseite ıst russh'aun; alle gelbliche Zejchnung isı hier scharfer, als oben, der vorletzte und letzle Vorderrandsfleck der Vorderlliigel setzen sich in abgerissener Binde fort und die innere Binde der Hinterfligel zieht über den ganzen Flïgel. Die Fransen aller Flïgel sind schwärzlichgrau, an der Innenseite heller, als an der äusseren. Vom Geäder lässt sich wegen der dichten Beschuppung nichts ausnehmen.

\section{Elecheiste $\mathrm{T} \mathrm{l}$.}

Sumptuosella m. Tafel 5, Figur 9. Nur vier IIanuchen. Der pomposella an Nächsten, ein Drittcl grösser, derselbe Flïgelschnilt, dieselbe Bildung der Körpertheile. Kopf und Palpen weiss, das Endglied der lelzteren vor dem Ende schwarz, Fülıler schwarz, Beine weiss und schwarz geriıgelı. Vorderflügel matt goldbratm mit drei gelblichweissen gleich weit von einander entfernten Querzeichungen, von denen die ersteren beiden als schmale, schräg mach atıssen gestellıe Bänder erscheinen, das innere fast bis zum Innenrande, das äussere nur bis zur Mille der Flügelbreite reicht, die dritte aber einen breiteren, am Vorderrande hängendeı und nach inneı keilförmig zulanfenden Flecken bildel. Die beiden inneren Flecken haben an ilrem Ende blass goldfarbe Schuppen und auf dem Innenrande steht vor der ersten Querbinde ein gelblichweisser, von der zweiten, so wie vor dem Vorderrandsflecke und in fler Flïgelspitze ein matl goldschimmender kleiner Fleck. Die Hinterflïgel, die Fransen aller Flügel und die Unterseite sind bräunlichgrau, nut an Vorderrande der Vorderflügel findet sich der zweite und dritte Querfleck bleichgell) angedeutet.

\section{Pterophoridae.}

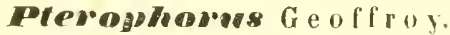

Aridus $\mathrm{Z}$.

Laelus Z. 
Verreichniss

der von Herrn Albert Kindermann 1848 - 1850 um Samsun, Amasia, Tokat, Siwas und Diarbekir gesammelten Schmetterlinge *).

\section{R ll 0 O l a a l}

Equites II.-Seh.

Provión L.

* Podulirius L. Bei Amasia und Tokat.

* Alexcunor Es p e r. Bei Amasia; selır selten.

* Iachaon L. Ueberall bis an den Euphrat, in nicht zu hoch gele genen Gegenden.

\section{Thersis F a b.}

Cerysii Go d. Zwisehen Amasia und Diarhekir allenthalben häulig.

Doritis F a b.

Apollinus II erbst. In Gesellschaft der vorigen Art.

Apollo L. Anf den Tokateralpen in selır grossen Exemplaren.

Anemosyne L. Bei Amasia; selten auf hochgelegenen Bergwiesen.

\section{Pierides B.}

piemis S chk.

* Cralaegi L.
* Brassicae L.
* Napi L.
Chloridice II b.

Daplidice L. Allenthalben bis Diarbekir.

Callidice Es p. Var. chrysidice H.-Sch. Einzeln anf den Tokateralpen.

Antheoctersis B.

Eupheme Es p. Nicht selten in sehr grossen, unten lebhaft gell gefarbten Exemplaren zwisehen Amasia und Diarbekir.

Ausonia Esp. Fast ïberall; unten schr lebhaft gelb und griin gezeichnet.

Penia Freyer. Wenige vertlogene Exemplare bei Malatia. Charlonia Donzel, Amnales de la société entom. de France 1551 planche 8 ans der Berberei, steht sehr nahe oder ist vielleicht dieselbe Art.

Gruneri II.-Sch. Zwischen Amasia und Diarbedir.

Damone B. Im Gebirge bei Irgana Maden sehr sellen.

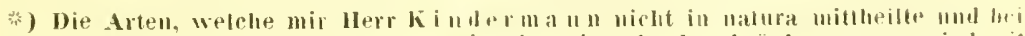

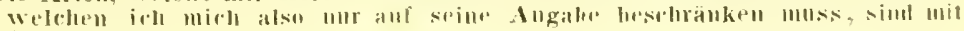
* bekeichnel. 
Colioss $\mathrm{F}$ a b.

Edusu L. und Var. helice II I. Ueberall.

* Chrysotheme E sp. Nur bei Samsun.

* Iyale I. Allenthalben bis Diarbekir.

* Rhamni Ueberall.

Henadocente B.

\section{Lycaenoidae B.}

\section{Thecele F a b.}

Acaciale $\mathrm{F}$ a b.

Alicis Es p.

Spini S. V.

Rubi L.

Bei Amasia und Tokat.

Ledereri II.-Sch. Einzeln bei Amasia auf holen Bergen in felsigen (regenden.

Nogelli II.-Sch. Bei Amasia und Tokat mit einfärbig schwarzloranner Oberseite; von Siwas östlich die Varietät mit orangegelbem Mittchaume.

Polyomonoretes L at.

Virganreate L. Bei Tokat im Gubirge an Bächen.

Ignilus H.-Sch. Zngleich mit tem vorigen; das Weibchen sehr sallen. Ochimus H.-Sch.

Asabinus II.-Sch. Bei Amasia.

Thersamon Es P.

Eurydice II uf n. Var. candens II.-Sclı. Aul' den Tokateralpen.

Alciphron Rotte mb. (hipponoë Es p.) Einzeln bei Amasia.

Dorilis $11 \mathrm{uf}$. (circe S. V.) Selten bei Amasia.

Plilaeas L. Ueberall.

\section{Iyceenci $\mathrm{F}$ a b.}

Boetivn L.

Telicanus II e r b st.

Bei Amasia.

Balcamica Freyer. Von Amasia bis Diarbekir in loch gelegenen Gegenden an Strüuchern fliegend.

Tiresias H $\mathrm{n}$ f 1 . (amyulas S. V.) anch die Var. coretas 0 . und polysperchon Bergstr. hei Amasia.

Trochilus Freyer. Amasia.

Dardams F reye a r den Tokateralpen.

Hylas S. V. Ueberall.

Bavius Ev. Bei Tokat auf tief und heiss gelegenen Wiesen.

Zephyrus H.-Sch. In Gesellschaft von bavins.

Euripylus Fre yer tab. 573. Bei Tokat. Die Unterseite mml das Weibchen ist genau, wie bei Zephyrus, das Männchen aber obeu braul : virlleicht nur Var, von sephyrus. 
Lomi \%. Bei lmasia.

Aleris 11 ॥l'u. (ayestis S. V.) Bei Tokat und Amasia.

Chiron II u [ n. (eumedon Esp.) Xuf den Tokateralpen.

Anteros Fr eyer. An kräuterreichen Ilügelı und Bergen von Samsun his Tokat.

Boisduvali II.-Sch.

Myrrha H.-Sch. $\}$ Auf den Tokateralpen.

Amandus II b. (icarius Es p.) Bei Tokat anf hochgelegenen Wiesen.

Candalus II.-Sch. Amasia; selten.

Icarus $\mathrm{H} \| \mathrm{f}$. (alexis S. V.) Ueherall und sehr variirend. Mämuchen oft kanm von haber Grösse; Weihchen oben ganz hellblau mit rothen Randflecken; anch die Varietüt thersiles B. nicht selten.

Adonis S. V. und Var. cerouns II b. Auf hohen Bergen hei Tokal.

Argestes B e rgstr. (dorylas S. V.) Bei Amasia einzeln.

Corydon Scop. Auf den Tokater Alpen. Das Männchen oben milch-

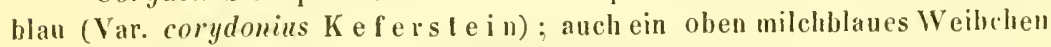
(Var. $\subseteq$ maris colore) mutcr gewöhulichen braunen gesammelt.

* Admetus E s p.

* Ripperti B.

Bei Amasia und Tokat.

Daplunis S. V. Var. Steveni II.-Seh. Bei Tokat. Auch ein vollhommener Hermaphrodit, links mänulich, rechts weiblich, wurde gefunden.

IIopfferi H.-Sch.

Poseidon $\mathrm{K} \mathrm{d} \mathrm{m.}$

Dolus B. Var. epidolus B.

Actis H.-Seh.

$\left.\begin{array}{l}\text { Iphigenia H.-Sch. } \\ \text { Damocles II.-Sch. }\end{array}\right\}$

Auf den Tokateralpen.

Damon S. V.

Panagaea H.-Seh.

Argiolus.L.

* Jolas 0. Bei Amasia ; selten.

Hyacinthus II.-Sch.

* Diomedes II ufn. (alcon S.V.)

Astraea Fre yer.

Cyllarus Fab.

Auf höheren Bergen bei 'Tokat.
Alle bei Tokat; letztere auch bei Amasia. Acis S. V. Var. bellis Fre yer. Alsus S. V. Ueherall. 


\section{Nymphalides $B$. \\ Limsenitis Fab.}

Cumilla S. V. Bei Amasia.

\section{Dielifuere $\mathrm{F}$ a b.}

Athalia Esp. Auf holien Bergen bei Amasia und Tokat.

Arlemis S. V. Var. orientalis H.-Sch. Nur wenige Exemplare bei Arganil Maden.

Arduinma Esp. Var. rhodopensis Fre y e r. Nur in der nächsteu Umgegend von Diarbelir.

Phoebe S. V.

* Didyma F a b. Bei Amasia und Toliat.

* Trivia S. V

Argynate F ab.

Hecale S. V.

* Ino E s p.

* Dapline S. V.

In hoch gelegeneu Gegenden bei Tohat.

Latonia L. Ueberall.

* Niobe L.

* Aglaja L.

* Adippe S. V. und Varietät cleodoxa 0 .

Paplia L.

Alle in gebirgigen Gegenden um Amasia; paphia selır selten.

Pandora S. V. Von Samsun bis Tokat; scheint uicht südlicher zu gelien.

Treacessa F a b.

Jonia Fisch. von Waldh. Bei Amasia; sellen.

* Cardui L. Ueberall; von den Ebenen bis zu den Alpen.

*Atalanta $\mathrm{L}$.

* Io L.

* Antiopa L.

* Polychloros L.

* Urlicae L.

$\because$ Triangulum F a b.

C. album $\mathrm{L}$.

Bei Amasia: atulanta selteı.

Bei Amasia nul Tokal.

\section{Satyroidae B \\ Mippencelece F a b.}

Galathea L. Var. procida llerbst.) Beide in höheren Gebirge hei Hertha IIh. Yar. larissa IIh.

Amasia mud Tokat. 


\section{Erebia B.}

* Medusu S. V. Im höheren Gehirge und aul den Alpen bei Tokn. Afra Fab. Auf den IIocheheneu vou Siwas östlich bis an deu Euphral.

Sratyons L a t.

* Proserpina S. V. In heissen Thialern bei Amasia.

* Ilermione $\mathrm{L}$.

Bryce 0.

Phaedru L.

Statilimus H u fl. Var. fatua Fre y er.

Im höheren Gebirge von Tokat his an die

Alpen.

Briseis L. und Var. pirata II ï b n e r. Bei Amasia und Tokat in schr grossen Exemplaren mit lebhafter Unterseite; die Var. pirata ohen lebhalt orkergelb: sellen.

Bischoffi H.-Sch. In den Niederungen bei Amasia.

Anthe B o eber und Var. hanifa II.-Sch. (ich sah seiller Ucbergänge) bei Amasia und Tokat.

* Semele L. In Gesellschaft der vorigen.

* Arethusa S. V.

Geyeri ll.-Sch. $\}$ Auf höheren Bergen bei Amasia.

Beroë Freyer. Auf den 'Tokateralpen. Ilinterflïgel nuten röthlich braungrau.

Pelopea Klug. Auf den höchsten Alpen bei Tokat.

Mniszechi II -Sch. In heissen Thäern von Amasia bis an den Euphrat. Anthelea Hb. Amasia, Tokat bis an den Euphrat; am häuligsten bei Tschesme Maden.

Prenenge II.-Sch.

Clymene L.

* Roxellana $\mathrm{F}$ a $\mathrm{b}$.

* Maera L.

* IIiera 0.

* Megaera L.

* Egeria L.

Amasia, Tokat.

\section{Episepliele II.-Sch.}

* Lycaon II ufn. (eudora S. V.) Diarbekir.

Janira L. Var. telmessia Z. Allenthalben gemein.

Tithonus L

Ida Fs p.

Bei Amasia.

Coeseoseysupdece II.-Sch.

* Arcania 1. Bei Amasia und Tokat.

Leander F a b. Einzeln bej Tokat.

Pumphilus L. und Var. Lyllus Es p. Ueberall. 


\section{Hesperioidae.}

mespenifs $\mathrm{L}$ a $\mathrm{t}$.

Halvarum ().

Marrubii Rh. Var. gemima L ed.

Bei Amasia.

Lavaterae $\mathrm{F}$ a $\mathrm{b}$.

Proto Esp.

Cynarae $\mathrm{B}$.

Sidae $\mathrm{F}$ a b.

Carthami Hb.

Alveus Hb. und Var. fritillum 0 .

Bei Amasia und Tokal.

Alveolus $11 \mathrm{~b}$.

Eucrate Es p.

Phlomidis II.-Sch.

Marloyi B.

Tesellum IIb. Auf den Tokateralpen.

* Thanmas II uf n. (linea S. V.)

* Lineola 0.

Aclaeon Es p.

4" Comma L.

Alcides II.-Sch.

Bei Amasia; alcides sellen.

Ueberall.

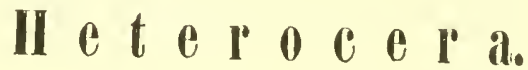

Thyridides H.-Sch.

Theyopis II!

Fenestrina S. V. Bei Tokat.

\section{Sesioidae IB.}

Prementromere S c lı h.

Myrmosaeformis H.-Sch. Bei Amasia; von Iferru II an n anch bei Brissa gesammelt.

\section{Sesire Fab.}

Sanguinolenta $\mathrm{m}$. (lengyraeformis H.-Sch.) Sliziformis H.-Sch.

Orlalidiformis in.

Philanthiformis L a s p (braconif: H.-Sch)

Bei Amasia.

Prosopiformis 0 .

Elampiformis II.-Sclı 
Doleriformis $11-S \mathrm{ch} .49$.

boryceraeformis m.

Lomalineformis $m$.

Bui lojurluclisl.

Miniacea m. (minianiformis ti le yer.) hei Tokat.

\section{Sphingoidae B}

\section{mirceogrosere 0 .}

* Fuciformis L. $0 \mathrm{chsh}$. Anf hochgelegenen Bergwiesen lei Toliat. Croatica Es p. Bei Amasia; selter.

Slellatarum L. Ueberall.

\section{Plezengan B.}

Gorgoniades If b. In llochgebirge von Siwas ösllich.

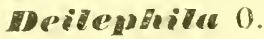

Porcellus L. In Gesellschaft des vorigen.

Euphorbiae L. Amasia, Tokat.

* Gralii S. V.

Liroruica $\mathrm{Es}$ p (limeala Fab.)

Mit der vorigen zugleich: flocl selten.

\section{Suncupithers 0.}

hindermanni m. Zwei Pare bei Argana Maden in Begaltung im Frase in der Nähe von Wejden gefangen.

\section{Syntomides H.-Sch.}

symtomis Illiger.

phegen L In hochgelegenen Gegenden hei Amasia.

\section{Vercliar B.}

: Punctala Fab. Bei Samsun. Jch sah sie nichl in Nalur mud möclite sie eber liur hyalina Freyer lialten.

\section{Zygaenoidae $\mathrm{B}$.}

\section{zygreme fia h.}

Rubicundus II b. Amasia.

Himos S. V.

Brizale E s p. Bei Tokat anf hoehgelegenen Wahlwiesen Scabiosal Hb.

Punclum 0. Achilleae Esp. Trifolii Es p

Lomicerae Es j. Bei Amasia und Toliat. 
66

Meliloli Es p. Mit der Var. Stentsii Fre yer mntermischt anl hochgelegenen Waldwiesen bei Tokat.

Graslini m. Ein defectes Stuck hei Diarbekir.

* Filipendulae L.

* Tramsalpina $1 \mathrm{~h} \mathrm{~h}$.

Medicaginis $\mathrm{H} \mathrm{l}$.

Laphria Freyer.

Dorycuii 0.

Sedi Fal.

Laela Esp.

Ganymedes H.-Sch.

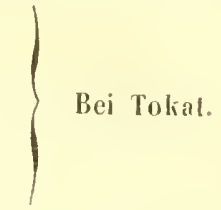

Formosa H.-Sch. Nur bei Amasia; sellen.

Carniolica Scop. (onobrychis S. V.) Ueherall in sehr grossen lebhaften Exemplaren.

Ine Leach.

Temicornis $Z$. Amasina H.-Sch.

Amasia.

\section{Epialoidae H.-Sch.}

Epeinters F a l.

* Sylvinns L. In Iloclıgebirge von Amasia.

Amasinus II.-Sch. Ein Männchen von Amasia.

\section{Cossina H.-Sch.}

\section{Eurreglire B.}

Pantherina Hb. Amasia.

Stggoirr La 1 .

Amasina H.-Sch. Amasia.

\section{Saturniina H.-Sch.}

Srrtersaier S c h k.

* Pyri S. V. Bei Tokat sehr liäufig.

Spini S. V. Bei Amasia und Tokat, doch selten.

\section{Bombycides 1.}

Howdoyer B.

* Otus Drury. Selten bei Amasia anf Cypressen

* Nenstria L. Bei Amasia und Tolat. 
"raslrensis l.

* Franconica falt.

Trifolii s. V. und Var. medicagmis $B \mathrm{kh}$.
Ber Amasia warl Tokal.

\section{Liparides B.}

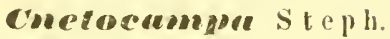

* Pilyocampa Fab. Zwischen Samsun und Amasia vicle Vester an Pinien.

\section{Poortecsice St e pl.}

* Chrysorrhoea L.

* Amriflua S. V. Bei Amasia und Tokat.

Demerien II.-Sch.

Terebyuthi Freyer. Zwisehen Samsun und Tokat allenthatben häufig.

Lapidicola II.-Sch. Wohl nur kleine Var. von atlantica. H.-Sch. Die kanpe im Juli bei Amasia nnd Tokat häufig unter Steinen; sie leht gesellschaftlich, nälırt sich von dürren Grïsern und liefert den Schmetterling Aufangs September.

* Dispar L. Bei Imasia und Tokat.

\section{D.gngire 0 .}

Dubia Ta us elı er. Viel lebhafter und mit mehr Gell, als die russischen Exemplare; wie Herrich-Schäfer's Figur 163. Bei Amasia Tokat und iiber den ganzen Gebirgszug von Siwas östlich bis an den Eirplirat verbreilet.

\section{Eithosioidae $B$.}

setione se h k.

Irrorella L. In Hochgebirge und auf ten Alpeu von Tokat und Amasia.

Citreosine $\mathrm{F}$ a b.

Camiola If b. Wie die rorige.

\section{Euprepioidae.}

Eomyetien $B$.

Grammica L. mid Var. striata Bkh. Im Hochgebirge mul ouf Mpen hei Tokat und Amasia.

\section{Depopoine C. II t is.}

Pulchella I. Bei Amasia mul Tokat. 


\section{Vesseophiofrs is tepli.}

: Russula L. Auf den Tokaleralpen.

\section{C'alePanonperd Lat.}

Domimula L. Die gelhe Varietät (rossica Ko l e ll a ti) im Hochgebirge von Tokat.

* Hera L. Bei Amasia.

Ancliae steph.

* Villica L.

* Purpurea L.

Bei Amasia und Tokat.

* Aulica L. Bei Tokat im höheren Gebirge.

\section{Noctuina.}

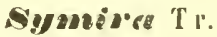

Dentinosa F l' e y er. Von Amasia bis Diarbekir in den Ebenen; Ranpe gesellschaftlich auf Euphorbien.

* Nervosa S. V. Bei Amasia und Tokat.

Dilopere B.

* Coeruleocephala L. Bei Amasia.

\section{Huyaphila 'T r.}

Glandifer'a S. V.

Algae $\mathrm{F}$ a b.

Bei Amasia und Tokat.

Receptricula IIl.

\section{AcBosuctre 0.}

* Rumicis L. Amasia

Euplurasiae II b. II.-Sch. (Die helle, bei Paris gemeine Art) bei Amasia.

\section{Spinatberopos B.}

* Spectrum S. V. Bei Tokat.

Dilucida II b. In sehr dunklen Exemplaren bei Amasia.

Thoipolareaen T r.

Fimbria L.

Subsequa S. V. und Var. consequa Ilh.

Promuba L. Ind Var. imnaba llb.

Iiı höher" Geburg voll Amasia.

\section{Dpigemie B.}

Polygoma S. V. Auf den Tokateralpen. 


\section{Cluesotis $B$.}

Multangula H b.

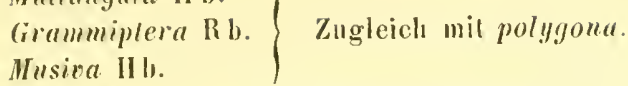

Flammatra S. V. Aeusserst gemein bei Diarhekir; nuter jedem Steine, den man nmwendet, trilt man einige Schmolterlinge.

Agnolis $\mathrm{T} r$.

* Fimbriola Ilb. Im Gehirge von Tokat.

Trilici L. Var. hilaris F r e yer. Ein Stiick, wahrscheinlich von Amasia.

* Siguifera S. V.

* Forcipula S. V. Von Amasia.

Flavimu H.-Sch.

* Sencia II h und Var. aequa II h. Agricola B.

Clavis 11 u $\mathrm{fn}$. (segetum $\mathrm{S}$. V.

Exclamationis L.

Suffusa S. V.

In Gebirgsgegenden bei Tokat; suffusu auch auf den Alpei.

\section{Inepepiare B.}

Dumerili D u p. Ein blasses Exemplar bei Amasia.

\section{Iracenese 'T $\mathrm{l}$.}

Abjecta H h. Anf den Tokater Alpen.

Peregrina $\mathrm{T}$ r. Bei Amasia.

\section{Dinathoceirs B.}

Filigramma Es s.

Carpophaga $\mathrm{B}$ o r k h.

In Tokater Gebirge.

Irregularis II u f $\mathrm{n}$. (echii B k h.) Bei Amasia.

\section{Hitaras Guenée.}

Ochrolenca S. V. Bei Amasia.

\section{Poline Tr.}

Cappa II b.

Ruficincta B.

Amasia

Montana II.-sch. In Gebirge hei 'Tokat.

Aplecter B.

Serratilimea Tr. Gebirgsgegend hei Tokat.

Eneroppin B.

Adululrix II b. Gemein von Samsun bis Ausiu. Die Puppe an Fusse von Rhus codiums zu linden. 


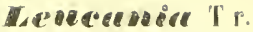

Comma L.

L. album L.

Hohe Bergwiesen bei Toliat.

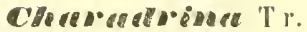

Cubicularis S. V. Im Ilochgebirge von Tokal; anch anl' den Alpen Exiqua Ilb. Bei Tokat in Niederungen.

\section{Oortensian Tr.}

Lota L. Auf hohen Bergen bei Tokat.

Pistacina S. V.

Ypsilou S. V.

Bei Tolial.

\section{Trabione $\mathrm{Tr}$.}

Ferrago Ev. Auf hochgelegenen Gebirgswiesen. Die Schmellerlinge im Sommer Abends vom Grase geschöpft: wohl kaum eiue Ianlhia und weit elıer zu Luperina gehörig.

Chetarentere B.

$\left.\begin{array}{l}\text { Hyperici s. V. } \\ \text { Radiosa Es p. }\end{array}\right\}$ Bei Amasia.

\section{CTeOpHereat B.}

Antirmini II b.

Opalina H b.

Olivina H.-Sch.

Bei Amasia und Tokat.

\section{Creculliat $\mathrm{Tr}$.}

Jerbusci L. Bei Amasia und Tokat.

Samtonici ll b.

Argentina Fab. $\quad$ Vou Siwas östlich anf hohen Bergen.

Plousin Tr.

Graphica H.-Sch. Häılig bei Amasia und Tokat.

Ni II b. Bei Amasia.

\section{Hetiothe is $\mathrm{T}$ l.}

Dos Fre y e r. Ein Paar defecte Stiicke anf feuchten Wiesen bei Amasia. Coguata il b. Selten bei Amasia.

Frivaldsaliyi $\mathrm{Tr}$.

Dipsacen S. Y.

Pelligeras. T.

Armigera $\mathrm{H}$ b.

Boisdurali hb.
Alle bei Amasia und Tokat. Friraldshyi bei Tage an EchimmBliullen, Laudeli als haupe zueleich mit ler von Boisdurali an 
Lanuleti B.

Delphinii L.

Virlorina So dof f sky.

Ien Bliblhen und Samen einer mir nicht näher bezeichueten Silene.

Rhollites Ev. (anrorina II.-Sch.) Im Tokater Gebirge; sellen.

actiones linenée.

Rupicola S. Y. Im Hochgebirge von Amasia und Tokat selten.

Aconsetial $\mathrm{T}$ r.

Uramia Fre yer.

Tilanir Es p.

Lucilla II uf $\mathrm{n}$ (solaris S. V.)

Alle bei Amasia und Tokat.

: Luctuosa S. V.

Cretocutra ja h k.

* Elocala E s p. Bei Tokat.

Neonymplea II b. Bei Amasia; Raupe auf Süssholz.

Disjuncla $\mathrm{Hb}$.

Eulychea Tr.

Bei Amasia an Eichen: sellen.

Ophieesa Tr.

Algira L.

Stolida F a b.

Cayliro Hb.

Singularis Koll a r Famma von Sïdpersien.

Alle bei Amasia.

* Lndicra $\mathrm{H} \mathrm{b.}$

Lusuria L.

Zetres hb.

Insuluris R b. Bei Samsun und Amasia.

Nixoclentis m.

Inamoena H b. Var. ingrala II.-Sch. Amasia.

Suava II b. Amasia.

Glyphica L.

Mi L.

\section{Euclidtare T r.}

Bei Amasia und Tokat.

Thutpocternes m.

Wagneri II.-Sch. Auf den Tokater Alpen.

Purpurina S. V.

Amoena ll b.

Parallela li re yer.

Pamouica Fre yer.

Ostrina II h. in Varietiten.

Alle bei Amasia ; ostrina umat purpurina anch bei Tokal.

(ilarea H b. 


\section{Metoponin D $\mathrm{D} p$}

Eximia Fre yer. In Gärten bei Amasia an Matoen. Die Ranpe soll wie die von Plusia geformi sein.

Vespertalis $1 \mathrm{lb}$. (vespertina $\mathrm{Tr}$.)

Flava II b. ( Ravida 0.)

Leptosia II b.

Aenea S. V.

Leda II.-Scl.

Bei Amasia und Tokat.

$$
\text { Henminice T } \text {."*). }
$$

Derivalis $\mathrm{Hb}$.

\section{Hypema T r.}

Antiqualis $\mathrm{II} \mathrm{b}$.

Ravalis H.-Sch.

Lividalis $11 \mathrm{~b}$.

Melia ful née.

Calcaria S. V.

\section{Geometroidae.}

remonie ll h.

Cloraria Hb.

Acietcetive $\mathrm{Tr}$.

Flaceolaria $\mathrm{Hl}$ b.

Circuitaria II b.

Mutata Tr.

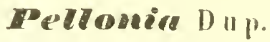

Calabra Var. Iabidaria $\mathrm{Z}$.

Do.thostionis II.-Sch.

Cribrata S. V.

Calcularia m.

$$
\text { Bistore L a ch. }
$$

Pomonarius II b.

*) Von hier an muss ich mich auf blosse Auf\%ählung des Gesammelten heschräıken, da nahere Notizen mir nicht mitgetheilt wurden. 


\section{Vyerloites in.}

Licidaria II b. Kleiner und ranher beschuppt, als die französischen. Amỵgdalaria II.-Sch.

\section{Honntrate 'Tr.}

Perversaria B.

Rhomboidaria S. Y.

$$
\text { Cuoptios T'. }
$$

Stevenaria B.

Onustaria H.-Sch.

\section{Fielocior $\mathrm{T}$ r.}

Fascioluria HI f 1 . (cebraria II h.) Nicht die Var, baltearia.

$$
\text { Pleresicuene D U p. }
$$

Legutaria II.-Sch. Amasia; anch im Taurus.

\section{Sceodiosers B.}

Conspersaria S. Y.

$$
\text { Eusrarere H.-Sch. }
$$

Telaria II.-Sch.

Jacularia $\mathrm{H} \mathrm{b}$.

$$
\text { Aspilates T } \mathrm{I} \text {. }
$$

Strigillaria 11 b.

$$
\text { Apleasted II.-Sch. }
$$

Omonntu Fuess Iy.

D.thotirtere It b.

Plumbaria Fab.

Cervinata S. V.

Zomata II Ifu. (mensuraria S. V.)

\section{furcitis li.}

Lilhorylala $\mid \mathrm{ll}$ b.

Columbula Ml e t z n e r.

Boisduvaliala D

Obsiluria m.

Numidaria II.-Sch. 
Putridaria II.-sch

Fruslala Tr.

Permixlaria II.-sch.

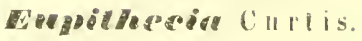

Pumilaria $\| \mathrm{h}$

\section{Pyralidoidae.}

Aglossir Lai.

Euprealis $11 \mathrm{~b}$.

Pinquinalis $\mathrm{L}$.

\section{pyotis L.}

Perlusalis 11 b.

Consecrutalis m. (cruentalis Kollar in lit., non D I ponche l). Zwei Männchen. Herr Ko t s c lı y fand diese Art auch in Südpersien. Grösse einer mitlleren netricalis; Fïhler, Palpen und Beine wie bei dieser Art gebildet. Die Yorderflügel sind kïrzer, breiter und stumpfer als bei nefricalis, lucht olivbrann mit breiten gleichfarbigen Fransen und laben ein wie bei nelricalis angelegles gleichfarbiges, heiderseits licht braungelb beschattetes Mittelfeld, dessen Vorderrand lieller gestrichelt ist. Die Hintertlïgel sind blutrolh, etwas ins Ziegelrolle ziehend : iltre Basis und ein wie bei netricalis geformles Querband sind goldgelb: an der Innenseite des lelzleren bildet die Grundfarbe nur ein schmales, einnärts elwas verwaschenes Band. Die Unterseite ist blutroth. an der Pasis goldgelh. Die äussere Mittellinie gränzt anf allen Flïgeln die Farbe nach aussen sehr scharf ab; diese ist einwärts in die goldgelbe Basis verwaschen, aussen von einem goldgelben Querbande hegrenzt; alle Flügel haben feine blutrotle Miltelpuncte.

Honestalis 'Tr. lialis $\mathrm{D} \| \mathrm{p}$.

Colchicalis II. - Sch. Ein Mannchen; vielleicht nur Var. von massi-

\section{Grambites II.-Sch.}

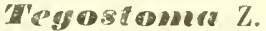

Venustalis m. Ich erhiclt nur Ein WVeibchen. Es stimmt in Grösse, liabitus und Flïgelschull genau mil sionlalis D 1 p. (s/ggialis T r.) überein mad hat anch in Zeichnong ler Oberseite einige Achulichlieit mit dieser Art, der Stirubildung nach gehörl es aber zu Tegostoma. Der Körper ist schwarzhrann, spitz zulaufend, mit kurzem Legestachel, die Beharming der ['rust mol Boine ist hränulichegelb, Kopl und Bücken elwas dunklpe gefärlt. 
Die Stirne hat eine spatenformige hornige Verlängerung, ibler welehe die. mit langen, horstig abstehenden, schwarz und gelb gemischlen Haren besetzten Palpen horizontal in Koufeslänge vorstehen; Nehenpalpen fehlen. Due Zunge ist spiral. Die Grundlarbe der Vorderlligel ist gelblicligrau, durch feine schwarze Atome derart rerelunkell, dass nur das miltlere Briltel des Flïgels wie bei siculalis heller gewölit erscheint. Dieses ist von zwei schwarzen, grobstrichigen unregelmäsigen, wie bei siculalis angeleglen Querlinien eingefasst, von denen die innere ganz verloschen ist, die äussere aber aus einem etwas schürferen Vorderrandsfleck entspriugt; zu beiden Seiten dieses Fleckens ist der Grund am lichtesten gelbbraun; auch längs der ganzen ans diesem Flecken entspringenden Querlinie ist das Gelbhraune des Millelfeldes am deutlichsten und auf der Querrippe steht eine undeutliche schwärzliche Makel. Das Saumfeld hat dic gelbe Farbe durch schwarze Atome fast ganz verdeckt und durch seine Mille liuft eine verloschene schwarze Querlinie; am Samme stehen die schwarzen Alome ganz dichl gel:äuft, nach innen zu werden sie aber spïrlicher, daher hier das Schwarz in Hille sehmutzigweiss, von da his zum Innemrande schwarzgran. Die Hinterllïgel sind schwarz und haben (ungefähr wie atralis) eine schmale schmutziggelbe Querbinde, welche vom Vorderrande bis zur Milte des Fliigels reicht und da plötzlich aufhört; ihre Fransen sind zur inneren Ijilfte schwarz, zur äusseren se! mulzig weiss. Unten siud die Vorderflïgel ron der Basis bis zur äusseren Mitlellinie strohgetb mit zwei grossen rundenglell schwarzen Hakeln, unter welchen der Discus malt schwitrzlich ist; das Saumfeld ist schwarz, wurzelwärts zackig und daselbst schr scharf rom Gelb abgegrenzt, vou einer strohgelhen nuterbrochenen Querbinde durchzogen. Die llinterflügel sind schwarz, die Miltelbinde ist strolıgelb, viel reiner und schärfer als oben, der Vorderrand und eine verloschene Binde vor dem Saume sind brännlichgell. Die Fransen aller Flägel sind zur inneren IIälfte schwarz, zur äusseren weisslichgelb, an der Vorderfligelspitze hier ebenfalls heller, als an den übrigen Stellen.

arocyme it.

Cacumimalis Ev

Alralis $\mathrm{Hb}$.

Holges ir

Cimgulata L. ( - alis S. V'.)

Pygmacalis D $\| \mathrm{p}$.

Purpuralis L.

Vespertalis II.-Sch

Superba Fiveyer.

Hucosalis II.-Sch.

Limbopunclalis H.-Sell. 
Aenealis S. $\mathrm{V}$.

Aerealis II b.

Opacalis II $\mathbf{b}$.

Cruentalis H b. (Bourjolalis D 18 B.)

Comptalis Ev.

Flavalis S. V.

Virginalis D u p.

Fimbrialalis H.-Sch.

Pustulalis H b.

Politalis S. V.

Umbrosalis F. R.

Cymorealli II b.

Dentalis S. V. Sehr gross and hell gefärbt.

Stenier Gi unée.

Suppandalis II b.

Carnealis ' $\mathrm{T} \mathrm{r}$.

Ophialis Tr.

\section{Eucluster.}

Splendidalis II -Selt. Herr Herrich-Sehäffer zieht diese Art zo Botys, wovon sie aber ihre langen, his über die Flitgelspitze hinansreichenden Fülıler entfernen. Il errich-Schäffer's figur zeigt diese Länge nicht richtig und ist woht mach einem Exemplare mit abgebrochenen Fühlern verfertigt.

\section{Cremobes f a b.}

Malacellus D u p.

Incertellus H.-Sch.

Aridellus $\mathrm{Thb}$.

Perlellus Scopoli.

Bellus $\mathrm{H} \mathrm{b}$

\section{Aneverstion $\mathrm{Z}$.}

Punctella Tr.

\section{Myelois $\%$.}

Rufella D up. und Var. crudella Z.

Gilneolella T r.

Anliquella $\mathrm{HI} .-\mathrm{Sch}$.

Pumicosa m. Zwei Männehen von Diarbekir. So gross wie Rippertellu, derselbe Flügelschuitt, aber fast noch robuster gebaut. Der Hinterleib und alle übrigen Körpertheile sind weiss, die Palpen anliegend beschuppl, in Kopfeslänge gerade vor- und etwas anfwärts steltend, das Endglied sehr 
kurz unu stumpf; die Nebenpalpen sind ganz lutz und fadenförmig, die Zunge ist spiral. Die Fühler sind dick, borstenförmig, ohne Krümmung oder Schupenwulst, mit nuten ahgesetzten, kurz nud dicht bewimperten Gliedern. Die Beiue sind kräftig, anliegend beschuppt, olne Auszeiclnung, die IInterschienen mit den gewöhnlichen 2 Paar Spornen. Rücken und Vorderfiigel sind weiss mit leinen grauen Atomen bed'clit, wodurch sie ein himssleinfarhiges Ansehen erhalten. Alle hippen der Vorderfligel bleihen rein weiss, am Anfang und Ende der Querrippe steht ein feiner schwarzer Punct, gröbere schwarze Puncte noch am Saume zwischen den Rippen; die Fransen sind breit, weiss, mitten vou einer grauen Längslinie durclızogen. Die Hinterllïgel sind weiss mit schwachen schwarzen Miltelpunclen, braungrau angeflogenen Rippen und zerstrenten schmutziggranen Schuppen um dieselben. Unten sind die Vorderflügel aschgrau, am Saume weiss gerandet, die Hinterllügel sammt den Fransen weiss; der Mittelpunct ist hier slärker, als auf der Oberseite und grane Atome sind nur wenige rorbanden.

\section{IRncese H.-Scl.}

Allotriella II.-Selı.

\section{Episcienire Z.}

Prodromella $\mathrm{H}$ b.

Aucylosis $Z$

Cinnamomella D $\mathrm{D}$.

Rhodochrella II.-Sch.

Nepreoplengy $\mathrm{Z}$.

Alpigenella D up. (Wagnerella Freyer.)

Subochrella I.-Sch.

Carnella L.

Penpelia 7.

Lencochrella II.-Scli.

\section{Tortricina.}

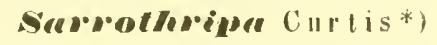

RevaganaS. Y.

\section{Teness tr.}

Cristana S. V.

\section{Tonloix T r.}

Lathoniana II b.

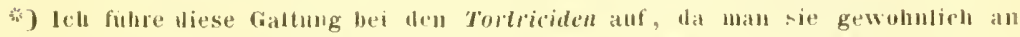
dieser stelle sucht; es gilt abre vou ilu cheufalls las in ther Ammerkung \%u Earius silinuena Gesitgle. 


\section{Tineina.}

tychere L a $\mathrm{t}$.

Appendiculata Esp. Bei Tokit.

Euplocernoes L a $\mathrm{t}$.

Fuesslinellus $\mathrm{S}$ u I zer. Die ron II er joh-s chaffer Figur $z+1$ 243 abgehildete Varietä.

Ophisa $\mathrm{C} r$ a m er.

Laevigatellus II.-Sch.

Irasifera $\mathrm{Z}$.

Luridella Z.

Hypsoloptere Fab.

Verbascellus S. V.

Gelectein $Z$.

Egenella H.-Sch.

Irapoetla S chk.

Kindermanni H.-Sch.

Decopbeand L a 1 .

Amasiella H.-Sch.

Pterophoridae L.

Pentadaclylus L.

$$
\text { Ptenopleones Ge of itoy. }
$$



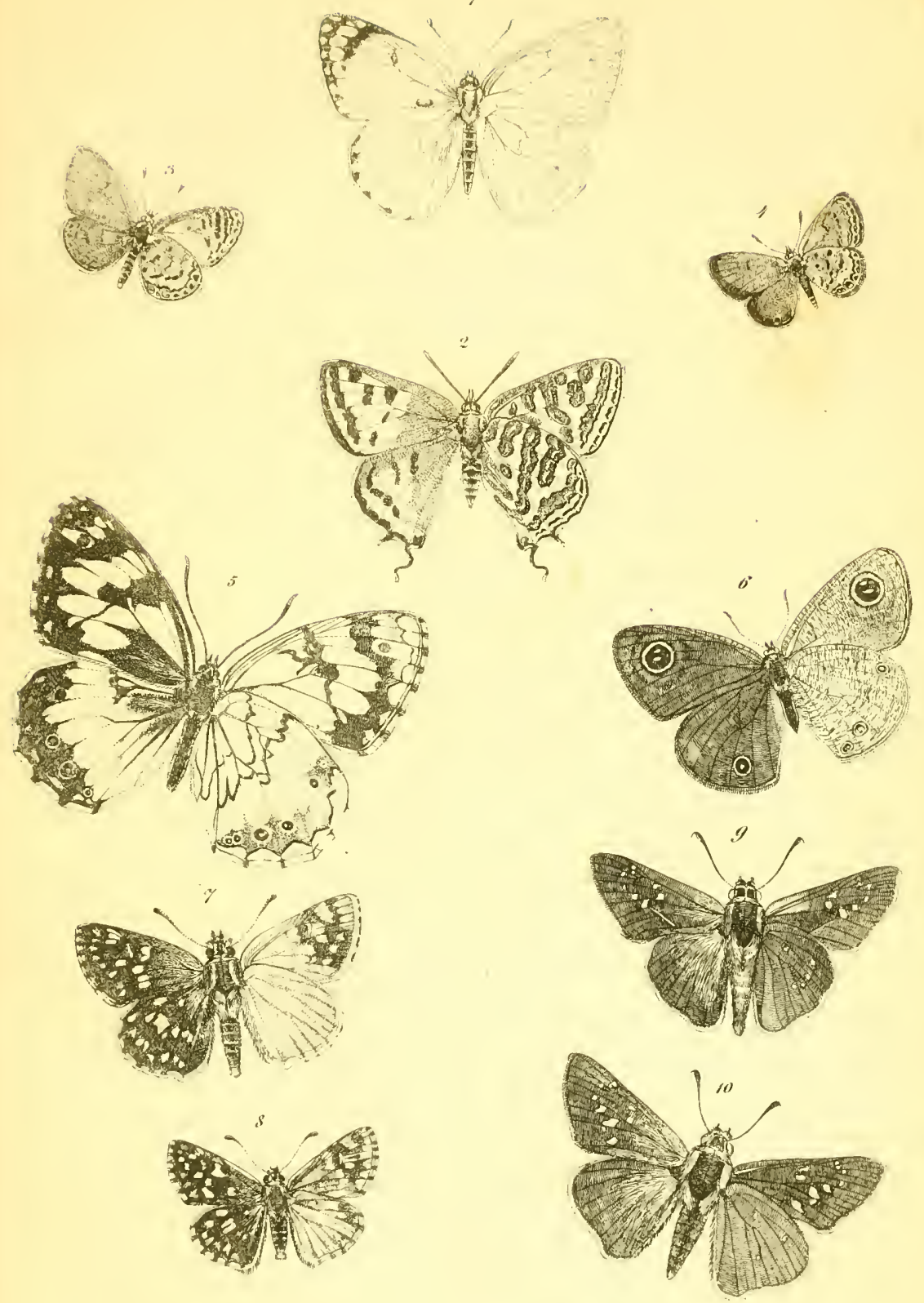

, Melmeres fremesler (Jlir.

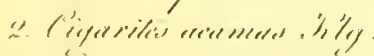

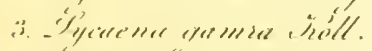

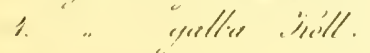

5. Higenerserterior lilere. Mlop.

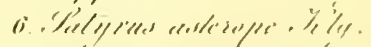

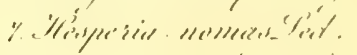

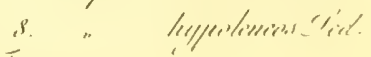




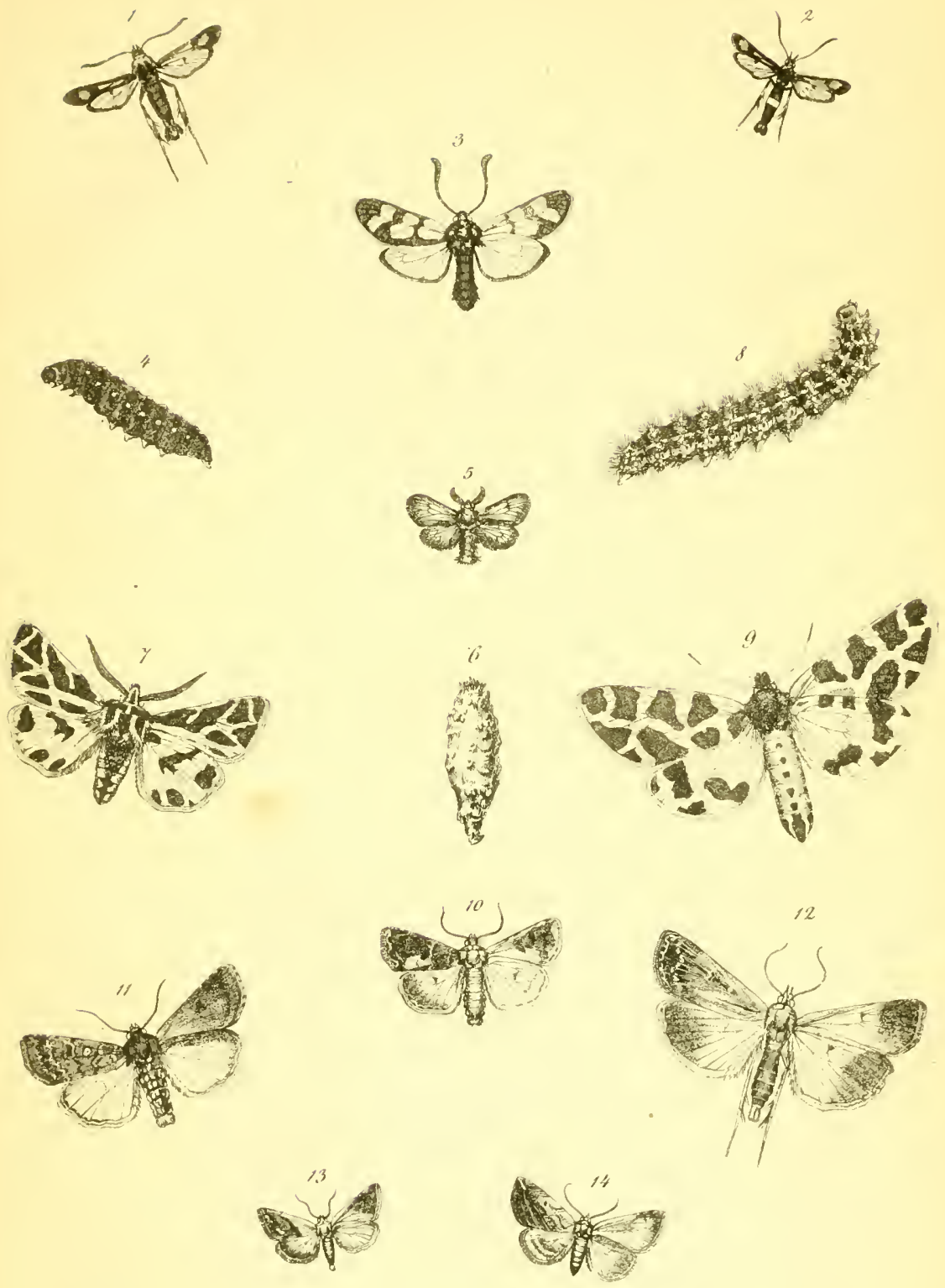

1. Pesiar azonoa-Lert.

2. pipiziformis-ted.

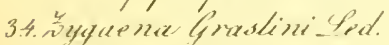

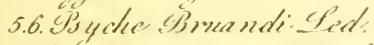
7. Ornogygues detherater Lid.

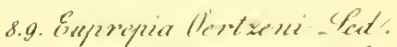

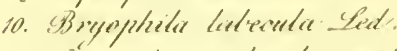

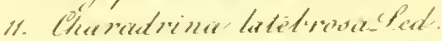

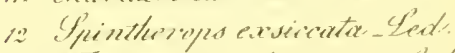

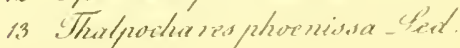





\section{8}
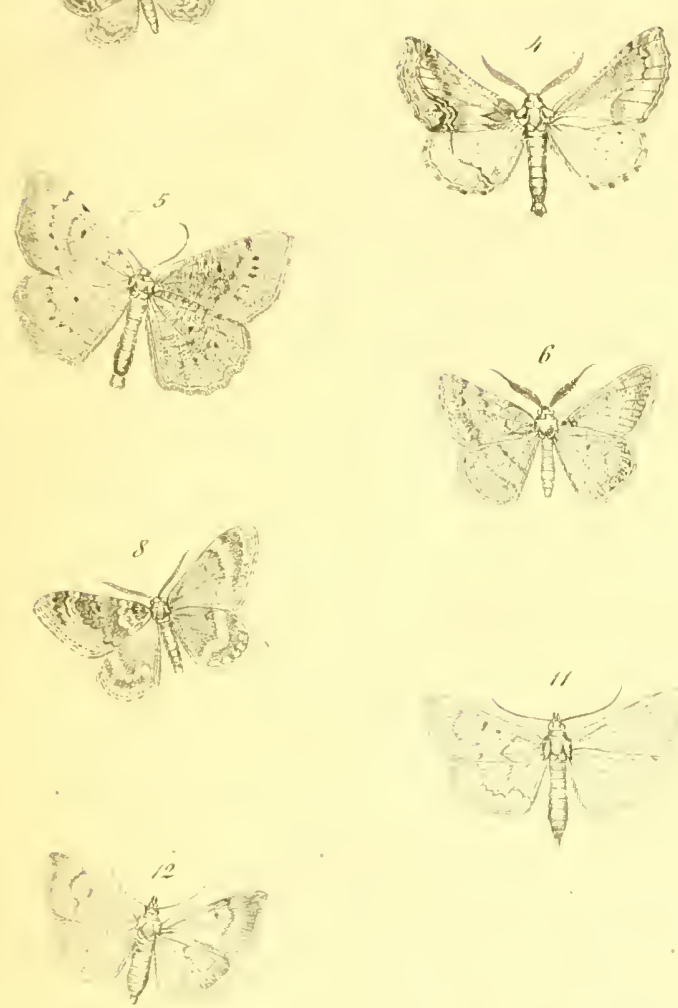
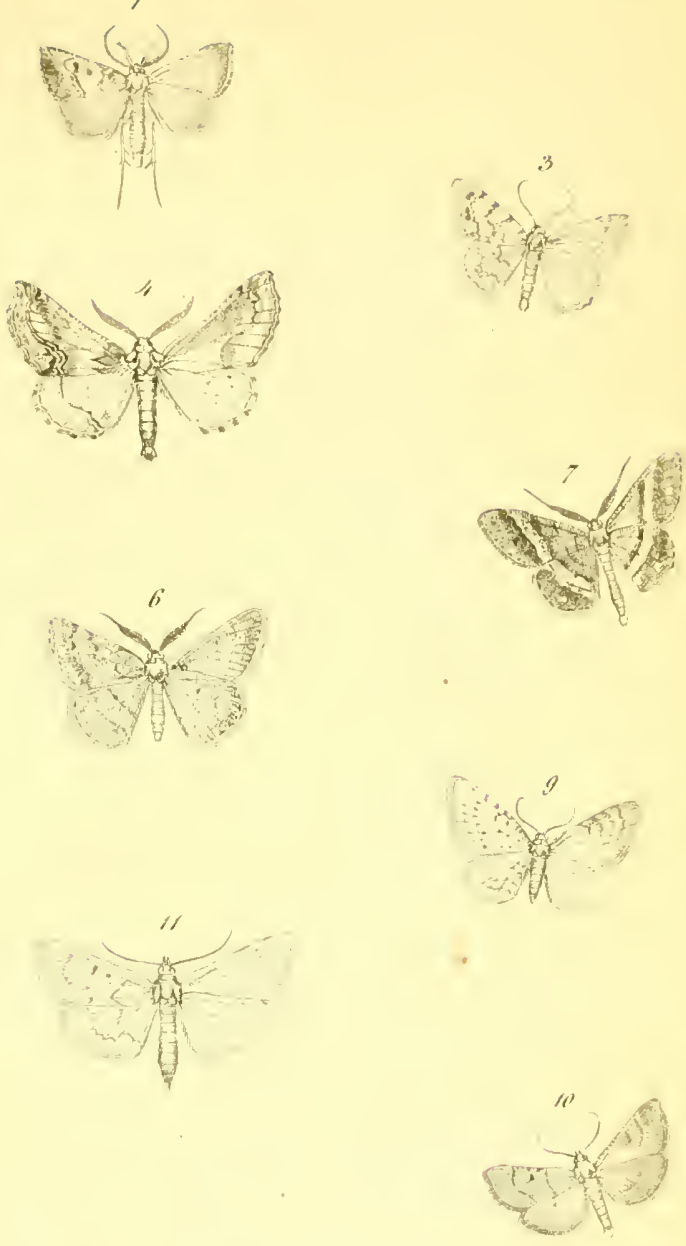

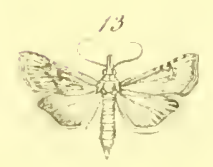

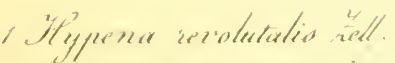

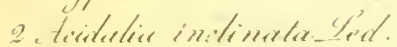

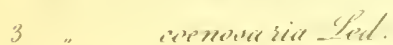

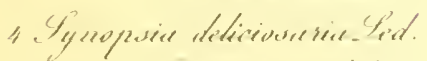

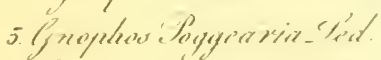

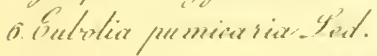

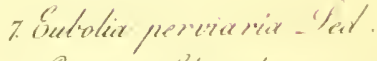

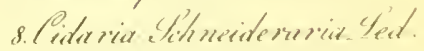

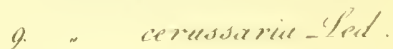

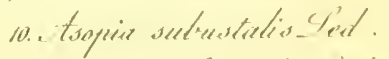

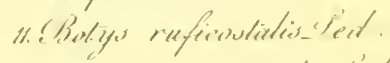

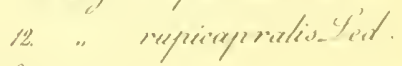




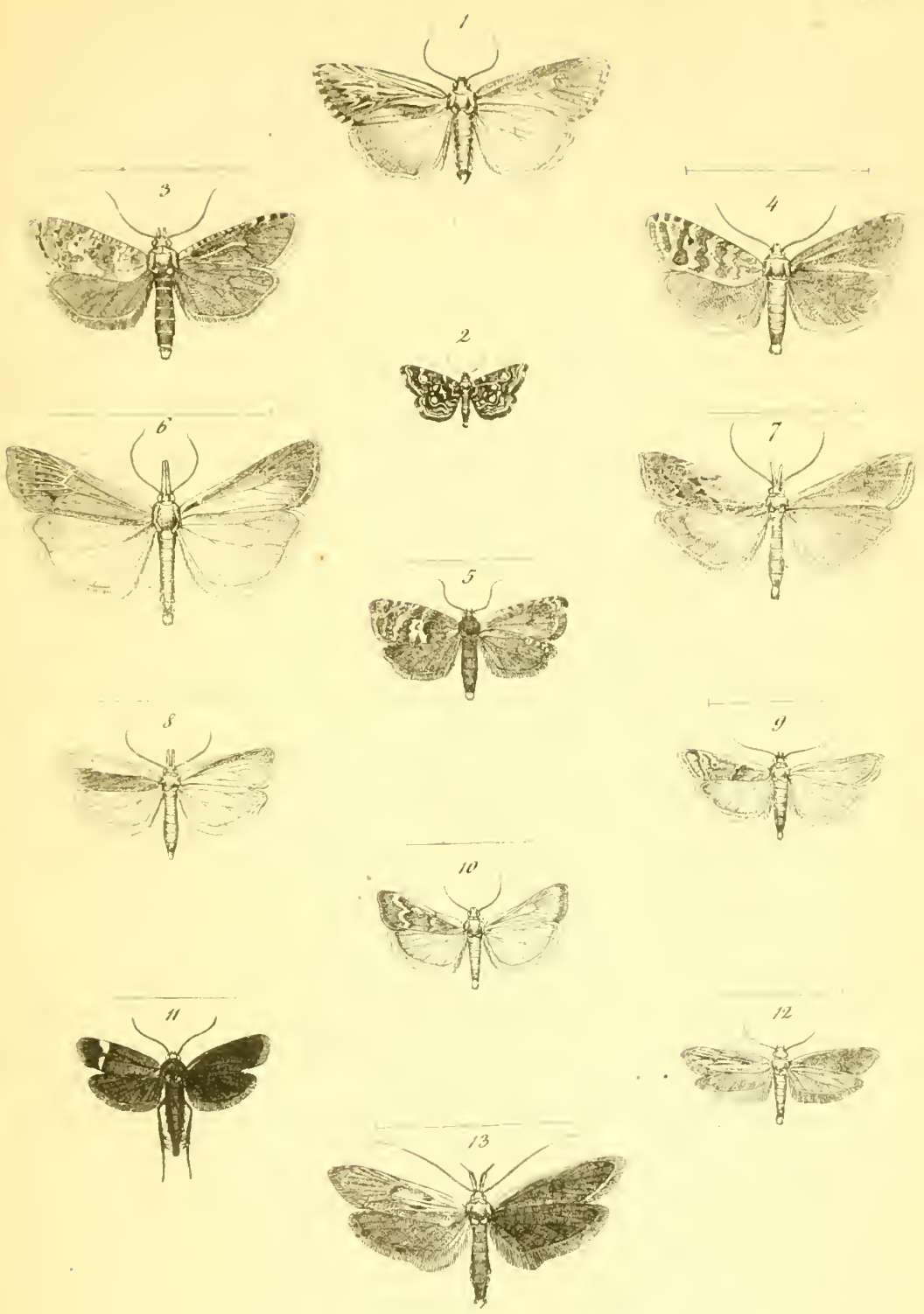

1. Ylyperuthymax fulourita. Led.

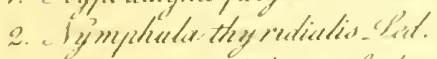

3. Coceryer siertridulanse. Sedt.

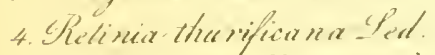

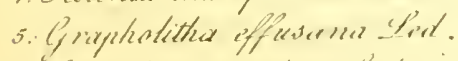

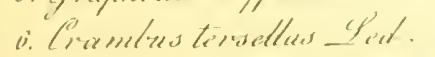

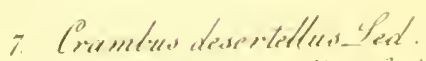
8. -twerastin ichmeller-Lid.

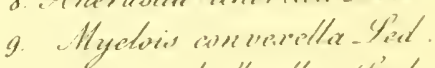
10. "iglrealle - "pit. 11. . theshen nender a 5 . 13. . tpetetrise lerlles-Ped: 


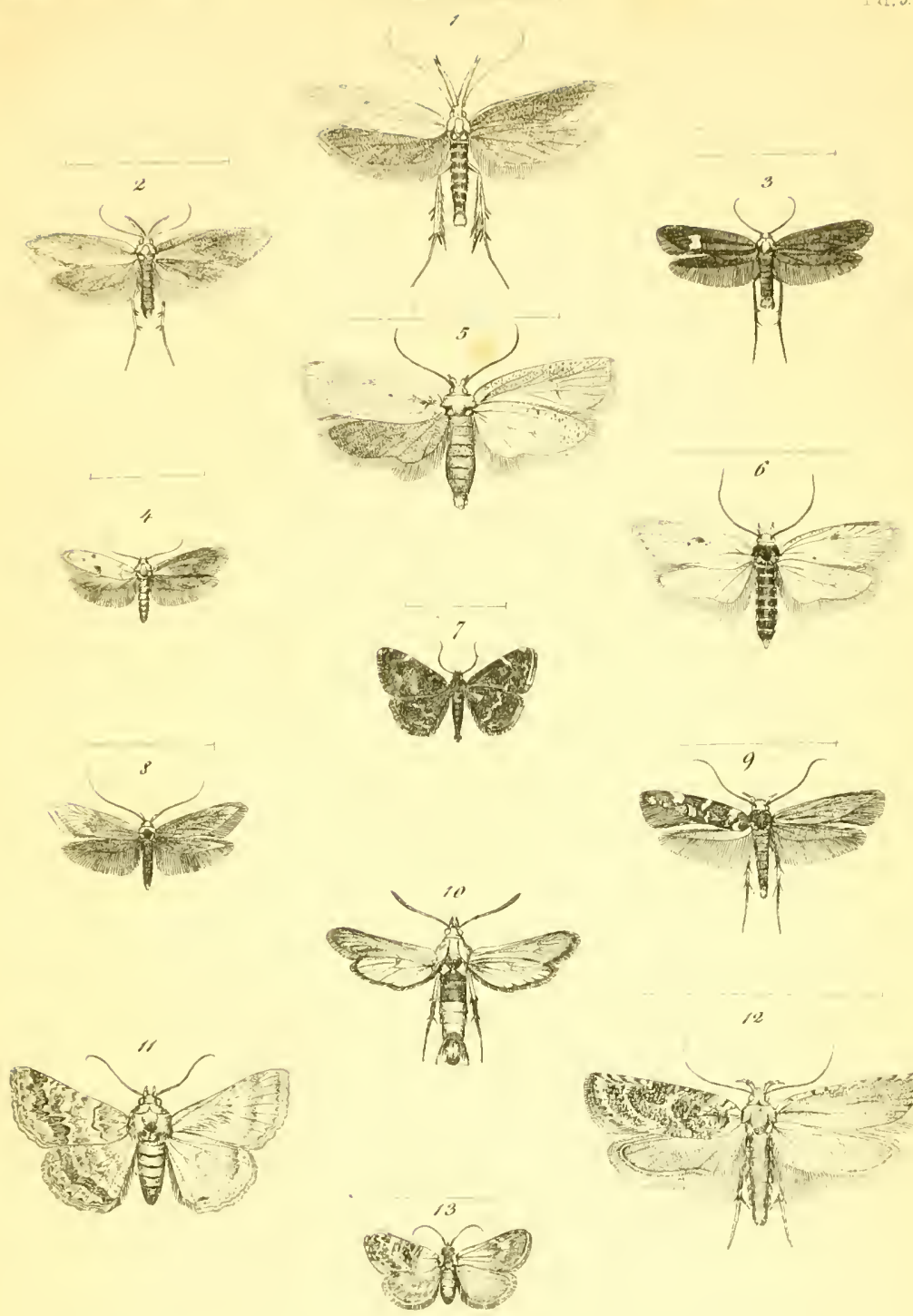

12

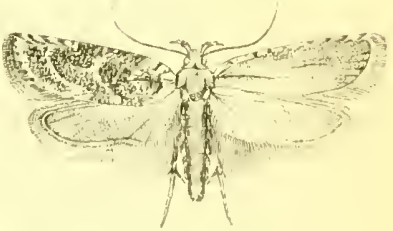

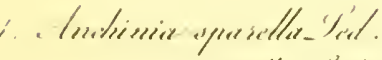

2 . lerrigelles - Vied.

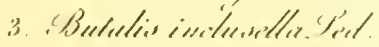

4 - desietelle Viol.

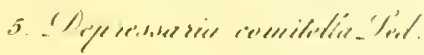

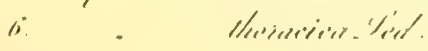

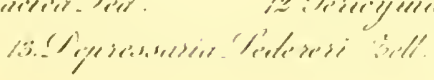

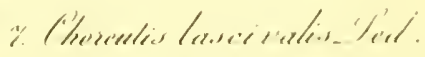

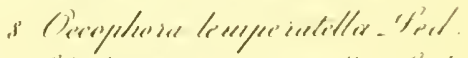

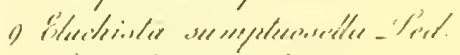

10. Yisier yous rieter - Vird.

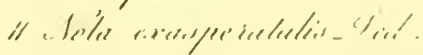

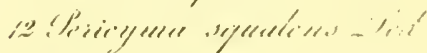







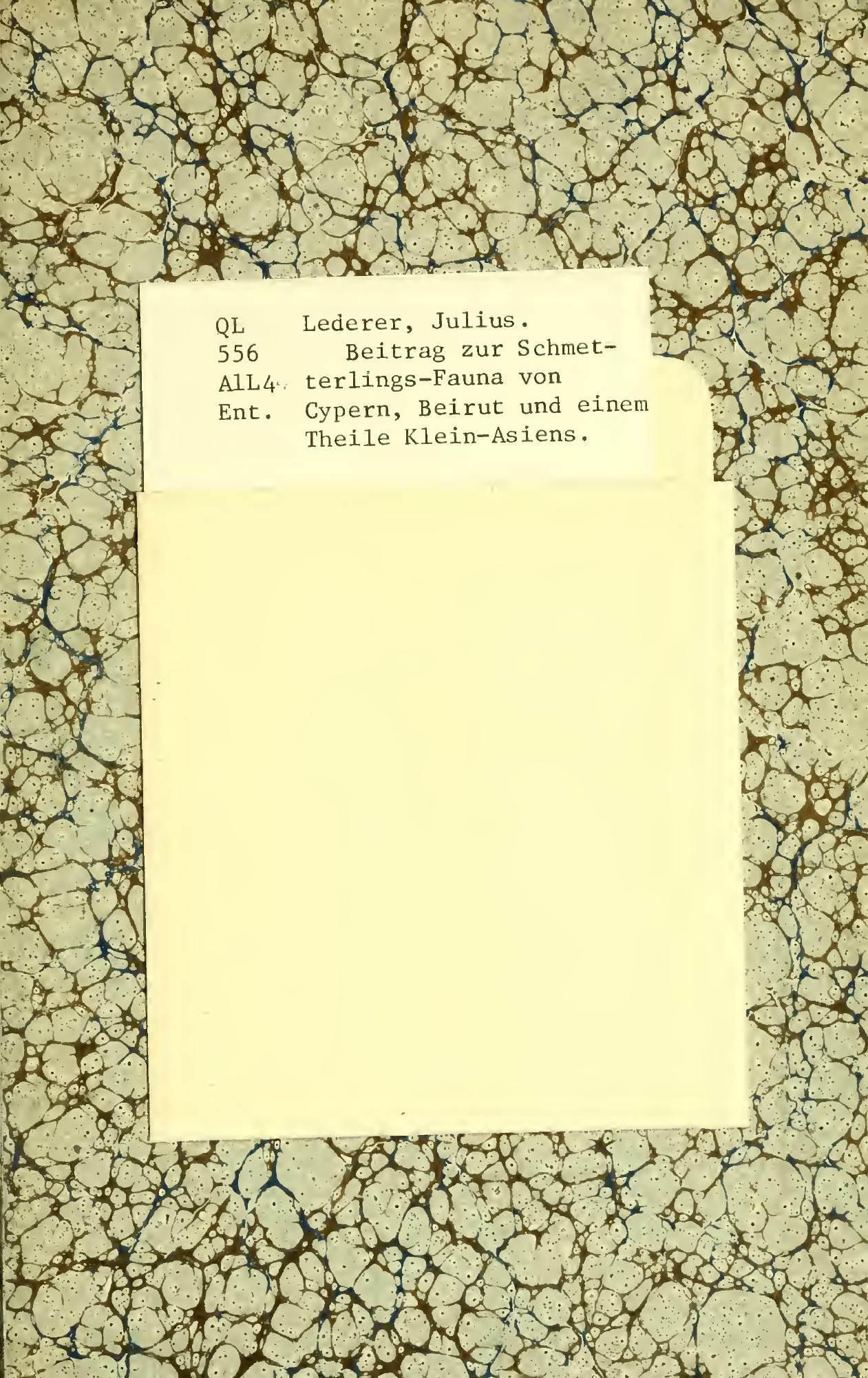




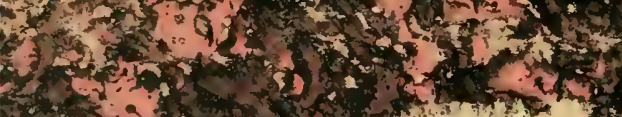

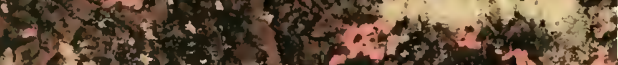

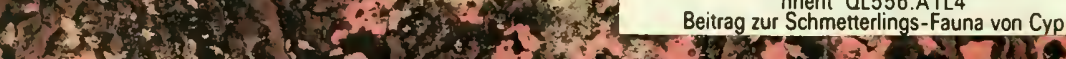

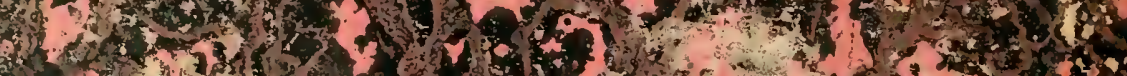

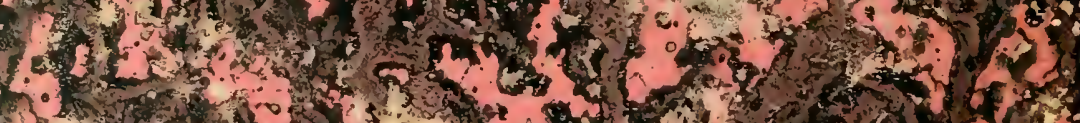

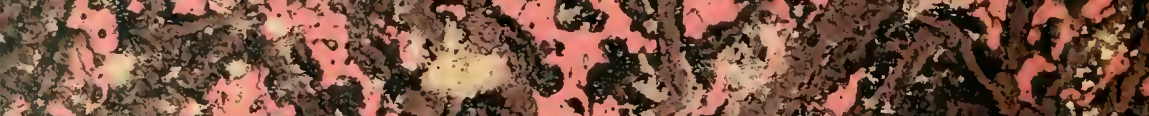

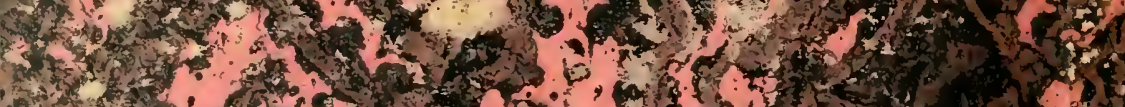

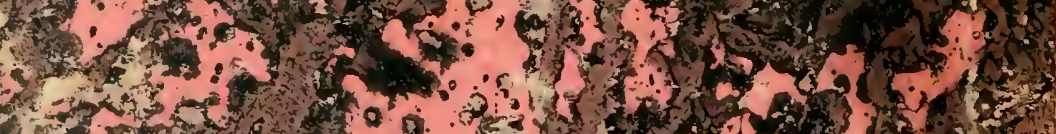

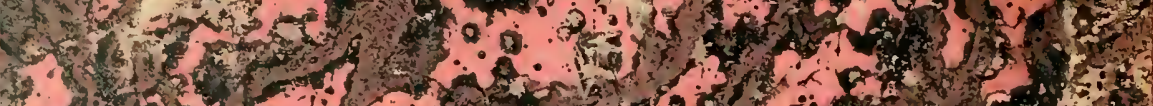

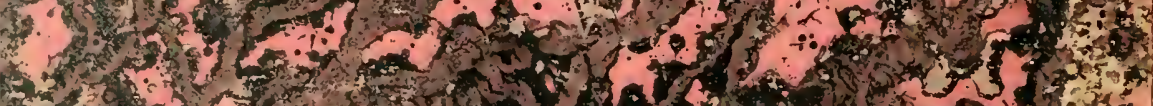

